\title{
ESPECTROSCOPIA DE CORRELAÇÃO BIDIMENSIONAL GENERALIZADA E SAMPLE- SAMPLE APLICADA AO ESTUDO DA TRIPSINA PANCREÁTICA BOVINA
}

Luciane Sussuchi da Silva

Orientador: Prof. Dr. Marinônio Lopes Cornélio 


\section{Luciane Sussuchi da Silva}

\section{ESPECTROSCOPIA DE CORRELAÇÃO BIDIMENSIONAL GENERALIZADA E SAMPLE-SAMPLE APLICADA AO ESTUDO DA TRIPSINA PANCREÁTICA BOVINA}

Dissertação apresentada para obtenção do titulo de Mestre em Biofísica Molecular junto ao Programa de Pós-Graduação em Biofísica Molecular do Instituto de Biociências Letras e Ciências Exatas da Universidade Estadual Paulista "Júlio de Mesquita Filho”, Campus de São José do Rio Preto.

\section{BANCA EXAMINADORA}

Prof. Dr. Marinônio Lopes Cornélio

Professor Adjunto

UNESP - São José do Rio Preto

Orientador

Prof. Dr. Marcelo Andrés Fossey

Professor Assistente Doutor

UNESP - São José do Rio Preto

Prof. Dr. Luiz Alberto Colnago

Pesquisador

Embrapa Instrumentação Agropecuária - São Carlos

São José do Rio Preto, 19 de março de 2010 
Silva, Luciane Sussuchi da.

Espectroscopia de correlação bidimensional generalizada e samplesample aplicada ao estudo da tripsina pancreática bovina / Luciane Sussuchi da Silva. - São José do Rio Preto : [s.n.], 2010.

59 f. : il. ; $30 \mathrm{~cm}$.

Orientador: Marinônio Lopes Cornélio

Dissertação (mestrado) - Universidade Estadual Paulista, Instituto de Biociências, Letras e Ciências Exatas

1. Espectroscopia de infravemelho. 2. Espectroscopia de correlação bidimensional. 3. Proteínas. I. Cornélio, Marinônio Lopes. II.

Universidade Estadual Paulista, Instituto de Biociências, Letras e Ciências Exatas. III. Título.

CDU - 543.42

Ficha catalográfica elaborada pela Biblioteca do IBILCE

Campus de São José do Rio Preto - UNESP 


\section{Resumo}

Neste trabalho a tripsina pancreática bovina é utilizada como proteína alvo na aplicação da espectroscopia de correlação bidimensional investigando os processos de desenovelamento e re-enovelamento. A espectroscopia de correlação bidimensional generalizada proposta por Noda (Noda, 1993) tem crescido em aplicações e novas técnicas de correlação 2D têm sido desenvolvidas. Assim como em RMN 2D, picos espectrais são espalhados em uma segunda dimensão, simplificando a visualização de espectros complexos, por serem constituídos de bandas sobrepostas ajudando na resolução espectral, de similar modo foi desenvolvido técnicas de analises para o infravermelho. O desenvolvimento de um software para obtenção da correlação generalizada e correlação sample-sample (Sasic, et al., 2000) foi uma etapa importante neste estudo, entretanto a associação entre estes resultados torna a abordagem do problema de desenovelamento e re-enovelamento mais rica em detalhes.

A análise de correlação bidimensional sample-sample (2D-SS) indica uma temperatura de desenovelamento em $48^{\circ} \mathrm{C}$ que é corroborado por DSC $\left(49^{\circ} \mathrm{C}\right)$. Além dessa, temperaturas de pré-transição em $31^{\circ}, 37^{\circ}$ e $43^{\circ} \mathrm{C}$ e pós-transição em $54^{\circ}, 59^{\circ} \mathrm{e}$ $69^{\circ} \mathrm{C}$ foram reveladas por $2 \mathrm{D}$ sample-sample. O perfil do termograma obtido por DSC indica que o processo de desenovelamento é do tipo múltiplo estado o que valida a descoberta de temperaturas de pré e pós-transição. A análise generalizada revela as estruturas secundárias e os eventos seqüenciais envolvidos em cada uma destas transições. A partir da equação de van't Hoff é obtido o valor da entalpia de desenovelamento $28,1 \mathrm{kcal} / \mathrm{mol}$, já a análise calorimétrica por sua vez fornece um valor para a entalpia aparente de $59,3 \mathrm{kcal} / \mathrm{mol}$. 


\section{Abstract}

In this work the bovine pancreatic trypsin is used as the target protein in the application of two-dimensional correlation spectroscopy investigating the processes of unfolding and refolding. The two-dimensional generalized correlation spectroscopy proposed by Noda (Noda, 1993) has grown into applications and new 2D correlation techniques have been developed. As well as in 2D NMR spectral peaks are spread across a second dimension, simplifying the complex spectra view because they are made up of overlapping bands increasing the spectral resolution of similar way was developed techniques of analysis to the infrared technique. The development of software for obtaining generalized correlation and correlation sample-sample (Sasic, et al., 2000) was an important step in this study, however the association between these results makes the approach to the problem of unfolding and refolding richer in detail.

The two-dimensional sample-sample correlation analysis (2D-SS) indicates a temperature of unfolding at $48^{\circ} \mathrm{C}$ which is corroborated by DSC $\left(49^{\circ} \mathrm{C}\right)$. In addition to this, pre transitions temperatures in $31^{\circ} 37^{\circ}$ and $43{ }^{\circ} \mathrm{C}$ and post transition in $54^{\circ}, 59^{\circ}$ and $69^{\circ} \mathrm{C}$ were revealed by $2 \mathrm{D}-\mathrm{SS}$. The profile of the thermogram obtained by DSC indicates that the process of unfolding is of the type of multiple state that validates the discovery of temperatures of pre and post transition. The generalized analysis reveals the secondary structures and sequential events involved in each of these transitions. From the van't Hoff equation is retrieved a value of the unfolding enthalpy of 28.1 $\mathrm{kcal} / \mathrm{mol}$, from the calorimetric analysis the value for the apparent enthalpy was 59.3 $\mathrm{kcal} / \mathrm{mol}$. 


\section{Abreviaturas}

2D - Two-Dimensional

BPT - Bovine Pancreatic Trypsin

$\mathrm{C}_{\mathrm{p}}$ - Capacidade calorífica a pressão constante

CD - Circular Dichroism

DSC - Differential Scanning Calorimetric

FTIR - Fourier Transform Infrared Spectroscopy

IR - Infrared

RMN - Ressonância Magnética Nuclear

$\mathrm{T}_{\mathrm{m}}-$ melting temperature 


\section{Lista de Figuras}

Figura 1: Estrutura tridimensional da tripsina pancreática bovina constituída de $34 \%$ de folha $\beta$ e $10 \%$ de hélice $\alpha$. Em azul, as pontes dissulfeto (PDB: 2BLV).

Figura 2: Seqüência de autoclivagens da tripsina pancreática bovina (Prestrelski, et al., 1991)

Figura 3: Esquema geral de obtenção de espectros de correlação 2D (Noda, et al., 2004)

Figura 4: Mapa de contorno esquemático de um espectro de correlação 2D síncrono com o espectro de referência (A) unidimensional no topo e na lateral (Noda, 1993)...... 6

Figura 5: Mapa de contorno esquemático de um espectro de correlação 2D assíncrono com espectro de referência unidimensional no topo e na lateral. A área sombreada indica intensidade de correlação negativa (Noda, 1993). 8

Figura 6: Mapa de contorno da correlação síncrona sample-sample para o processo de evaporação de uma mistura de MEK, $d$-tolueno e polestireno (Noda, et al., 2004)....... 11

Figura 7: Corte ortogonal obtido do espectro de correlação síncrono sample-sample, construído para a RNase A na região de 1600 a1700 $\mathrm{cm}^{-1}$ com correção de linha de base. Os espectros são medidos entre 26 e $78^{\circ} \mathrm{C}$ com incremento de $1^{\circ} \mathrm{C}$ (Wang, et al., 2006).

Figura 8: Espectros de infravermelho na região de amida I' da tripsina pancreática bovina em $0,05 \mathrm{mM}$ de Tris-HCl e pD 7,2 dependentes da temperatura com correção de linha de base. Os espectros representam a variação de temperatura de 25 a $77^{\circ} \mathrm{C} \mathrm{com}$ incremento de $4^{\circ} \mathrm{C}$.

Figura 9: Comportamento térmico dos números de onda referentes à absorção das folhas

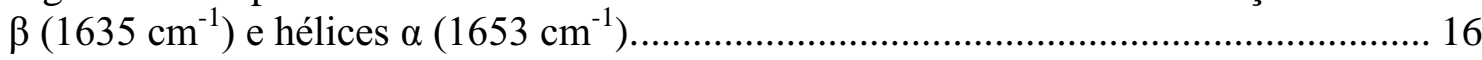

Figura 10: Comportamento térmico do número de onda referente às folhas $\beta\left(1635 \mathrm{~cm}^{-1}\right)$ com intensidade normalizada e ajuste sigmoidal. 16

Figura 11: Ajuste linear da equação de van't Hoff para a obtenção da entalpia aparente de desnaturação.

Figura 12: Superfície de correlação sample-sample, construído a partir de dados de infravermelho para o desenovelamento da BPT a $\mathrm{pD} 7,2 \mathrm{com}$ a variação de temperatura entre 25 e $79^{\circ} \mathrm{C}$ e incremento de $2^{\circ} \mathrm{C}$.

Figura 13: Corte ortogonal do espectro de correlação sample-sample, construído a partir de dados de infravermelho para o desenovelamento da $\mathrm{BPT}$ a pD 7,2 com a variação de temperatura entre 25 e $79^{\circ} \mathrm{C}$ e incremento de $2^{\circ} \mathrm{C}$. 20

Figura 14: Corte ortogonal do espectro de correlação sample-sample, construído a partir de dados de infravermelho para o desenovelamento da BPT a pD 7,2 com a variação de temperatura entre 25 e $47^{\circ} \mathrm{C}$. 21

Figura 15: Corte ortogonal do espectro de correlação sample-sample, construído a partir de dados de infravermelho para o desenovelamento da BPT com a variação de temperatura entre 25 e $37^{\circ} \mathrm{C}$. 
Figura 16: Corte ortogonal do espectro de correlação sample-sample, construído a partir de dados de infravermelho para o desenovelamento da BPT a pD 7,2 com a variação de temperatura entre 37 e $47^{\circ} \mathrm{C}$. 22

Figura 17: Corte ortogonal do espectro de correlação sample-sample, construído a partir de dados de infravermelho para o desenovelamento da BPT a pD 7,2 com a variação de temperatura entre 49 e $79^{\circ} \mathrm{C}$.

Figura 18: Corte ortogonal do espectro de correlação sample-sample, construído a partir de dados de infravermelho para o desenovelamento da BPT a pD 7,2 com a variação de temperatura entre 49 e $59^{\circ} \mathrm{C}$. 24

Figura 19: Corte ortogonal do espectro de correlação sample-sample, construído a partir de dados de infravermelho para o desenovelamento da BPT a pD 7,2 com a variação de temperatura entre 59 e $79^{\circ} \mathrm{C}$ 24

Figura 20: Mapa de contorno da correlação síncrona generalizada para o desenovelamento da BPT pD 7,2 entre 29 e $33^{\circ} \mathrm{C}$ na região de $1600-1700 \mathrm{~cm}^{-1}$......... 27

Figura 21: Mapa de contorno da correlação assíncrona generalizada para o desenovelamento da $\mathrm{BPT}$ pD 7,2 entre $29^{\circ}$ e $33^{\circ} \mathrm{C}$ na região de $1600-1700 \mathrm{~cm}^{-1} \ldots \ldots \ldots . .28$

Figura 22: Mapa de contorno da correlação síncrona generalizada para o desenovelamento da $\mathrm{BPT}$ pD 7,2 entre $35^{\circ}$ e $39^{\circ} \mathrm{C}$ na região de $1600-1700 \mathrm{~cm}^{-1}$......... 29

Figura 23: Mapa de contorno da correlação assíncrona generalizada para o desenovelamento da $\mathrm{BPT} \mathrm{pD} 7,2$ entre $35^{\circ}$ e $39^{\circ} \mathrm{C}$ na região de $1600-1700 \mathrm{~cm}^{-1} \ldots \ldots \ldots . . .30$

Figura 24: Mapa de contorno da correlação síncrona generalizada para o desenovelamento da BPT pD 7,2 entre $41^{\circ}$ e $45^{\circ} \mathrm{C}$ na região de $1600-1700 \mathrm{~cm}^{-1}$......... 31

Figura 25: Mapa de contorno da correlação assíncrona generalizada para o desenovelamento da BPT pD 7,2 entre $41^{\circ}$ e $45^{\circ} \mathrm{C}$ na região de $1600-1700 \mathrm{~cm}^{-1}$......... 32

Figura 26: Mapa de contorno da correlação síncrona generalizada para o desenovelamento da BPT pD 7,2 entre $45^{\circ}$ e $51^{\circ} \mathrm{C}$ na região de $1600-1700 \mathrm{~cm}^{-1}$......... 33

Figura 27: Mapa de contorno da correlação assíncrona generalizada para o desenovelamento da BPT pD 7,2 entre $45^{\circ}$ e $51^{\circ} \mathrm{C}$ na região de $1600-1700 \mathrm{~cm}^{-1}$......... 34

Figura 28: Mapa de contorno da correlação síncrona generalizada para o desenovelamento da $\mathrm{BPT} \mathrm{pD} 7,2$ entre $51^{\circ}$ e $55^{\circ} \mathrm{C}$ na região de $1600-1700 \mathrm{~cm}^{-1}$......... 35

Figura 29: Mapa de contorno da correlação assíncrona generalizada para o desenovelamento da $\mathrm{BPT}$ pD 7,2 entre $51^{\circ}$ e $55^{\circ} \mathrm{C}$ na região de $1600-1700 \mathrm{~cm}^{-1}$......... 36

Figura 30: Mapa de contorno da correlação síncrona generalizada para o desenovelamento da $\mathrm{BPT}$ pD 7,2 entre $57^{\circ}$ e $63^{\circ} \mathrm{C}$ na região de $1600-1700 \mathrm{~cm}^{-1} \ldots \ldots \ldots . .37$

Figura 31: Mapa de contorno da correlação assíncrona generalizada para o desenovelamento da BPT pD 7,2 entre $57^{\circ}$ e $63^{\circ} \mathrm{C}$ na região de $1600-1700 \mathrm{~cm}^{-1} \ldots \ldots \ldots . . .38$

Figura 32: Mapa de contorno da correlação síncrona generalizada para o desenovelamento da $\mathrm{BPT}$ pD 7,2 entre $67^{\circ}$ e $71^{\circ} \mathrm{C}$ na região de $1600-1700 \mathrm{~cm}^{-1}$......... 39

Figura 33: Mapa de contorno da correlação assíncrona generalizada para o desenovelamento da BPT pD 7,2 entre $67^{\circ}$ e $71^{\circ} \mathrm{C}$ na região de $1600-1700 \mathrm{~cm}^{-1}$......... 40

Figura 34: Curva de DSC mostrando capacidade calorífica molar aparente da agregação da BPT $30 \mathrm{mg} / \mathrm{mL}$ em a pD 7,0 e razão de aquecimento de $6^{\circ} \mathrm{C} / \mathrm{h}$. 
Figura 35: Deconvolução da capacidade calorífica aparente da transição endotérmica. (-) curva experimental, (-) sub-transições e (-) curva calculada pela soma das subtransições.

Figura 36: Espectros de infravermelho dependentes da temperatura da tripsina pancreática bovina após correção de linha de base na região de amida I'. Os espectros representam a variação de temperatura de $45^{\circ}$ a $25^{\circ} \mathrm{C}$ com incremento de $2^{\circ} \mathrm{C}$ em 0,05 $\mathrm{mM}$ de Tris- $\mathrm{HCl}$ e $\mathrm{pD} 7,0$.

Figura 37: Mapa de contorno do espectro de correlação sample-sample, construído a partir de dados de infravermelho do re-enovelamento da BPT a pD 7,0 com variação de temperatura de $45^{\circ}$ a $25^{\circ} \mathrm{C}$ e incremento de $2^{\circ} \mathrm{C}$ 45

Figura 38: Corte ortogonal do espectro de correlação sample-sample, construído a partir de dados de infravermelho do re-enovelamento da BPT a $\mathrm{pD} 7,0$ com a variação de temperatura de $45^{\circ}$ a $25^{\circ} \mathrm{C}$ e incremento de $2^{\circ} \mathrm{C}$. 46

Figura 39: Mapa de contorno da correlação síncrona generalizada para o reenovelamento da BPT pD 7,0 entre $45^{\circ}$ e $41^{\circ} \mathrm{C}$ na região de $1600-1700 \mathrm{~cm}^{-1}$. 47

Figura 40: Mapa de contorno da correlação assíncrona generalizada para o reenovelamento da BPT pD 7,0 entre $45^{\circ}$ e $41^{\circ} \mathrm{C}$ na região de $1600-1700 \mathrm{~cm}^{-1}$. 48

Figura 41: Mapa de contorno da correlação síncrona generalizada para o reenovelamento da $\mathrm{BPT} \mathrm{pD} 7,0$ entre $37^{\circ}$ e $33^{\circ} \mathrm{C}$ na região de $1600-1700 \mathrm{~cm}^{-1}$............. 49

Figura 42: Mapa de contorno da correlação assíncrona generalizada para o reenovelamento da BPT pD 7,0 entre $37^{\circ}$ e $33^{\circ} \mathrm{C}$ na região de $1600-1700 \mathrm{~cm}^{-1}$.............. 50

Figura 43: Mapa de contorno da correlação síncrona generalizada para o reenovelamento da $\mathrm{BPT} \mathrm{pD} 7,0$ entre $33^{\circ}$ e $29^{\circ} \mathrm{C}$ na região de $1600-1700 \mathrm{~cm}^{-1}$............. 51

Figura 44: Mapa de contorno da correlação síncrona generalizada para o reenovelamento da BPT pD 7,0 entre $33^{\circ}$ e $29^{\circ} \mathrm{C}$ na região de $1600-1700 \mathrm{~cm}^{-1}$. 


\section{Sumário}

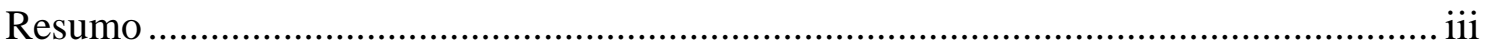

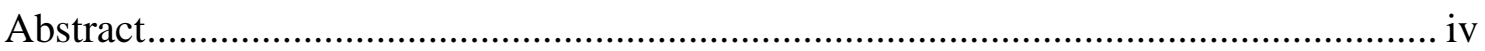

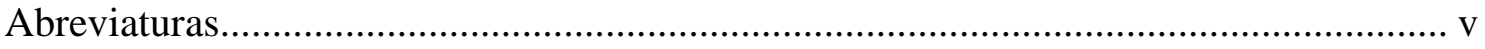

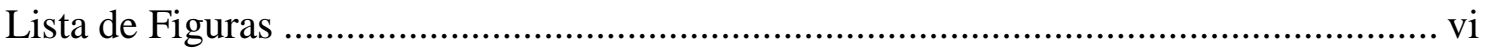

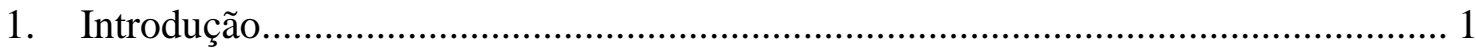

2. Espectroscopia de Correlação Bidimensional ............................................................ 3

2.1. Espectroscopia de Correlação Bidimensional Generalizada............................... 3

2.2. Propriedades dos Espectros de Correlação 2D Generalizados ........................... 6

2.3. Espectroscopia de Correlação Sample-Sample .................................................. 9

2.4 Propriedades dos espectros de correlação sample-sample ................................ 11

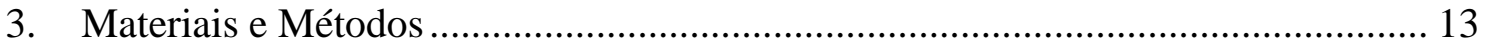

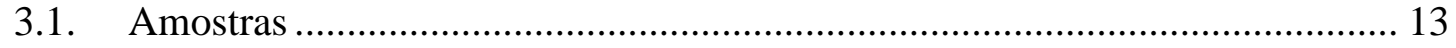

3.2. Obtenção dos espectros de infravermelho .................................................... 13

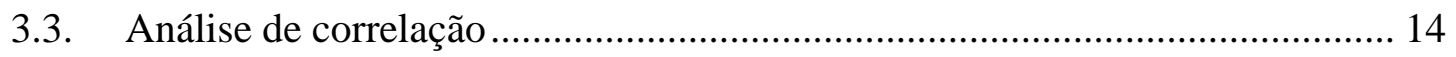

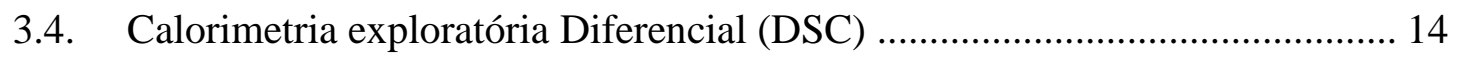

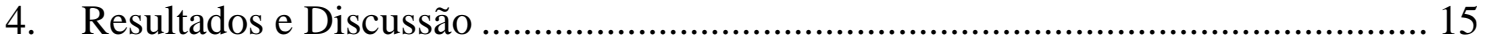

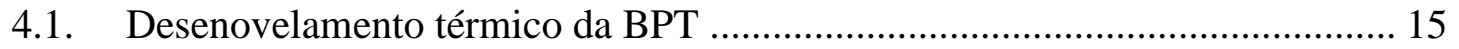

4.1.1 Análise de correlação sample-sample-2D ................................................ 19

4.1.2 Análise de correlação bidimensional generalizada................................... 26

4.1.3 Perfil de calorimetria exploratória diferencial (DSC) ............................ 41

4.2 Re-enovelamento térmico abaixo da transição principal ................................. 44

4.2.1 Análise de correlação sample-sample-2D .............................................. 45

4.2.2 Análise de correlação bidimensional generalizada.................................. 47

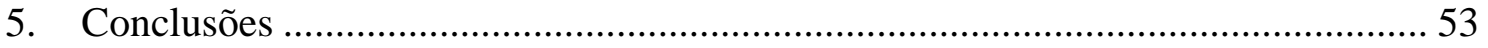

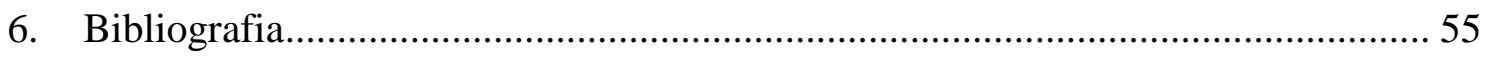

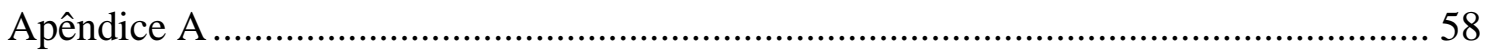




\section{Introdução}

A tripsina pancreática bovina é uma serino-protease amplamente estudada com 223 resíduos de aminoácidos e seis pontes dissulfeto (Figura 1). É uma proteína globular com uma estrutura secundária em que predominam as folhas $\beta$ antiparalelas e possui dois domínios similares.

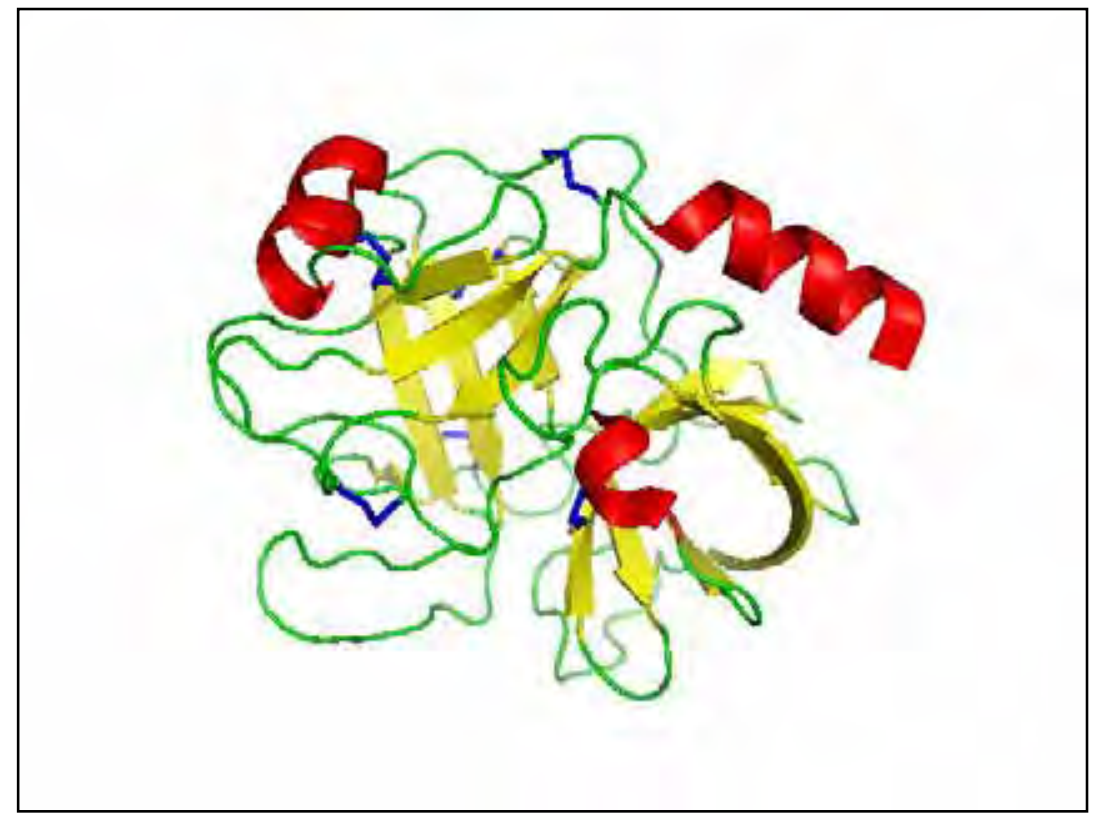

Figura 1: Estrutura tridimensional da tripsina pancreática bovina constituída de $34 \%$ de folha $\beta$ e $10 \%$ de hélice $\alpha . \mathrm{Em}$ azul, as pontes dissulfeto (PDB: 2BLV).

Em geral, a transição de pequenas proteínas globulares do estado nativo para o desnaturado é altamente cooperativa e tal transição pode ser descrita pelo modelo de "dois estados", onde nenhum estado intermediário é significativamente populado (Dill, et al., 2008; Dobson C. M., 1998). Em pH ácido, tanto $\alpha$ - quanto $\beta$-tripsina são bem caracterizadas pelo modelo de dois estados através de dados calorimétricos (Bittar, et al., 2003; Santos, et al., 2008).

No entanto, a estabilidade da tripsina é dependente do meio em que ela se encontra. Sabe-se que etanol-aminas, como o tris (hidroxi-metil) aminometano, a altas concentrações podem acessar o sítio ativo de serino-proteases e aparentemente prevenir 
a autoclivagem durante o re-enovelamento da proteína, embora o mecanismo exato de ação ainda não seja bem elucidado (Ohshima, et al., 2008).

O processo de autoclivagem da tripsina bovina é bem definido (Schroeder, et al., 1968; Smith, et al., 1969; Prestrelski, et al., 1991) e pode ser esquematizado pela Figura 2. A $\beta$-tripsina é a forma mais ativa da proteína, embora preparações comerciais possam conter quantidades significativas das formas $\alpha$ e $\psi$ (Smith, et al., 1969).

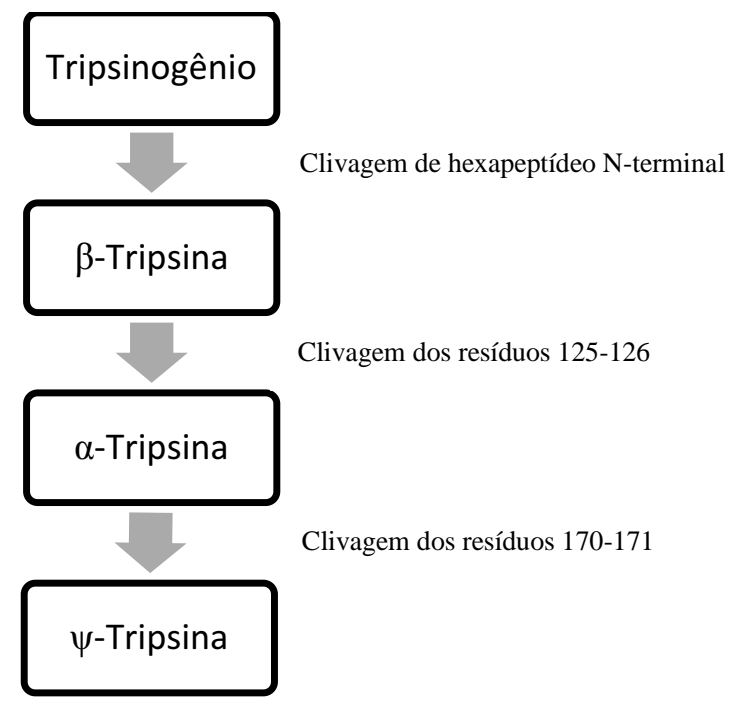

Figura 2: Seqüência de autoclivagens da tripsina pancreática bovina (Prestrelski, et al., 1991).

O desenovelamento e re-enovelamento da tripsina comercial serão estudados através das espectroscopias de correlação bidimensional sample-sample (Sasic, et al., 2000) e generalizada (Noda, 1993). A correlação sample-sample indica as principais transições envolvidas nos processos de desenovelamento e re-enovelamento, de modo que a dinâmica conformacional nestas transições pode ser avaliada pela correlação generalizada. Neste trabalho, ambas as análises de correlação são empregadas a partir da construção de uma rotina computacional desenvolvida em plataforma MatLab, já que nenhum software disponível permite o desenvolvimento da análise generalizada complementar a análise sample-sample. 


\section{Espectroscopia de Correlação Bidimensional}

\subsection{Espectroscopia de Correlação Bidimensional Generalizada}

A espectroscopia de correlação bidimensional generalizada foi proposta por Noda em 1993 (Noda, 1993), como uma extensão da espectroscopia de correlação bidimensional infravermelha formulada em 1989 (Noda, 1990). O novo formalismo matemático proposto fez da análise de correlação 2D uma ferramenta aplicável a diversas técnicas espectroscópicas como infravermelho (IR), infravermelho próximo (NIR), Raman, fluorescência, dicroísmo circular vibracional (VCD) e até mesmo cromatografia (Noda, 2008).

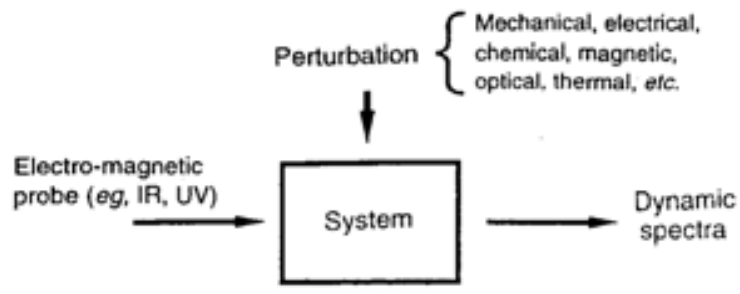

Figura 3: Esquema geral de obtenção de espectros de correlação 2D (Noda, et al., 2004)

A Figura 3 mostra o esquema básico para um experimento de correlação 2D baseado em uma perturbação externa. Uma perturbação externa estimula a amostra conduzindo a variação característica no espectro óptico. Esta variação espectral induzida pela aplicação da perturbação fornece os chamados espectros dinâmicos. Um conjunto de espectros dinâmicos obtidos, por exemplo, com o aumento da temperatura é então submetido à análise de correlação cruzada e fornece espectros de correlação bidimensional.

A intensidade espectral induzida por perturbação é dada por $y(v, t)$, observada para um dado intervalo da variável externa $t$ entre $T_{\min }$ e $T_{\text {máx }}$ e $v$ o número de onda. $\mathrm{O}$ espectro dinâmico $\tilde{y}(v, t)$ de uma amostra afetada pela perturbação externa é definido como 


$$
\tilde{y}(v, t)=\left\{\begin{array}{l}
y(v, t)-\bar{y}(v), \text { para } T_{\text {min }} \leq t \leq T_{\text {máx }}, \\
0
\end{array}\right.
$$

sendo $\bar{y}(v)$ é o espectro de referência do sistema. Normalmente, esta referência é assumida como espectro estacionário ou médio definido por

$$
\bar{y}(v)=\frac{1}{T_{m a ́ x}-T_{\min }} \int_{T_{\text {mín }}}^{T_{\text {máx }}} y(v, t) d t .
$$

O espectro de referência pode ser também selecionado como o espectro observado em algum ponto de referência antes do início da perturbação ou após o término. $\mathrm{O}$ espectro de referência pode ainda ser presumido como igual a zero, neste caso, o espectro dinâmico iguala-se à variação de intensidade espectral observada sob efeito da perturbação.

A correlação 2D é a comparação de padrões de variação de intesnsidade espectral ao longo da variável externa $t$, observada em duas variáveis espectrais diferentes $v_{1}$ e $v_{2}$, sob um intervalo de observação finito entre $T_{\min }$ e $T_{\text {máx }}$. Portanto, o espectro de correlação pode ser escrito como

$$
X\left(v_{1}, v_{2}\right)=\left\langle\tilde{y}\left(v_{1}, t\right) \cdot \tilde{y}\left(v_{2}, t\right)\right\rangle
$$

sendo que $X\left(v_{1}, v_{2}\right)$ representa uma medida quantitativa da comparação entre as variações de intensidade espectral $\tilde{y}(\nu, t)$ e o símbolo \langle\rangle denota a função de correlação cruzada usada para comparar as variáveis em $t$.

A função $X\left(v_{1}, v_{2}\right)$ é tratada convencionalmente como um número complexo,

$$
X\left(v_{1}, v_{2}\right)=\Phi\left(v_{1}, v_{2}\right)+i \Psi\left(v_{1}, v_{2}\right)
$$

compreendendo dois componentes ortogonais (real e imaginário), conhecidos como as intensidades de correlação 2D síncrona e assíncrona respectivamente. A correlação síncrona $\Phi\left(v_{1}, v_{2}\right)$ representa a similaridade ou tendência coincidente entre duas variações de intensidade em variáveis espectrais diferentes quando $t$ é alterado. Já a correlação assíncrona $\Psi\left(v_{1}, v_{2}\right)$ pode ser considerada como a não similaridade ou o caráter fora de fase das variações espectrais. 
Dadas as transformadas de Fourier, $\tilde{Y}_{1}(\omega) e \tilde{Y}_{2}^{*}(\omega)$, dos espectros dinâmicos no domínio da perturbação observados a $v_{1}$ e $v_{2}$, a intensidade de correlação bidimensional complexa da equação 2.4 é formalmente definida como

$$
\Phi\left(v_{1}, v_{2}\right)+i \Psi\left(v_{1}, v_{2}\right)=\frac{1}{\pi\left(T_{\text {máx }}-T_{\min }\right)} \int_{0}^{\infty} \tilde{Y}_{1}(\omega) \cdot \tilde{Y}_{2}^{*}(\omega) d \omega
$$

O teorema de Wiener-Khintchine fornece uma relação conveniente entre a correlação cruzada clássica de duas funções e suas respectivas transformadas de Fourier (ver apêndice A) de modo que as intensidades de correlação síncronas $\Phi\left(v_{1}, v_{2}\right)$ podem ser calculadas diretamente da função de correlação cruzada, sem a necessidade da transformada de Fourier dos espectros como

$$
\Phi\left(v_{1}, v_{2}\right)=\frac{1}{T_{\text {máx }}-T_{\text {mín }}} \int_{T_{\text {min }}}^{T_{\text {máx }}} \tilde{y}\left(v_{1}, t\right) \cdot \tilde{y}\left(v_{2}, t\right) d t \text {, }
$$

Para obter uma equação semelhante em simplicidade, as intensidades de correlação assíncronas $\Psi\left(v_{1}, v_{2}\right)$ a partir da função de correlação cruzada ortogonal de modo que

$$
\Psi\left(v_{1}, v_{2}\right)=\frac{1}{T_{\text {máx }}-T_{\text {mín }}} \int_{T_{\text {min }}}^{T_{\text {máx }}} \tilde{y}\left(v_{1}, t\right) \cdot \tilde{z}\left(v_{2}, t\right) d t \text {, }
$$

sendo $\tilde{z}\left(v_{2}, t\right)$ a transforamada de Hilbert do espectro dinâmico $\tilde{y}\left(v_{2}, t\right)$.

Assim como as intensidades de correlação síncronas da equação 2.6 a intensidades de correlação assíncronas na equação 2.7 não necessitam da transformada de Fourier dos dados, o que torna mais simples o calculo computacional das intensidades de correlação síncronas e assíncronas a partir dos espectros dinâmicos obtidos experimentalmente como dados discretos ao invés de funções contínuas. A manipulação eficiente de dados discretos é um importante aspecto da análise de correlação 2D. 


\subsection{Propriedades dos Espectros de Correlação 2D Generalizados}

Os espectros de correlação bidimensionais síncronos e assíncronos possuem propriedades que fornecem informações não notadas facilmente pelos métodos unidimensionais convencionais e também a seqüência de eventos que ocorre com o sistema sob perturbação. Estas propriedades vêm sendo bastante aplicadas no estudo de enovelamento e agregação de proteínas (Yan, et al., 2003; Iloro, et al., 2004; Ausili, et al., 2005; Filosa, et al., 2001; He, et al., 2005; Fabian, et al., 1999; Paquet, et al., 2001; Noda, 2008)

A Figura 2 mostra um exemplo esquemático de um espectro de correlação 2D síncrono representado como mapa de contorno. O espectro síncrono é simétrico com relação à linha diagonal que corresponde às coordenadas espectrais onde $v_{1}=v_{2} \mathrm{e}$ picos de correlação são encontrados dentro e fora da linha diagonal. $\mathrm{A}\left(v_{1}\right)$ e $\mathrm{A}\left(v_{2}\right)$ são o espectro de referência utilizado para a análise de correlação

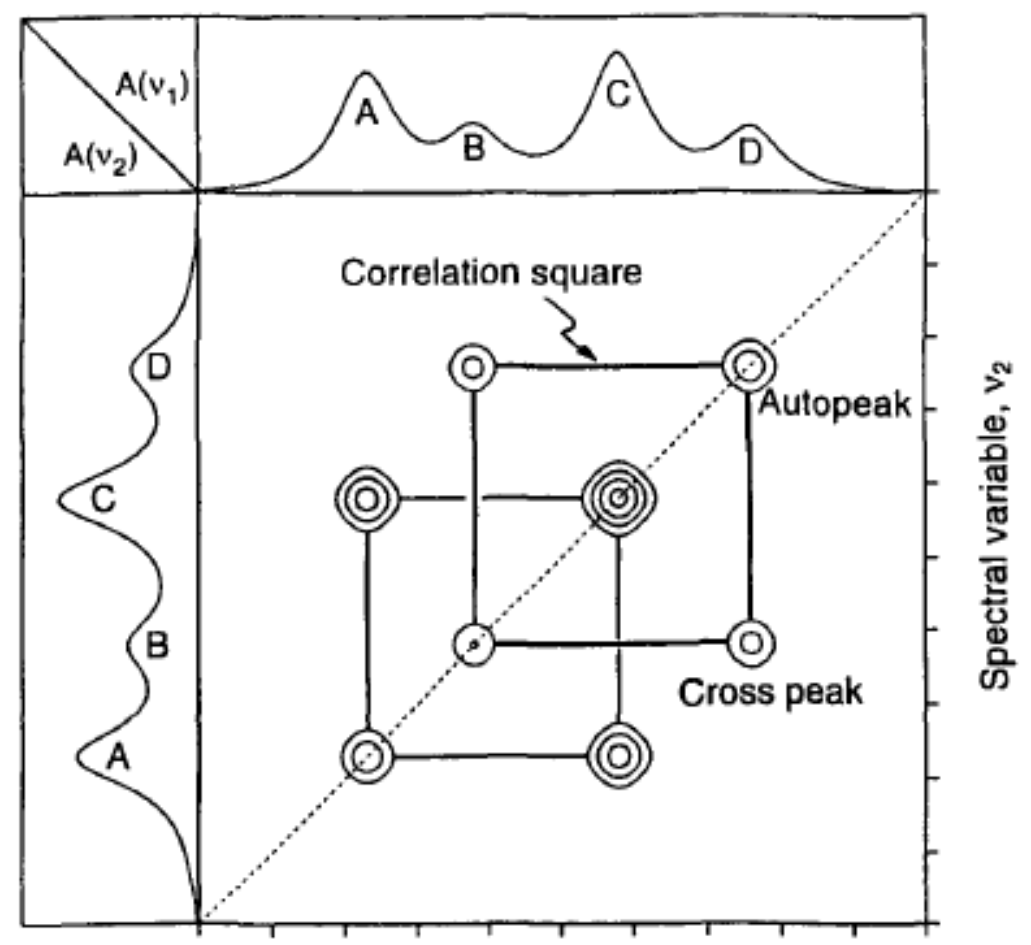

Spectral variable, $v_{1}$

Figura 4: Mapa de contorno esquemático de um espectro de correlação 2D síncrono com o espectro de referência (A) unidimensional no topo e na lateral (Noda, 1993). 
Picos localizados na linha diagonal são chamados autopicos por corresponderem à função de autocorrelação das variações de intensidade espectral observadas no intervalo entre $T_{\min }$ e $T_{\text {máx }}$. A intensidade dos autopicos de um espectro de correlação bidimensional síncrono é sempre positiva e representa a susceptibilidade de uma dada variável espectral $v$ variar a intensidade espectral quando uma perturbação externa t é aplicada ao sistema. Logo, uma região do espectro que sofre uma grande variação de intensidade sob um dado intervalo de perturbação irá apresentar um autopico forte, enquanto as regiões que permanecem constantes possuirão autopicos fracos ou simplesmente não haverá autopico. Na Figura 2 são encontrados quatro autopicos ou regiões que sofreram alteração com a perturbação externa chamados A, B, C e D.

Picos localizados fora da diagonal de um espectro síncrono são chamados de picos cruzados e representam mudanças simultâneas de sinais espectrais a dois números de onda diferentes, $v_{1}$ e $v_{2}$. Esta mudança sincronizada sugere a possível existência de origem relacionada ou acoplada das variações de intensidade espectral. Na figura 2, nota-se que as bandas A e C estão correlacionadas sincronamente, assim como as bandas B e D. Diferente dos autopicos, os picos cruzados podem ser positivos ou negativos. $\mathrm{O}$ sinal do pico cruzado é positivo quando as intensidades espectrais em $v_{1} \mathrm{e}$ $v_{2}$ aumentam ou diminuem ao longo da perturbação aplicada. No entanto, o sinal tornase negativo se uma das intensidades espectrais aumenta enquanto a outra diminui.

A Figura 3 é um exemplo esquemático de um espectro de correlação 2D assíncrono representado como mapa de contorno. O espectro assíncrono de variações de intensidade espectral dinâmicas representa mudanças seqüenciais ou sucessivas de variações de intensidade espectral medidas a $v_{1}$ e $v_{2}$. Este espectro é anti-simétrico com relação à linha diagonal e não possui autopico. Um pico cruzado assíncrono surge quando duas intensidades espectrais dinâmicas variam fora de fase, esta característica ajuda a fornecer o ordenamento seqüencial de eventos observados por técnicas espectroscópicas com uma dada perturbação. 


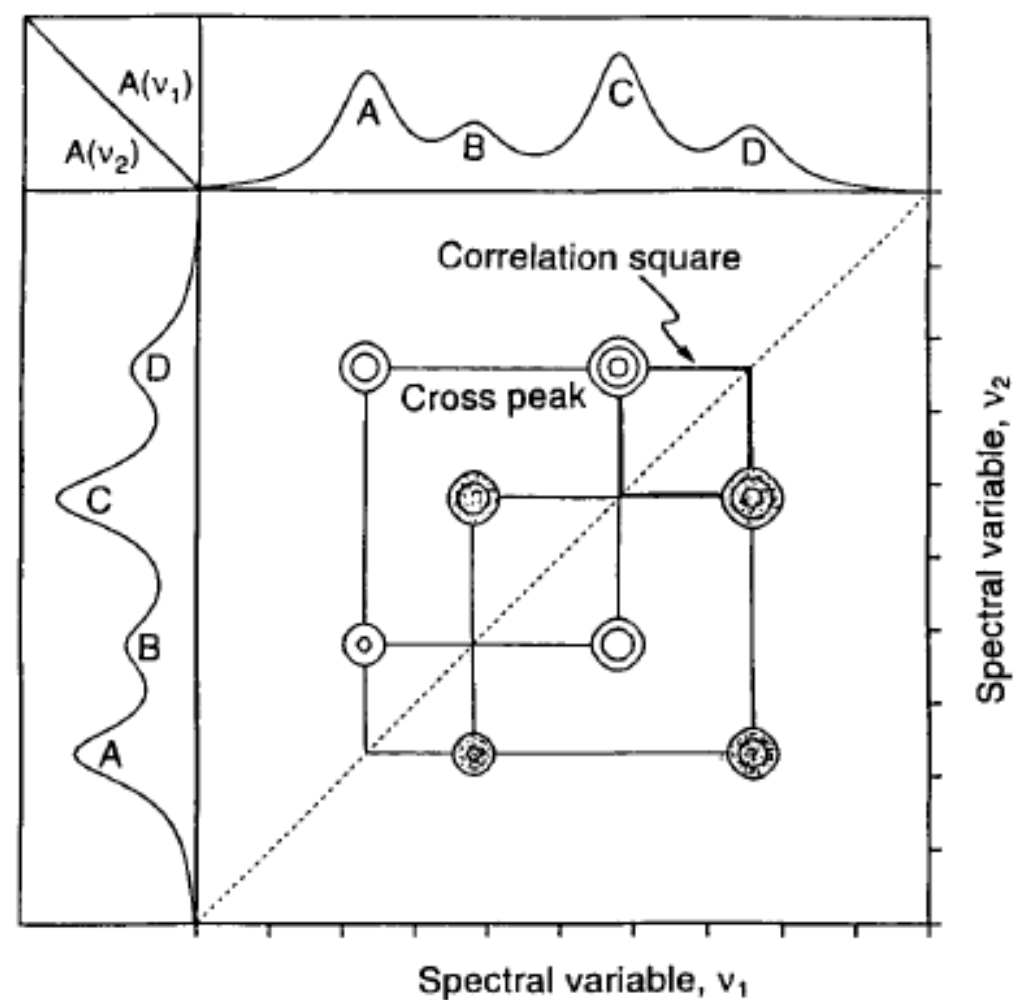

Figura 5: Mapa de contorno esquemático de um espectro de correlação 2D assíncrono com espectro de referência unidimensional no topo e na lateral. A área sombreada indica intensidade de correlação negativa (Noda, 1993).

O ordenamento seqüencial de eventos é dado regras de Noda (Noda, 1993). O sinal de um pico cruzado assíncrono é positivo quando a mudança de intensidade em $v_{1}$ ocorre predominantemente antes de $v_{2}$ e torna-se negativo se a mudança de intensidade em $v_{1}$ acontece depois de $v_{2}$. No entanto, a regra de sinal é invertida se o espectro síncrono possui sinal negativo na respectiva coordenada, ou seja, $\Phi\left(v_{1}, v_{2}\right)<0$. 


\subsection{Espectroscopia de Correlação Sample-Sample}

Os avanços no campo da espectroscopia bidimensional e o crescimento no número de artigos publicados são discutidos por Isao Noda (Noda, 2008) com base no Fourth International Symposium and the Second Asian Symposium on Two-dimensional Correlation Spectroscopy (2DCOS-2007).

Uma das extensões da correlação bidimensional generalizada foi proposta por Sasic (Sasic, et al., 2000) a qual chamou sample-sample correlation, diferente da correlação generalizada que mostra a correlação entre duas variáveis independentes (variable-variable correlation). A espectroscopia de correlação sample-sample fornece um novo espectro $2 \mathrm{D}$ onde se relacionam diferentes estados de perturbação e é totalmente complementar à análise de correlação 2D generalizada.

Este novo conceito de correlação é mais bem entendido quando se utiliza a notação matricial para os espectros de correlação. Isto é possível porque na prática os espectros são coletados como um conjunto de dados discretos ao invés de funções contínuas, de modo que um conjunto de espectros dinâmicos medidos a $m$ pontos igualmente espaçados na perturbação $t$ entre $T_{\min } \mathrm{e} T_{\text {máx }}$ é representado por $\tilde{y}\left(v, t_{j}\right)$ para $j=1,2, \ldots, m$. Logo, a matriz de dados espectrais pode ser escrita como

$$
Y=\left[\begin{array}{cccc}
\tilde{y}\left(v_{1}, t_{1}\right) & \tilde{y}\left(v_{2}, t_{1}\right) & \ldots & \tilde{y}\left(v_{n}, t_{1}\right) \\
\tilde{y}\left(v_{1}, t_{2}\right) & \tilde{y}\left(v_{2}, t_{2}\right) & \ldots & \tilde{y}\left(v_{n}, t_{2}\right) \\
\ldots & \ldots & \ldots & \ldots \\
\tilde{y}\left(v_{1}, t_{m}\right) & \tilde{y}\left(v_{2}, t_{m}\right) & \ldots & \tilde{y}\left(v_{n}, t_{m}\right)
\end{array}\right] .
$$

Esta matriz consiste de $m$ linhas de traços espectrais e $n$ colunas de variação de intensidade para determinado número de onda ao longo da variável externa. O espectro de correlação síncrona generalizado ou variável-variável, $\Phi_{\mathrm{vv}}$, que compara as mudanças de intensidade ao longo da variável externa para um par de variáveis espectrais pode ser representado como

$$
\Phi_{\mathrm{vv}}=\frac{1}{m-1} Y^{\mathrm{T}} Y,
$$


sendo $\Phi_{\mathrm{vv}}$ uma matriz de covariância simétrica $n \times n$. Um espectro de correlação assíncrona generalizado ou variável-variável, $\Psi_{\mathrm{vv}}$, é obtido se $Y$ é ortogonalizado, multiplicando a matriz original pela matriz ortogonal:

$$
\Psi_{\mathrm{vv}}=\frac{1}{m-1} Y^{\mathrm{T}} N Y
$$

A matriz $N(m \times m)$ é a matriz de transformação de Hilbert-Noda (Noda, 2000) dada por

$$
\begin{gathered}
N_{j k}=\left\{\begin{array}{cccc}
0 & \text { se } j=k \\
1 / \pi(k-j) & \text { se } j \neq k
\end{array}\right. \\
N=\frac{1}{\pi}\left[\begin{array}{ccccc}
0 & 1 & 1 / 2 & 1 / 3 & \ldots \\
-1 & 0 & 1 & 1 / 2 & \ldots \\
-1 / 2 & -1 & 0 & 1 & \ldots \\
-1 / 3 & -1 / 2 & -1 & 0 & \ldots \\
\ldots & \ldots & \ldots & \ldots & \ldots
\end{array}\right] .
\end{gathered}
$$

A correlação sample-sample é obtida com a transposição das linhas da matriz $Y$, ou seja, o espectro de correlação síncrona sample-sample, $\Phi_{\mathrm{ss}}$, é dado por

$$
\Phi_{\mathrm{ss}}=\frac{1}{m-1} Y Y^{\mathrm{T}}
$$

O mapa 2D síncrono sample-sample obtido é uma matriz $m \times m$ com a perturbação fornecida em ambos os eixos. Cada ponto representa a correlação entre um dado par de espectros, medidos a diferentes estados de perturbação, por exemplo, a diferentes temperaturas. Logo, a correlação síncrona sample-sample na equação 2.12 observa a similaridade ou colinearidade entre dois espectros.

A correlação síncrona sample-sample tem sido aplicada ao estudo de dinâmica de concentração de componentes (Noda, et al., 2004) e desenovelamento de proteínas (Wang, et al., 2006), entre outros. No entanto, diferente da correlação síncrona samplesample, a correlação assíncrona sample-sample, $\Psi_{\mathrm{SS}}$, não fornece intensidades de correlação com significado físico bem estabelecido (Noda, et al., 2004). 


\subsection{Propriedades dos espectros de correlação sample-sample}

Um exemplo das propriedades dos espectros de correlação sample-sample é dado pelo processo de evaporação espontâneo de uma mistura de metil-etil-cetona (MEK), $d$-tolueno e poliestireno, explorado por espectros de IR (Noda, et al., 2004). Sabe-se que, o MEK é altamente volátil e desaparece primeiro seguido pela evaporação gradual do $d$-tolueno, conduzindo a acumulação de poliestireno.

O mapa de correlação sample-sample da Figura 6 mostra maior intensidade de correlação no canto inferior esquerdo, correspondendo ao estágio inicial do processo de evaporação. A correlação cruzada (fora da diagonal) neste estágio também é alta, indicando que até cerca de 5 minutos os espectros lineares são muito similares e dominados pela contribuição do MEK.

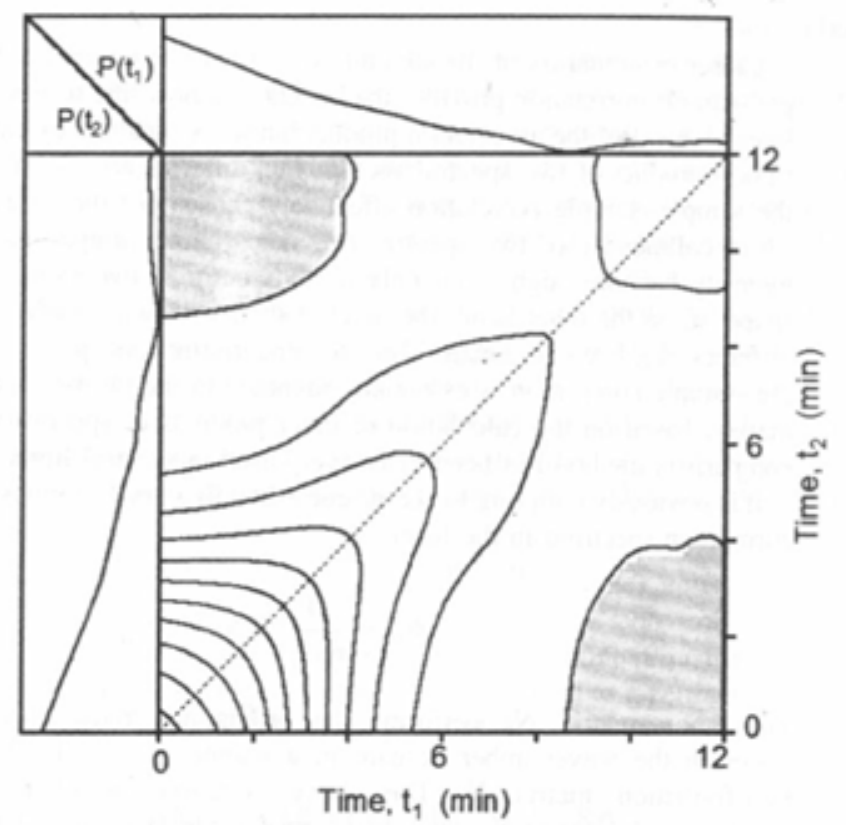

Figura 6: Mapa de contorno da correlação síncrona sample-sample para o processo de evaporação de uma mistura de MEK, $d$-tolueno e polestireno (Noda, et al., 2004).

Após os minutos iniciais as intensidades de correlação cruzada entre 6 e 7 minutos tornam-se menos intensas caracterizando a diferença entre os espectros com maior intensidade relativa de $d$-tolueno e os espectros ricos em MEK. Após 9 minutos 
surge uma correlação cruzada negativa, dada pela área sombreado do gráfico, que reflete a acumulação de poliestireno com traços espectrais muito diferentes da mistura original.

A espectroscopia sample-sample é especialmente utilizada para detectar tendências ou transições em uma série de espectros sob perturbação. Outra forma de representação destes mapas é proposta por Wang et al. aplicada ao estudo do desenovelamento induzido por temperatura da ribonuclease A (Wang, et al., 2006), que consiste em cortes ortogonais da representação pseudo-tridimensional da matriz de correlação sample-sample (Figura 7).

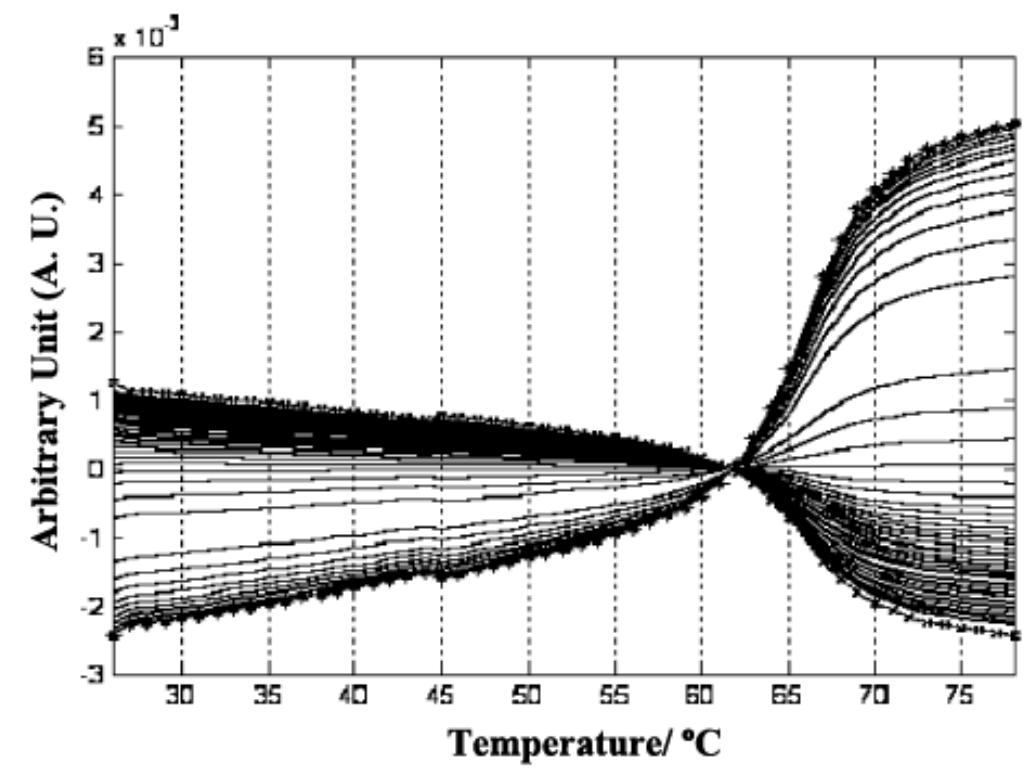

Figura 7: Corte ortogonal obtido do espectro de correlação síncrono sample-sample, construído para a RNase A na região de 1600 a1700 $\mathrm{cm}^{-1}$ com correção de linha de base. Os espectros são medidos entre 26 e $78^{\circ} \mathrm{C}$ com incremento de $1^{\circ} \mathrm{C}$ (Wang, et al., 2006).

A temperatura de transição, ou temperatura de desenovelamento, é dada pela convergência, seguido da abertura das linhas espectrais entre 61 e $71^{\circ} \mathrm{C}$. Uma perturbação na forma de linha entre 43 e $49^{\circ} \mathrm{C}$ sugere a existência de uma transição anterior ao desenovelamento global, chamada pré-transição. As estruturas secundárias envolvidas e sequiência de eventos em cada faixa de temperatura podem então ser exploradas através da espectroscopia de correlação bidimensional generalizada síncrona e assíncrona. 


\section{Materiais e Métodos}

\subsection{Amostras}

Tripsina pancreática bovina liofilizada (Boehringer Mannhein $\mathrm{GmbH}$ ), $\mathrm{HCl}$ (Merck), Tris (Sigma-Aldrich) e óxido de deutério 99,9\% (Sigma-Aldrich) foram utilizados como recebido dos fabricantes.

O tampão Tris- $\mathrm{HCl}$ foi preparado em deutério à concentração $0,05 \mathrm{M}$ e pD 7, sendo que $\mathrm{pD}=\mathrm{pH}+0,4$. As amostras de tripsina $30 \mathrm{mg} / \mathrm{mL}$ foram preparadas cerca de duas horas antes de cada experimento.

\subsection{Obtenção dos espectros de infravermelho}

Os dados de FTIR foram obtidos com o espectrômetro Nicolet Nexus 670 FTIR (Nicolet Instrument Co). As amostras foram colocadas em uma célula termostática (HARRICK) entre duas janelas de $\mathrm{CaF}_{2}$ com espaçador de Teflon de $56 \mu \mathrm{m}$. Pelo menos 40 minutos antes e durante a aquisição dos dados, o espectrômetro foi purgado continuamente com $\mathrm{N}_{2}$. Nos experimentos de desenovelamento e re-enovelamento foi utilizado um banho térmico externo (Thermo NESLAB RTE7) e os espectros foram coletados a cada $2^{\circ} \mathrm{C}$ nas faixas de $25-79^{\circ} \mathrm{C}$ e $45^{\circ}-25^{\circ} \mathrm{C}$, respectivamente. A temperatura real da amostra foi controlada por um termopar colocado diretamente na janela, sendo o tempo para equilíbrio de temperatura para medida do espectro de 10 minutos.

Espectros do tampão e da proteína foram coletados a resolução de $2 \mathrm{~cm}^{-1} \mathrm{sob}$ as mesmas condições usando o software OMNIC ESP 5.1. Cada espectro é resultante da média de 512 interferogramas. A subtração espectral entre proteína e tampão e a correção de linha de base dos espectros resultantes na banda de amida I' (1600 a 1700 $\mathrm{cm}^{-1}$ ) foi realizada no software GRAMS32 v.5.2. 


\subsection{Análise de correlação}

A análise de correlação 2D-IR dos espectros da tripsina bovina após correção de linha de base foi efetuada em um programa desenvolvido em plataforma MatLab (R2006a), utilizando a notação matricial proposta por Sasic (Sasic, et al., 2000). A correção de linha de base foi utilizada como pré-tratamento, pois têm se mostrado essencial na análise de correlação sample-sample (Wang, et al., 2006). Para os experimentos de desenovelamento e re-enovelamento aplicou-se primeiramente a correlação sample-sample para detecção de temperaturas pelas quais a proteína sofre variações estruturais significativas. A dinâmica conformacional em torno destas temperaturas foi então analisada pela correlação generalizada ou variável-variável.

\subsection{Calorimetria exploratória Diferencial (DSC)}

Medidas de DSC foram realizadas em um microcalorímetro VP-DSC, MicroCal. A taxa de aquecimento foi fixa a $6^{\circ} \mathrm{C} / \mathrm{h}$ e a pressão foi mantida em torno de $21 \mathrm{psi}$, na faixa de temperatura que varre de 15 a $85^{\circ} \mathrm{C}$. A preparação da linha de base foi feita com tampão deuterado $0,05 \mathrm{M}$ a pD 7,0 para amostra e referência. A concentração da proteína em solução de $30 \mathrm{mg} / \mathrm{mL}$ foi a mesma utilizada para as medidas de infravermelho. A análise de deconvolução e ajustes foram realizados no programa Origin 7, com um número mínimo de sub-picos e fator de ajuste $\mathrm{R}=0,99903$. 


\section{Resultados e Discussão}

\subsection{Desenovelamento térmico da BPT}

A Figura 8 representa os espectros de absorção no infravermelho da região de amida I' com o aumento da temperatura para a tripsina pancreática bovina, preparada em deutério com 0,05 mM de tampão Tris- $\mathrm{HCl}$ e pD 7,2. O espectro que representa a temperatura de $25^{\circ} \mathrm{C}$ apresenta uma banda centrada em torno de $1640 \mathrm{~cm}^{-1}$. Com o aumento da temperatura o centro tende a se deslocar para a região de número de onda maior e banda tende a se tornar mais simétrica (Wang, et al., 2006).

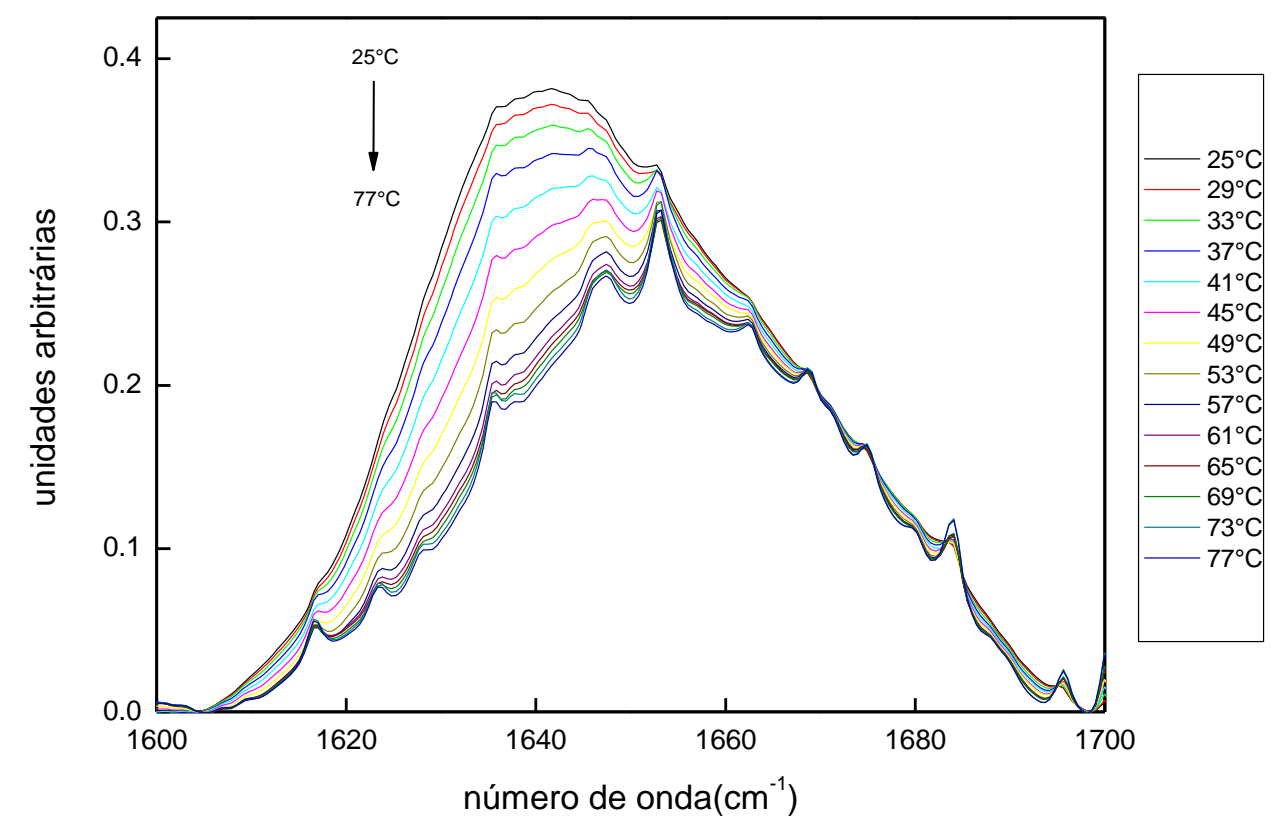

Figura 8: Espectros de infravermelho na região de amida I' da tripsina pancreática bovina em $0,05 \mathrm{mM}$ de Tris-HCl e pD 7,2 dependentes da temperatura com correção de linha de base. Os espectros representam a variação de temperatura de 25 a $77^{\circ} \mathrm{C}$ com incremento de $4^{\circ} \mathrm{C}$.

A Figura 9 permite acompanhar o perfil de estabilidade das folhas $\beta$ e hélices $\alpha$ através das intensidades de absorção em 1635 e $1653 \mathrm{~cm}^{-1}$, respectivamente. As folhas $\beta$, presentes em maior quantidade na tripsina, demonstram instabilidade térmica para altas temperaturas e um perfil de sigmóide, característico do desenovelamento de proteínas. 


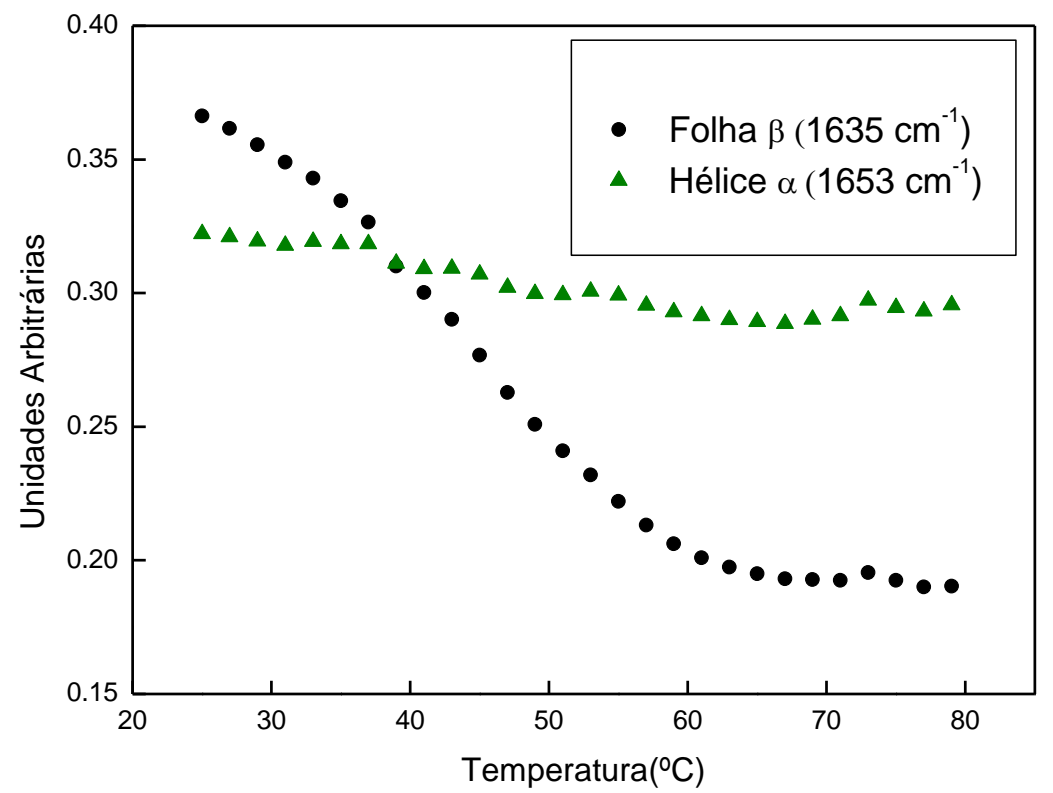

Figura 9: Comportamento térmico dos números de onda referentes à absorção das folhas $\beta\left(1635 \mathrm{~cm}^{-1}\right)$ e hélices $\alpha\left(1653 \mathrm{~cm}^{-1}\right)$.

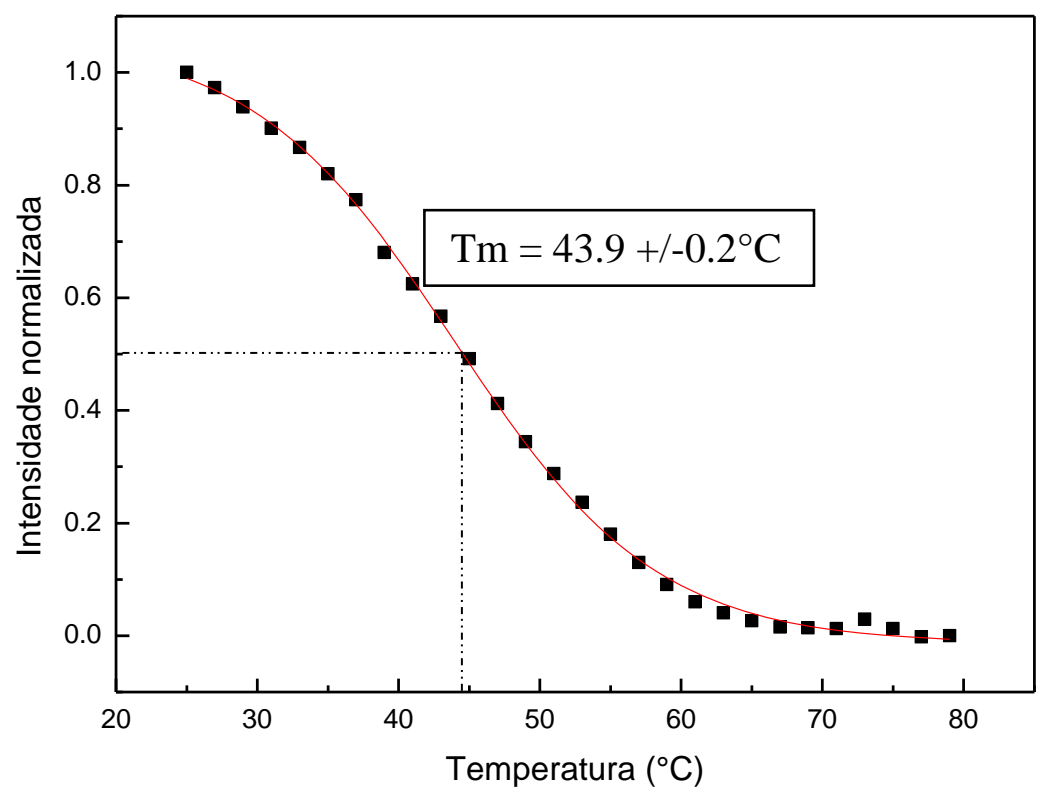

Figura 10: Comportamento térmico do número de onda referente às folhas $\beta\left(1635 \mathrm{~cm}^{-1}\right)$ com intensidade normalizada e ajuste sigmoidal. 
Um ajuste sigmoidal à curva com intensidade normalizada em $1635 \mathrm{~cm}^{-1}$ é mostrado na Figura 10. Este ajuste fornece uma temperatura média de desenovelamento em torno de $44^{\circ} \mathrm{C}$ para a BPT, valor próximo ao encontrado na literatura, $43^{\circ} \mathrm{C}$, para a forma $\psi$ da BPT através de dados espectofométricos (Smith, et al., 1969).

No entanto, a forte sobreposição que existe entre as bandas no espectro de infravermelho ainda deve ser resolvida através de técnicas de intensificação de resolução como autodeconvolução de Fourier, segunda derivada e ajuste de picos. Entretanto, a espectroscopia de correlação bidimensional têm se mostrado um avanço neste aspecto, além de fornecer informação a respeito dos eventos seqüenciais e importantes transições envolvidas no desenovelamento e enovelamento de proteínas.

A partir do comportamento da folha $\beta$ em $1635 \mathrm{~cm}^{-1}$ também é possível estimar a entalpia de van’t Hoff do processo de desenovelamento tomando a fração de folha $\beta$ nativa como

$$
f_{n}=\frac{I_{n}-I_{D}}{I_{N}-I_{D}}
$$

sendo $I_{N}$ e $I_{D}$ as intensidades de absorção da nativa e desnaturada, respectivamente, obtidas a partir do ajuste da sigmóide nas intensidades espectrais em $1635 \mathrm{~cm}^{-1}$. A fração desnaturada é dada por $f_{d}=1-f_{n}$ e a constante aparente de equilíbrio de desnaturação pode ser calculada a partir de

$$
K_{D}=\frac{f_{D}}{1-f_{D}}
$$

A entalpia pode então ser obtida a partir da chamada equação de van’t Hoff:

$$
\ln K_{D}=-\frac{\Delta H_{V H}}{R T}+\frac{\Delta S}{R}
$$

A Figura 11 mostra o ajuste linear de $\ln K_{D}$ por $1 / T$, onde o coeficiente angular é interpretado como $\Delta H_{V H} / R$ pela equação 4.3, indicando uma entalpia de desenovelamento de $\Delta H_{V H}=28,1 \pm 0,3 \mathrm{kcal} / \mathrm{mol}$. É importante ressaltar que o valor é estimado de modo indireto a partir das intensidades de absorção em $1635 \mathrm{~cm}^{-1}$. Calcula-se uma entropia próxima a temperatura de desenovelamento em torno de $\Delta S_{m}=88 \mathrm{cal} / \mathrm{mol} \mathrm{K}$. 


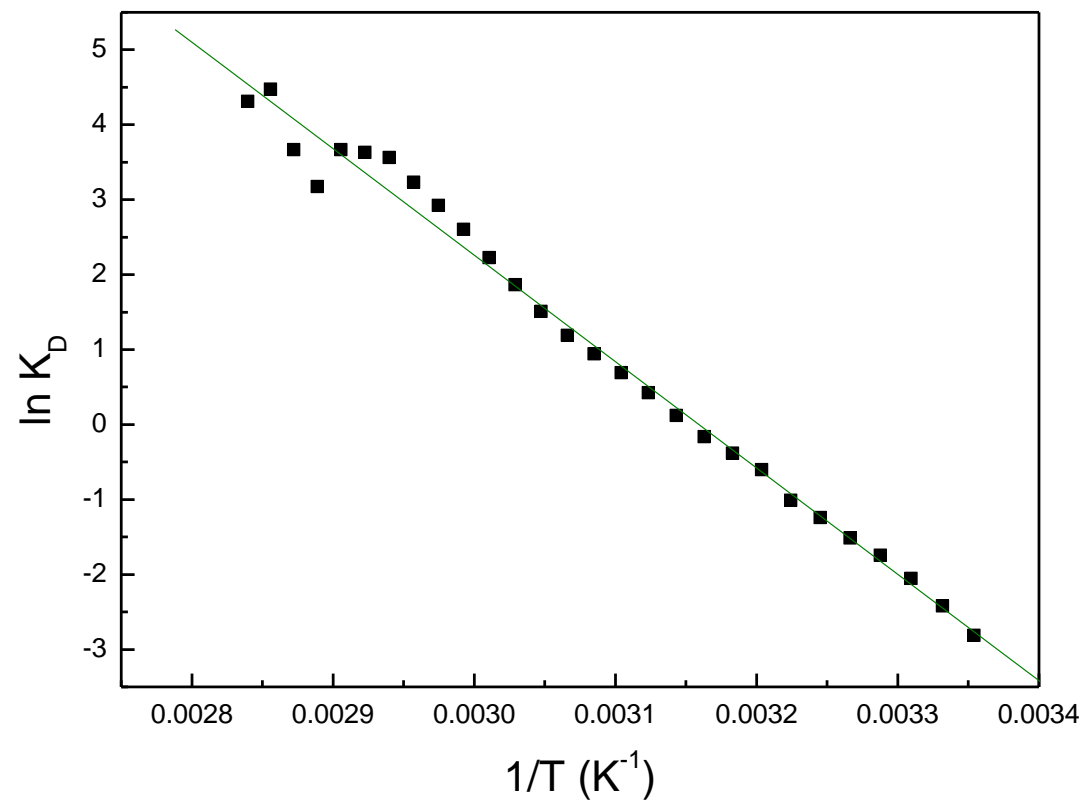

Figura 11: Ajuste linear da equação de van’t Hoff para a obtenção da entalpia aparente de desnaturação. 


\subsubsection{Análise de correlação sample-sample-2D}

A Figura 12 representa as intensidades de correlação bidimensional samplesample para o desenovelamento da BPT construída para os espectros de infravermelho obtidos de $25^{\circ}$ a $79^{\circ} \mathrm{C}$, com incremento de $2^{\circ} \mathrm{C}$. Nota-se, que a intensidade de correlação mais alta corresponde ao estágio inicial do processo e diminui até em torno de $50^{\circ} \mathrm{C}$, voltando a aumentar no estagio final. As temperaturas do estagio inicial e final tornam-se negativamente correlacionadas em torno de $50^{\circ} \mathrm{C}$, caracterizando uma transição de fase, neste caso, indicando a região principal do processo de desenovelamento.

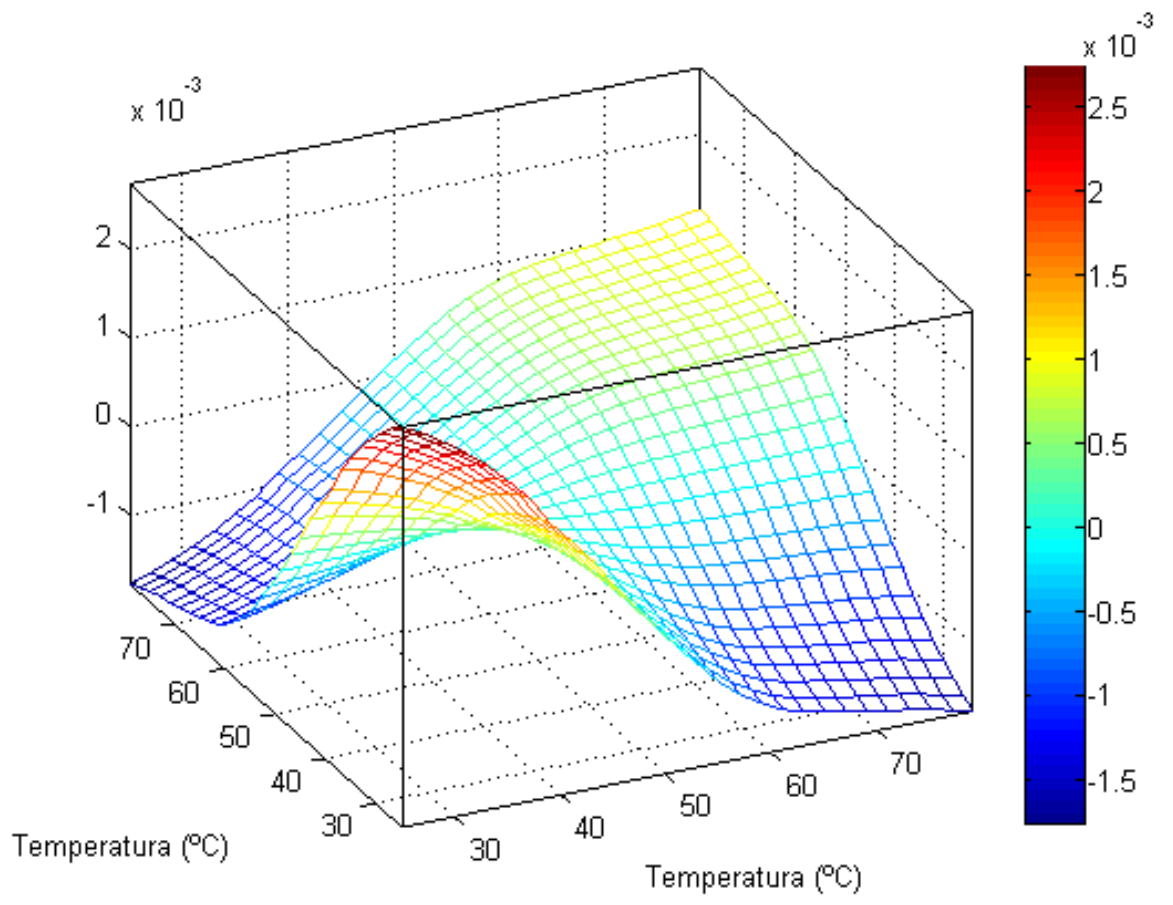

Figura 12: Superfície de correlação sample-sample, construído a partir de dados de infravermelho para o desenovelamento da BPT a pD 7,2 com a variação de temperatura entre 25 e $79^{\circ} \mathrm{C}$ e incremento de $2^{\circ} \mathrm{C}$.

A superfície de correlação sample-sample 2D também pode ser representada através de cortes ortogonais a fim de facilitar a visualização de temperaturas de transição envolvidas no desenovelamento protéico (Wang, et al., 2006). A Figura 13 mostra o corte ortogonal obtido a partir dos dados da Figura 11, observa-se uma temperatura de transição em torno de $48^{\circ} \mathrm{C}$ para a BPT que pode ser atribuída a temperatura de desenovelamento. $\mathrm{O}$ declínio acentuado e com irregularidades apresentado na Figura 13 entre as temperaturas de $25^{\circ}$ a $47^{\circ} \mathrm{C}$, indica que a BPT passa por mudanças conformacionais em uma faixa de temperatura mais extensa do que 
simplesmente uma abrupta variação em uma estreita região de temperatura. A presença de pequenas inflexões na forma de linha indicaria a localização destas transições conformacionais chamadas pré-transições.

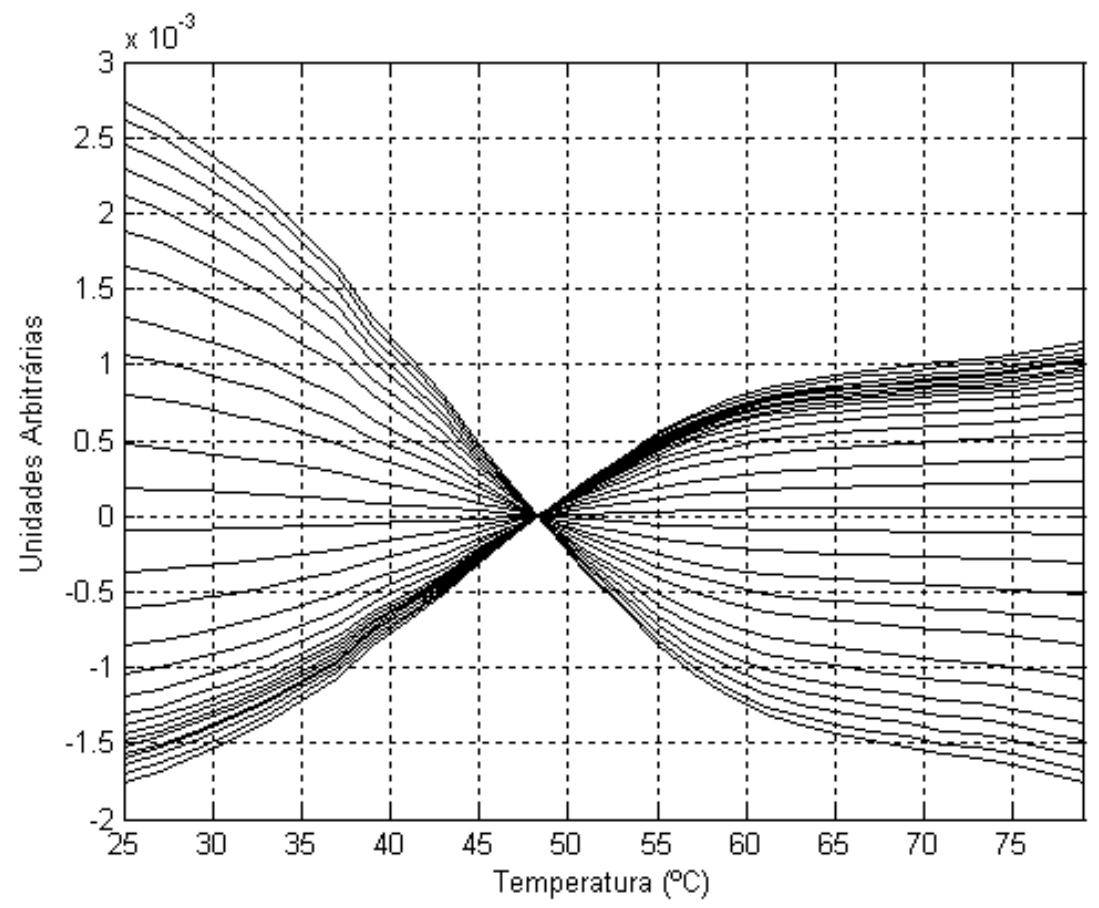

Figura 13: Corte ortogonal do espectro de correlação sample-sample, construído a partir de dados de infravermelho para o desenovelamento da BPT a pD 7,2 com a variação de temperatura entre 25 e $79^{\circ} \mathrm{C}$ e incremento de $2^{\circ} \mathrm{C}$.

Comparando-se este comportamento com o que é encontrado na literatura para a Ribonuclease A (Wang, et al., 2006), o perfil variacional do espectro obtido para a BPT indica que a mesma é conformacionalmente mais instável com o aumento de temperatura. Portanto, com base nestes indícios, prossegue-se com a análise para faixas de temperatura abaixo da transição principal; com a técnica de subdivisão de dados moving window, que em outras palavras consiste em realizar a correlação samplesample com um subconjunto de dados. É importante frisar que o número de linhas presente no corte ortogonal corresponderá ao número de espectros empregados na análise de correlação e o espectro de referência passa a ser a média no intervalo de temperatura utilizado. 
Utilizando o subconjunto de espectros entre $25^{\circ}$ e $47^{\circ} \mathrm{C}$ é obtida a correlação sample-sample na forma de corte ortogonal mostrada na Figura 14. Nota-se que abaixo da temperatura de desenovelamento se encontra um ponto de pré-transição, com a convergência das linhas ocorrendo em $37^{\circ} \mathrm{C}$. Uma leve inflexão na forma de linha pôde ser observada na região de $37^{\circ} \mathrm{C}$ na Figura 13, porém, caracterizado pelo tratamento de moving window na Figura 14.

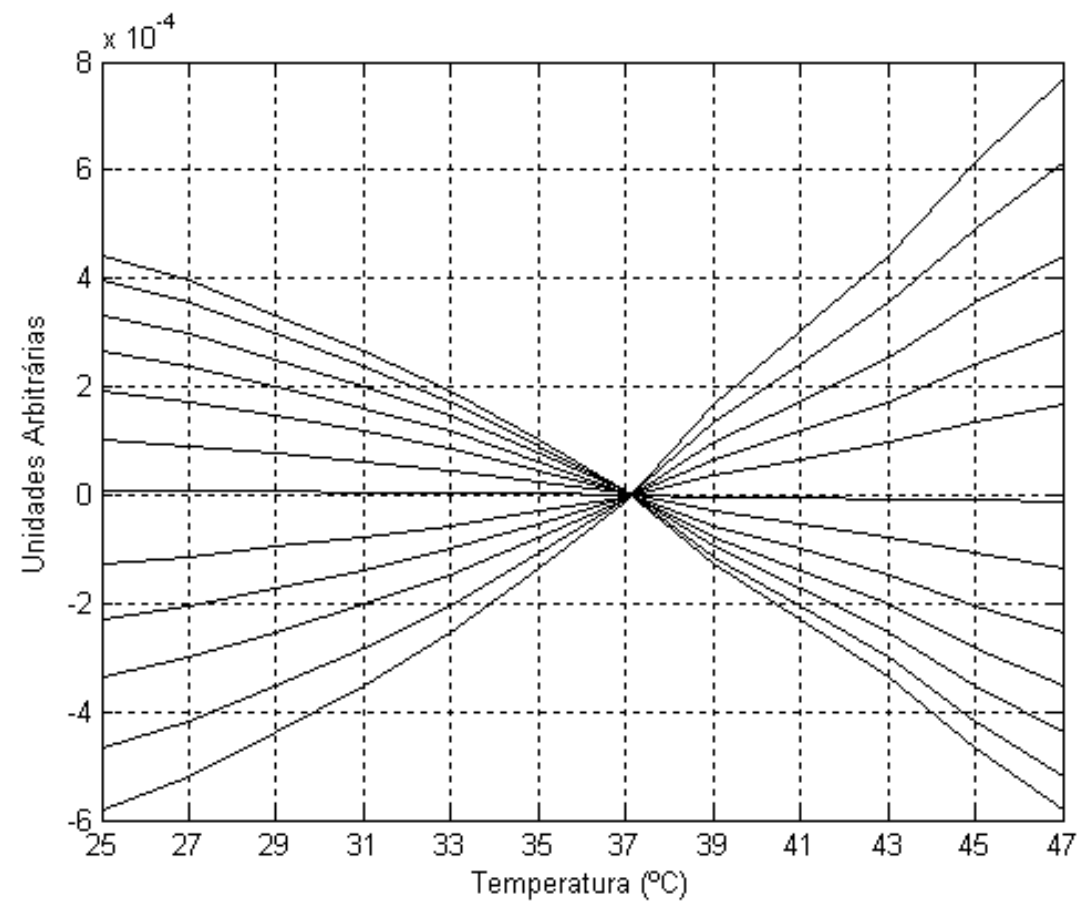

Figura 14: Corte ortogonal do espectro de correlação sample-sample, construído a partir de dados de infravermelho para o desenovelamento da BPT a pD 7,2 com a variação de temperatura entre 25 e $47^{\circ} \mathrm{C}$.

De semelhante modo, foi construída a Figura 15 , para a região entre $25^{\circ}$ e $37^{\circ} \mathrm{C}$, e a Figura 16, para a região entre $37^{\circ}$ e $47^{\circ} \mathrm{C}$, com o objetivo de avaliar o perfil da variação espectral em ambas as regiões. Pontos de pré-transição são encontrados em torno de $31^{\circ}$ e $42^{\circ} \mathrm{C}$, respectivamente. 


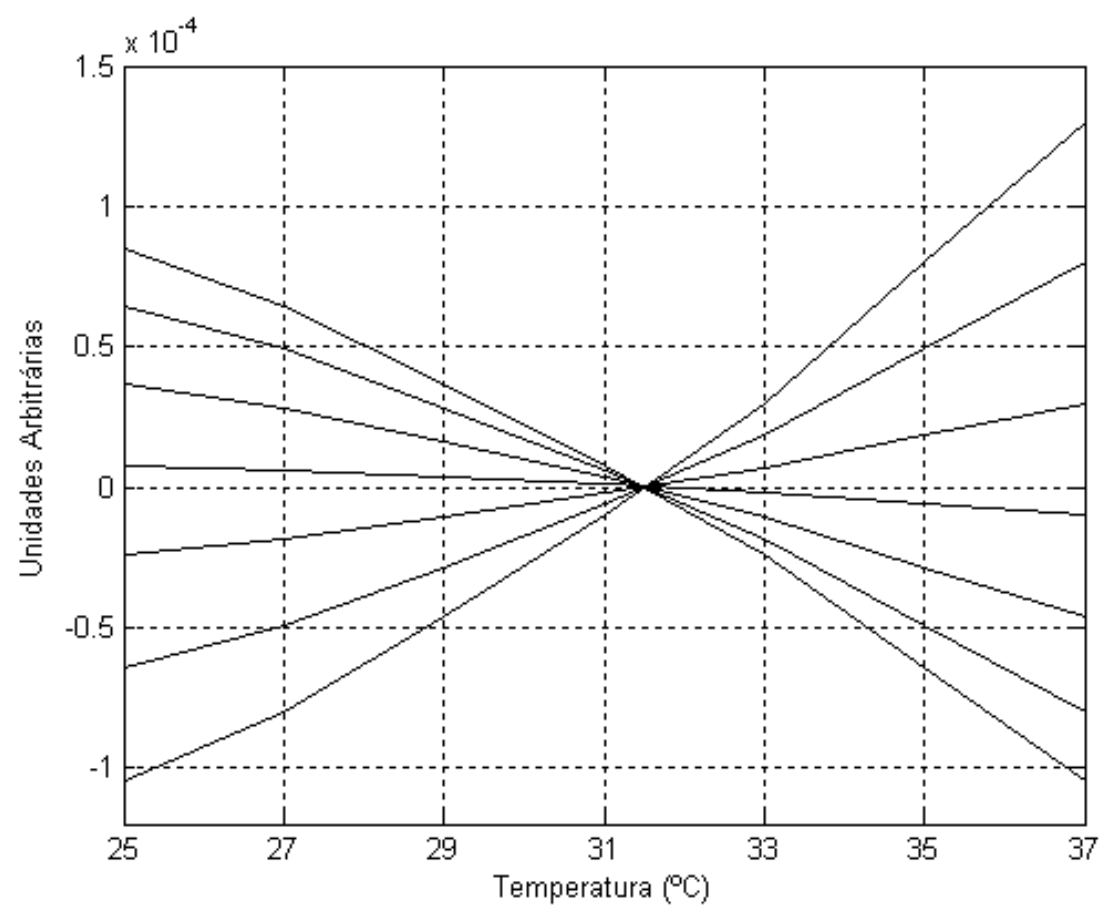

Figura 15: Corte ortogonal do espectro de correlação sample-sample, construído a partir de dados de infravermelho para o desenovelamento da BPT com a variação de temperatura entre 25 e $37^{\circ} \mathrm{C}$.

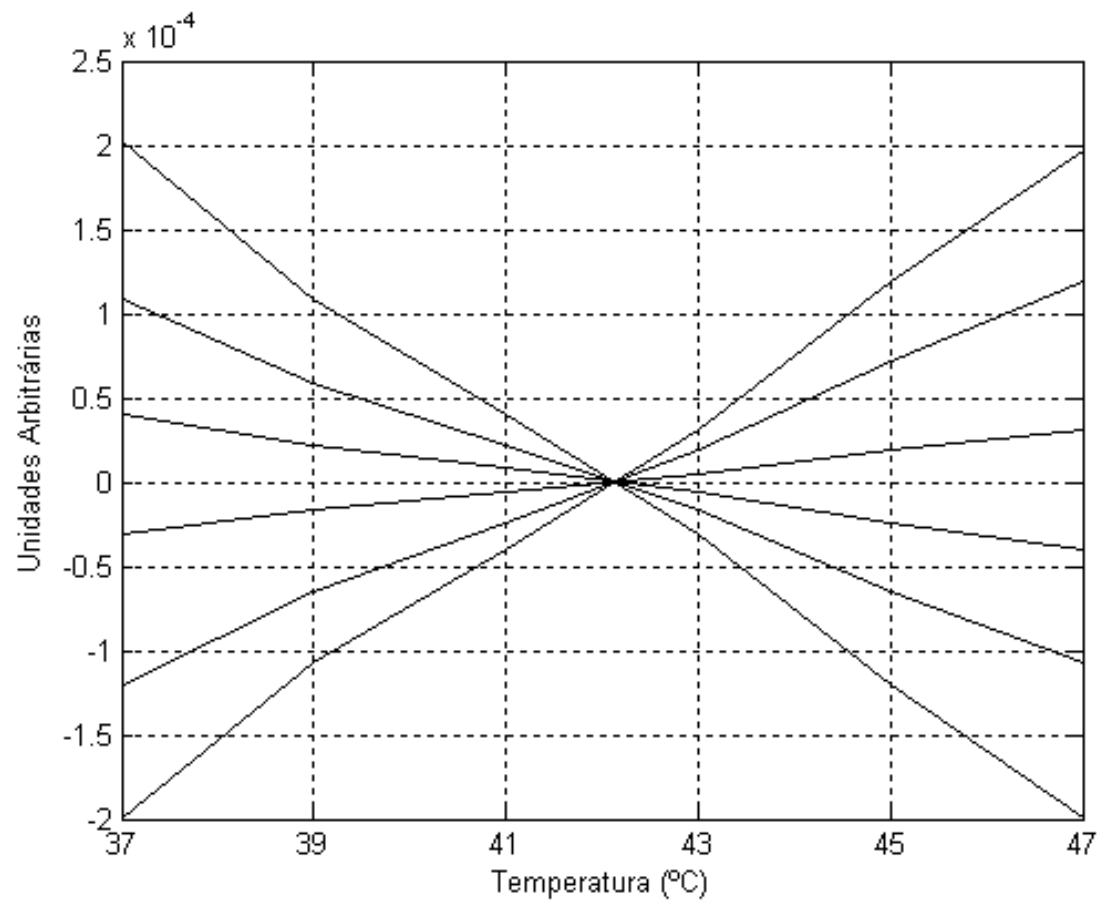

Figura 16: Corte ortogonal do espectro de correlação sample-sample, construído a partir de dados de infravermelho para o desenovelamento da BPT a pD 7,2 com a variação de temperatura entre 37 e $47^{\circ} \mathrm{C}$. 
Com a finalidade de estudar a possibilidade de ocorrência de alterações conformacionais acima da temperatura de desenovelamento, também foi avaliada a faixa entre $49^{\circ}$ e $79^{\circ} \mathrm{C}$ mostrada na Figura 17. Foi encontrado um ponto de transição em $59^{\circ} \mathrm{C}$, fazendo com que a avaliação inicial de confirmação de eventos pós-temperatura de transição principal fosse subdivido em duas sessões. A primeira sessão entre de $49^{\circ} \mathrm{e}$ $59^{\circ} \mathrm{C}$ é mostrada na Figura 18 e a segunda sessão entre $59^{\circ}$ e $79^{\circ} \mathrm{C}$ encontra-se na Figura 19, identificando mais duas temperaturas de pós-transição em $54^{\circ}$ e $69^{\circ} \mathrm{C}$.

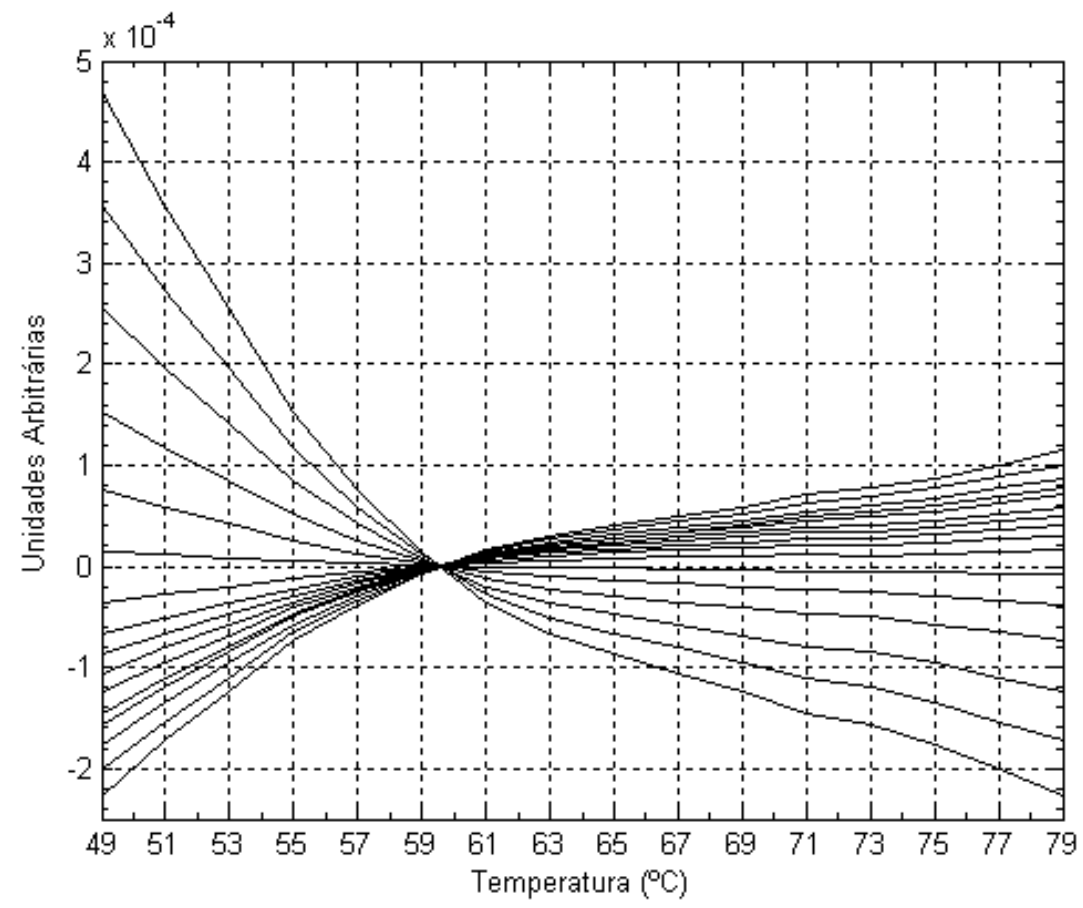

Figura 17: Corte ortogonal do espectro de correlação sample-sample, construído a partir de dados de infravermelho para o desenovelamento da BPT a pD 7,2 com a variação de temperatura entre 49 e $79^{\circ} \mathrm{C}$. 


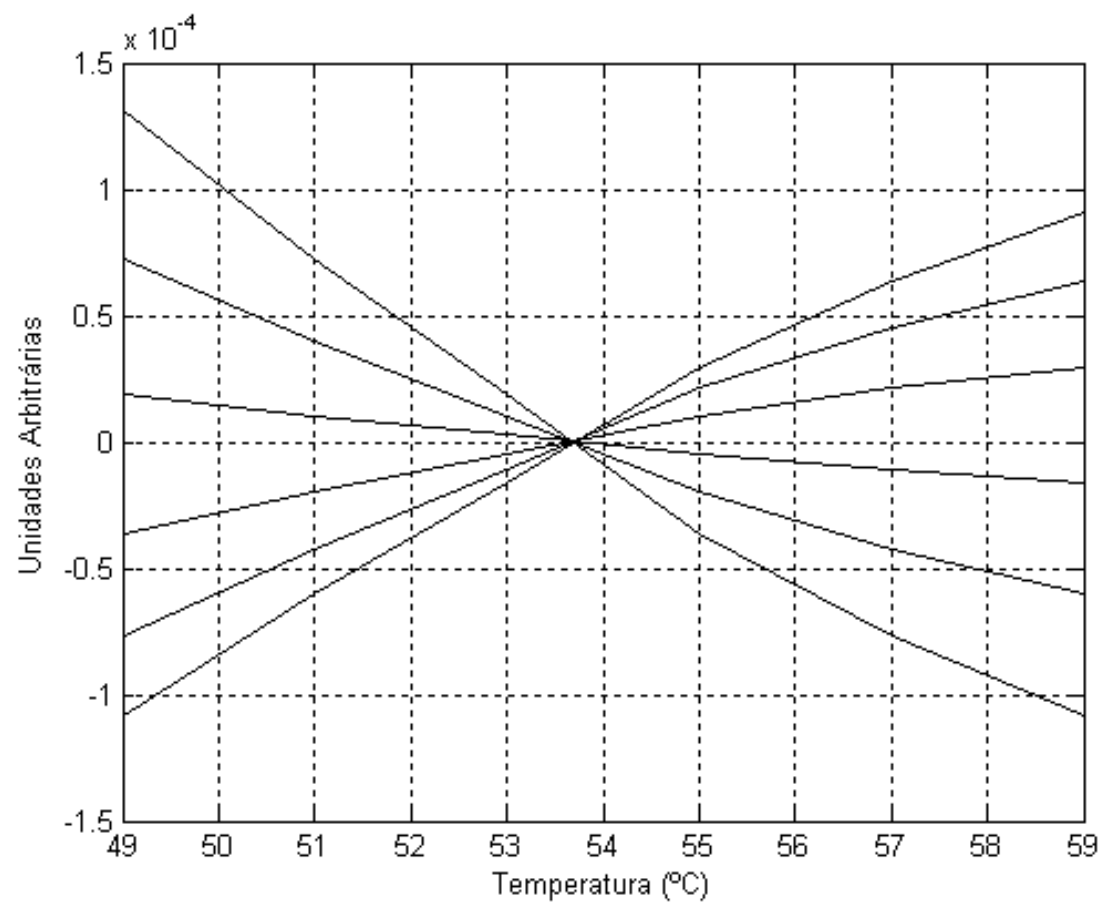

Figura 18: Corte ortogonal do espectro de correlação sample-sample, construído a partir de dados de infravermelho para o desenovelamento da BPT a pD 7,2 com a variação de temperatura entre 49 e $59^{\circ} \mathrm{C}$.

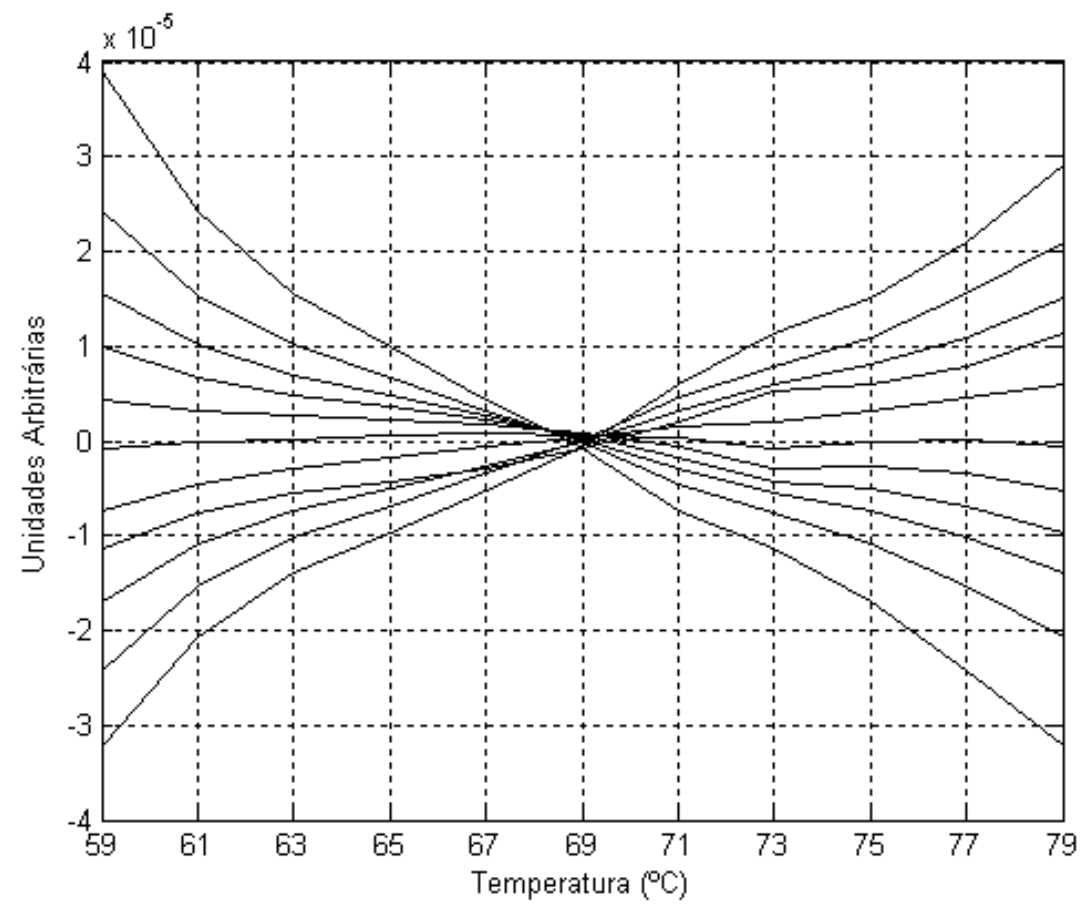

Figura 19: Corte ortogonal do espectro de correlação sample-sample, construído a partir de dados de infravermelho para o desenovelamento da BPT a pD 7,2 com a variação de temperatura entre 59 e $79^{\circ} \mathrm{C}$ 
Considerando que todos estes pontos obtidos na variação espectral sejam relevantes, quer abaixo quanto acima da temperatura de desenovelamento da proteína, ainda tem-se a necessidade de descrever a dinâmica de variação conformacional. Portanto, a análise é estendida para a espectroscopia de correlação bidimensional variable-variable em cada uma destas regiões, em ordem crescente com a temperatura, na busca de se descrever a dinâmica conformacional da BPT sob a influência da temperatura. 


\subsubsection{Análise de correlação bidimensional generalizada}

Para melhor descrever a evolução conformacional da BPT com o aumento da temperatura, as transições envolvidas no desenovelamento serão apresentadas em ordem crescente com a temperatura através de espectros bidimensionais de subconjuntos de dados.

A Figura 20 corresponde ao espectro síncrono da pré-transição entre $29^{\circ}$ e $33^{\circ} \mathrm{C}$. Os autopicos principais se encontram em 1633 e $1638 \mathrm{~cm}^{-1}$ que correspondem à estrutura de folha $\beta$, indicando que esta estrutura é a mais sensível a esta faixa de variação de temperatura. Um autopico menos intenso pode ser notado em $1656 \mathrm{~cm}^{-1}$, dando origem a picos cruzados positivos relativos às folhas $\beta$. De acordo com Prestrelski e co-autores, esta banda, geralmente atribuída somente a hélices $\alpha$, pode evidenciar voltas envolvidas no sítio de autoclivagem da BPT (Prestrelski, et al., 1991). Os picos positivos 1656x1633, 1656x1638 e 1633×1638 $\mathrm{cm}^{-1}$, são um indicativo do decréscimo da banda em $1656 \mathrm{~cm}^{-1}$ e, conseqüentemente, da autoclivagem da proteína nesta faixa de temperatura.

Picos cruzados negativos podem ser notados entre $1633 \times 1684 \mathrm{~cm}^{-1}$, assim como $1638 \times 1684 \mathrm{~cm}^{-1}$. O fato de $1684 \mathrm{~cm}^{-1}$ não possuir autopico intenso quando comparado ás folhas $\beta$ implica que pouca mudança ocorreu com a variação de temperatura neste número de onda. Ou seja, a diminuição nas intensidades espectrais correspondente às folhas $\beta$ (1633 e $1638 \mathrm{~cm}^{-1}$ ), ocorre sincronamente com alguma influência, ou ligeiro aumento, na banda correspondente a contatos intercadeias ou folhas $\beta$ antiparalelas $\left(1684 \mathrm{~cm}^{-1}\right)$.

De modo semelhante, picos cruzados positivos entre as bandas de folha $\beta$ (1633 e $1638 \mathrm{~cm}^{-1}$ ) e voltas $\left(1665,1669\right.$ e $\left.1675 \mathrm{~cm}^{-1}\right)$, embora sem autopico, pode ser relacionado à ligeira diminuição nas voltas $\beta$. O mesmo ocorre com picos cruzados relativos a folhas $\beta$ e as regiões de rearranjos de cadeia lateral $\left(1612 \mathrm{~cm}^{-1}\right)$, folhas antiparalelas ou fitas $\beta$ estendidas (1686, 1691 e $\left.1695 \mathrm{~cm}^{-1}\right)$. 


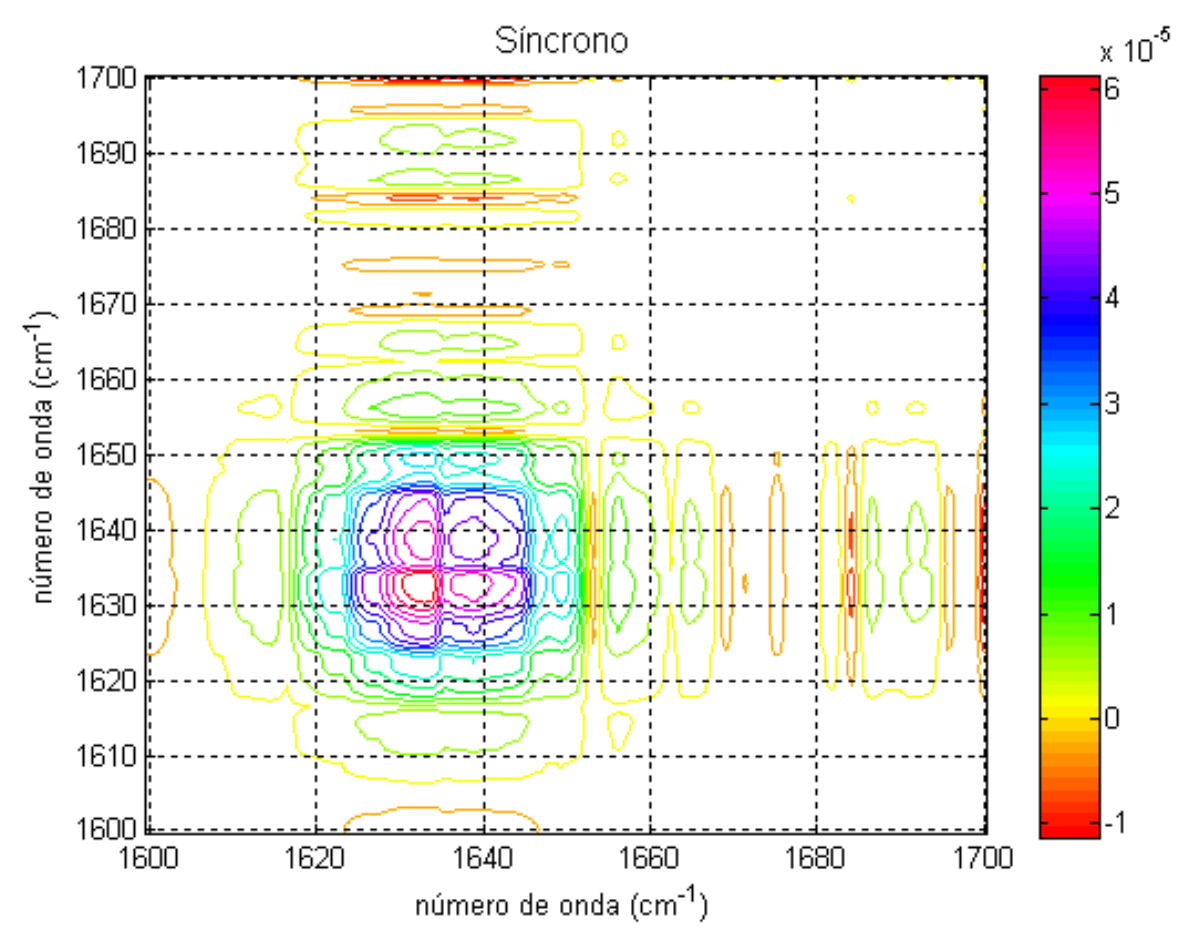

Figura 20: Mapa de contorno da correlação síncrona generalizada para o desenovelamento da BPT pD 7,2 entre 29 e $33^{\circ} \mathrm{C}$ na região de $1600-1700 \mathrm{~cm}^{-1}$.

Avaliando o mapa assíncrono mostrado na Figura 21, percebe-se que, abaixo da linha diagonal, picos cruzados negativos são encontrados entre $1653 \times 1633 \mathrm{~cm}^{-1} \mathrm{e}$ $1684 \times 1633 \mathrm{~cm}^{-1}$. Estes dois picos cruzados também possuem sinal negativo no espectro síncrono, indicando que as intensidades espectrais em nas hélices $\alpha$ (1653) e folhas $\beta$ antiparalelas ou contatos intercadeia $\left(1684 \mathrm{~cm}^{-1}\right)$ sofrem alteração antes da folha $\beta$ $\left(1633 \mathrm{~cm}^{-1}\right)$. No entanto, é necessário verificar que $1653 \mathrm{~cm}^{-1}$ não possui autopico síncrono (ver Figura 20), revelando que as hélices $\alpha$ pouco foram afetadas pela perturbação térmica na primeira região de pré-transição em torno de $31^{\circ} \mathrm{C}$.

Além destes, diversos picos cruzados surgem na região que compreende 1615 a $1650 \mathrm{~cm}^{-1}$. Em deutério, as posições da banda de folhas $\beta$ se localizam em média em torno de $1630 \mathrm{~cm}^{-1}$ com extremos que variam de 1615 a $1638 \mathrm{~cm}^{-1}$, e as estruturas desordenadas ou irregulares geralmente se localizam em $1645 \mathrm{~cm}^{-1}$ variando entre 1639 e $1651 \mathrm{~cm}^{-1}$ (Barth, 2007). Esta região, altamente sobreposta no espectro síncrono (ver Figura 20), mostra que folhas $\beta$ e estruturas irregulares podem ter diferentes padrões de vibração que respondem diferentemente à perturbação térmica. Estruturas irregulares surgem em 1642 e $1647 \mathrm{~cm}^{-1}$ com pico cruzado negativo $1647 \times 1642 \mathrm{~cm}^{-1}$, indicando 
que a estrutura irregular assinalada em $1642 \mathrm{~cm}^{-1}$ é mais sensível à perturbação do que em $1647 \mathrm{~cm}^{-1}$.

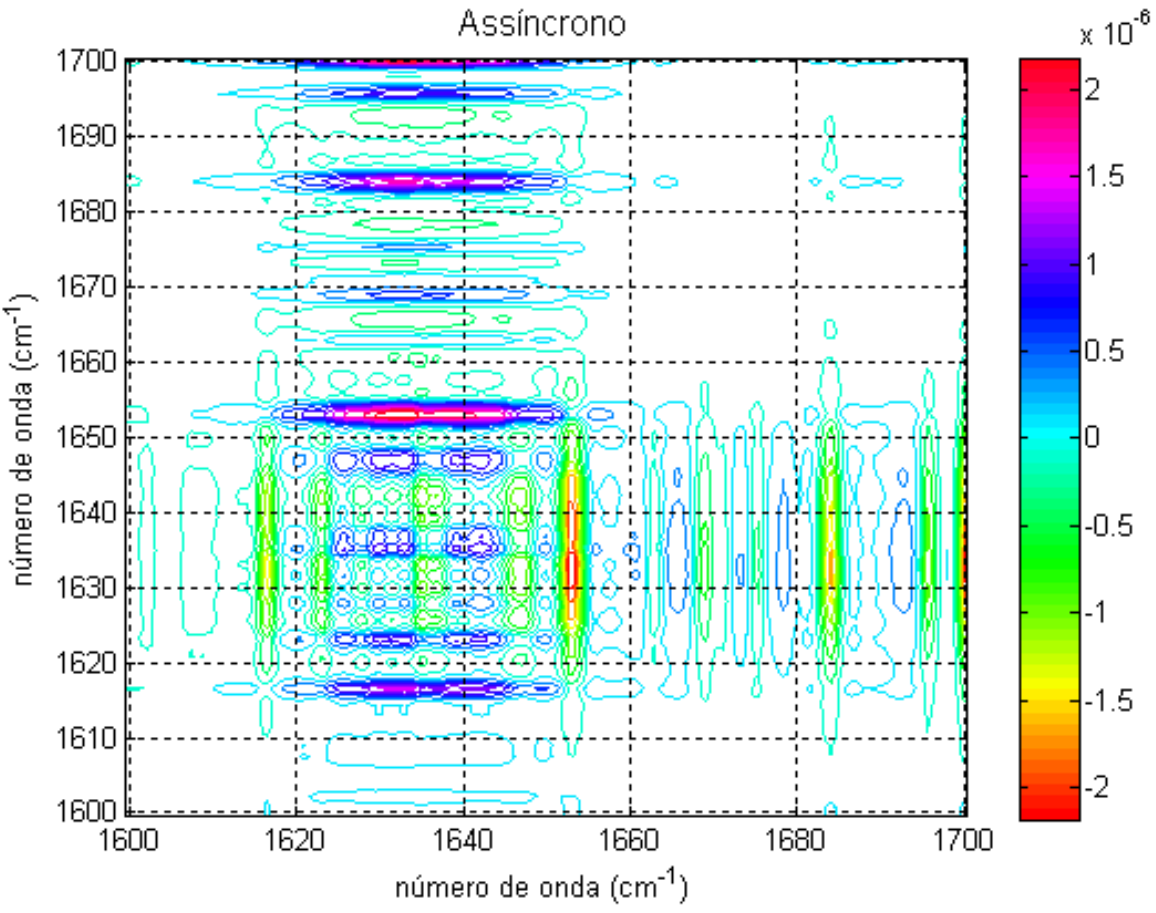

Figura 21: Mapa de contorno da correlação assíncrona generalizada para o desenovelamento da BPT pD 7,2 entre $29^{\circ}$ e $33^{\circ} \mathrm{C}$ na região de $1600-1700 \mathrm{~cm}^{-1}$. 
A Figura 22 é o mapa síncrono que representa as variações conformacionais envolvidas na segunda pré-transição, que é encontrada pela perturbação espectral na análise sample-sample, entre $35^{\circ}$ e $39^{\circ} \mathrm{C}$. A banda mais afetada corresponde à folha $\beta$ centrada em $1635 \mathrm{~cm}^{-1}$, e que se espalha por uma grande faixa de números de onda. Em comparação à pré-transição anterior, um pico cruzado positivo surge entre 1635 e 1684 $\mathrm{cm}^{-1}$ indicando que há diminuição na intensidade da folha $\beta\left(1635 \mathrm{~cm}^{-1}\right)$ simultaneamente a diminuição na folha $\beta$ antiparalela ou contatos intercadeias (1684 $\mathrm{cm}^{-1}$ ). Entretanto, $1684 \mathrm{~cm}^{-1}$ não possui autopico indicando pouca sensibilidade à variação de temperatura, no entanto, ainda apresenta alguma correlação devido à presença do pico cruzado.

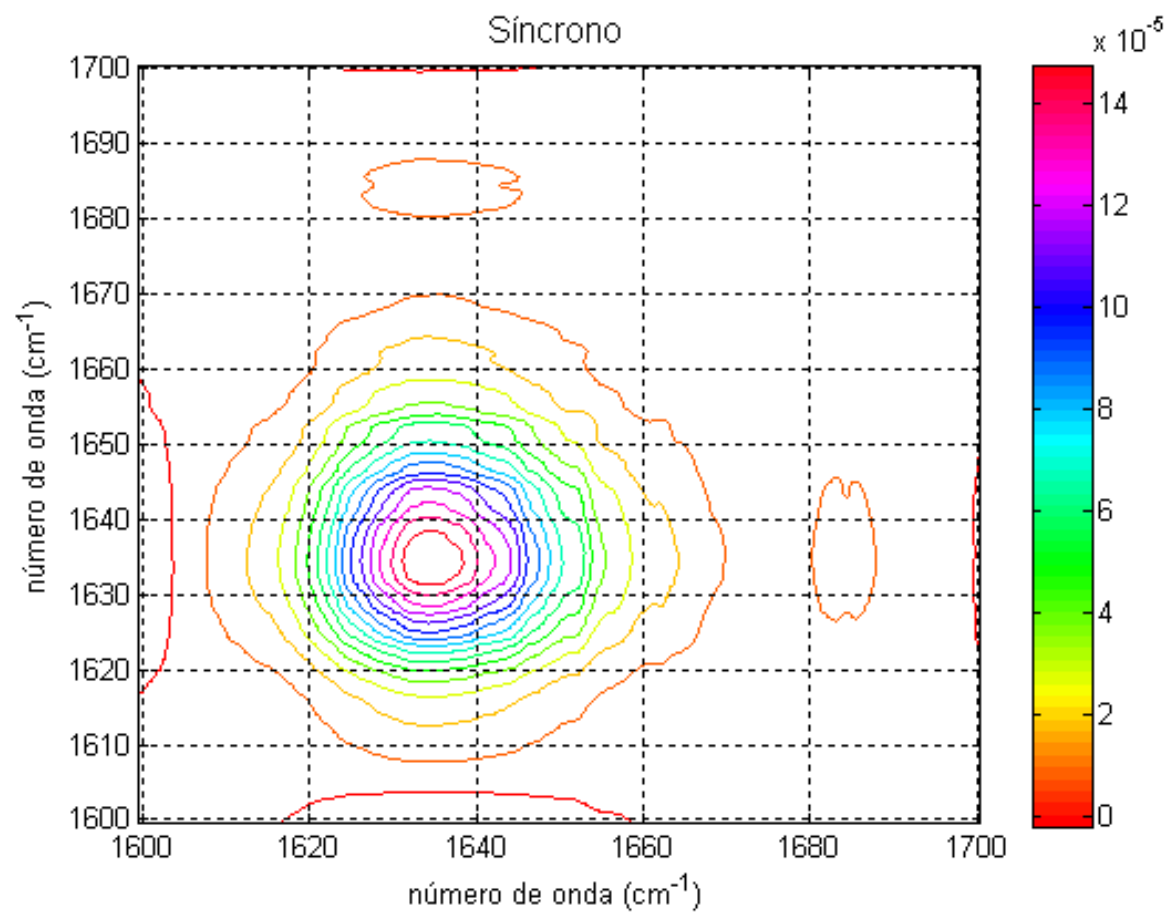

Figura 22: Mapa de contorno da correlação síncrona generalizada para o desenovelamento da BPT pD 7,2 entre $35^{\circ}$ e $39^{\circ} \mathrm{C}$ na região de $1600-1700 \mathrm{~cm}^{-1}$. 
O mapa assíncrono desta pré-transição se encontra na Figura 23. Analisando abaixo da linha diagonal, são encontrados dois picos cruzados positivos $1635 \times 1631$, $1635 \times 1625 \mathrm{~cm}^{-1}$ e um negativo $1638 \times 1635 \mathrm{~cm}^{-1}$, relacionados a folhas $\beta$. Logo, embora o pico síncrono esteja centrado em $1635 \mathrm{~cm}^{-1}$ (ver Figura 22), existem diferentes padrões de vibração para as folhas $\beta$, que respondem de modo diferente à perturbação.

Picos cruzados positivos são encontrados também entre 1646x1625, 1646x1630, $1646 \times 42,1653 \times 1638,1653 \times 1633,1669 \times 1633,1675 \times 1633,1684 \times 1633$ e 1695x1633 $\mathrm{cm}^{-1}$. As bandas correspondentes a estrutura desordenada ou irregular $\left(1646 \mathrm{~cm}^{-1}\right) \mathrm{e}$ hélices $\alpha\left(1653 \mathrm{~cm}^{-1}\right)$ podem ter tido o sinal síncrono (ver Figura 22) encoberto pelas bandas de vibração de folhas $\beta$. Aplicando as regras de Noda a este conjunto de picos cruzados, têm-se que alterações conformacionais nesta faixa de temperatura ocorrem primeiramente na estrutura irregular (1642 e $\left.1646 \mathrm{~cm}^{-1}\right)$, voltas $\beta\left(1669\right.$ e $\left.1675 \mathrm{~cm}^{-1}\right)$, fitas estendidas $\left(1695 \mathrm{~cm}^{-1}\right)$, hélice $\alpha\left(1653 \mathrm{~cm}^{-1}\right)$ e na folha $\beta$ em $1635 \mathrm{~cm}^{-1}$, a partir de então a folha $\beta$ em 1638, 1633, 1630 e $1625 \mathrm{~cm}^{-1}$ é afetada.

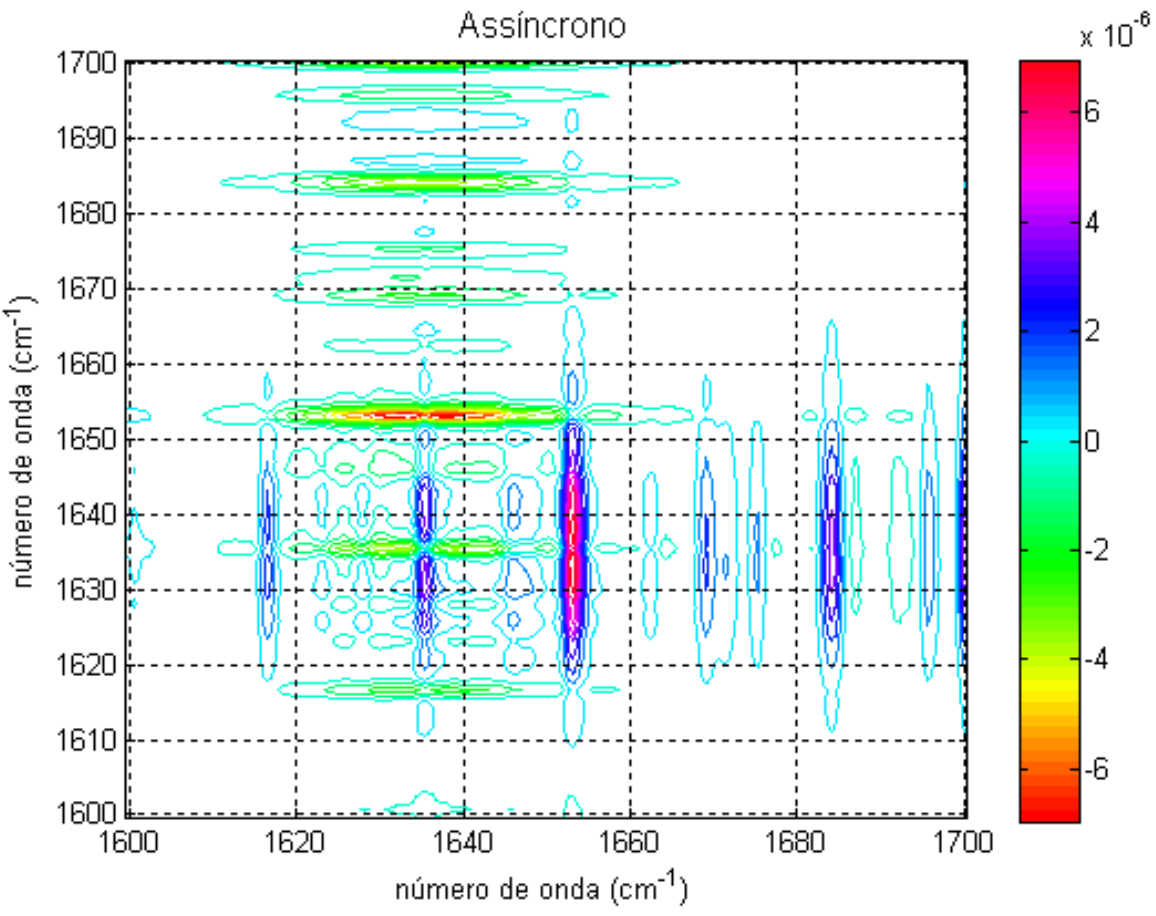

Figura 23: Mapa de contorno da correlação assíncrona generalizada para o desenovelamento da BPT pD 7,2 entre $35^{\circ}$ e $39^{\circ} \mathrm{C}$ na região de $1600-1700 \mathrm{~cm}^{-1}$. 
As Figuras 24 e 25 representam a terceira pré-transição que ocorre entre $41^{\circ} \mathrm{e}$ $45^{\circ} \mathrm{C}$. O mapa bidimensional síncrono mostrado na Figura 24 é dominado pela folha $\beta$, porém a banda é subdividida em autopicos em 1633, 1635 e $1638 \mathrm{~cm}^{-1}$. O pico cruzado positivo $1638 \times 1633 \mathrm{~cm}^{-1}$ indica a simultaneidade na alteração destas bandas. Um autopico em $1656 \mathrm{~cm}^{-1}$, que pode estar relacionado a voltas no sítio de autoclivagem BPT (Prestrelski, et al., 1991), fornece indícios que a autoclivagem da proteína ainda está ocorrendo.

Picos cruzados negativos são encontrados em 1669x1635, 1675x1635, $1684 \times 1635,1695 \times 1635 \mathrm{~cm}^{-1}$. Estes picos referem-se à correlação entre a região de folha $\beta\left(1635 \mathrm{~cm}^{-1}\right)$ e as bandas assinaladas para voltas (1669 e $\left.1675 \mathrm{~cm}^{-1}\right)$, folhas $\beta$ antiparalelas ou contatos intercadeia $\left(1684 \mathrm{~cm}^{-1}\right)$ e fitas estendidas $\left(1695 \mathrm{~cm}^{-1}\right)$, embora apenas a folha $\beta$ possua autopico.

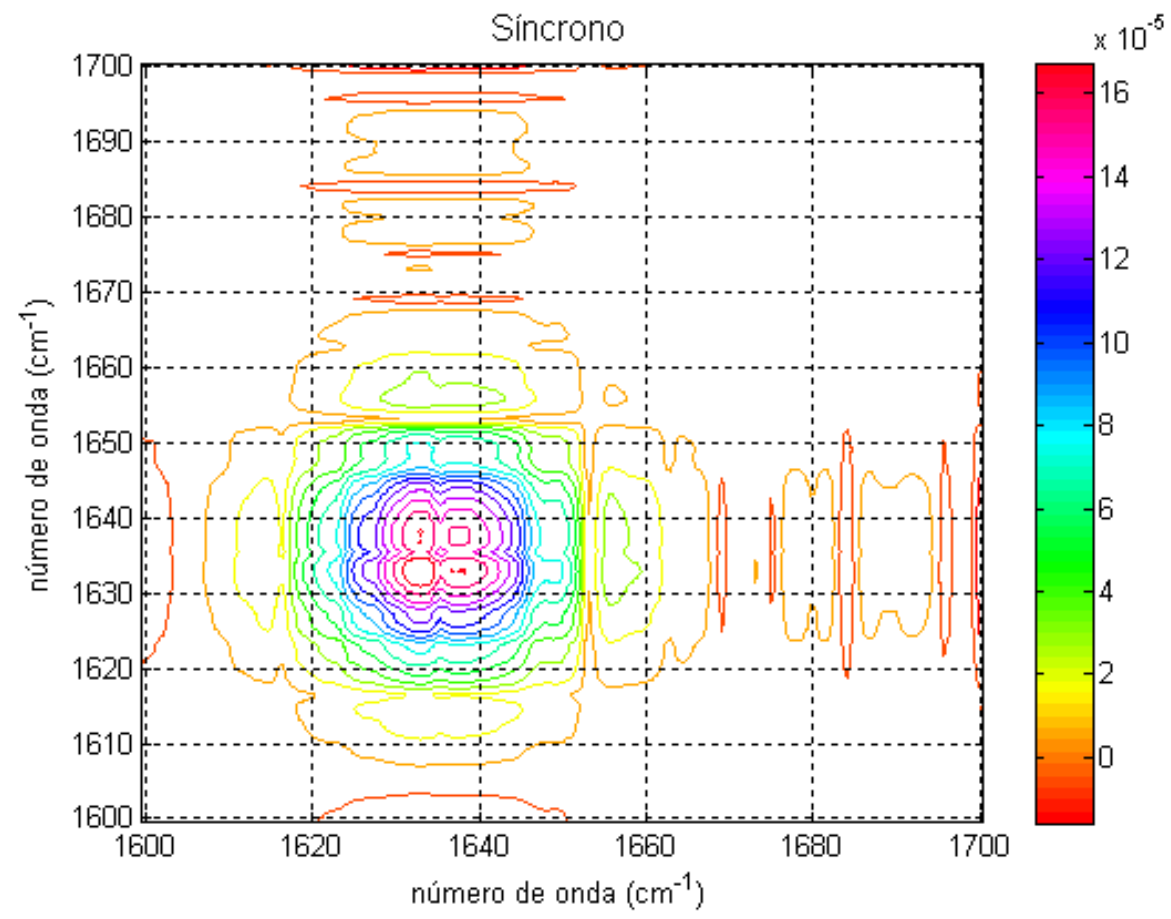

Figura 24: Mapa de contorno da correlação síncrona generalizada para o desenovelamento da BPT pD 7,2 entre $41^{\circ}$ e $45^{\circ} \mathrm{C}$ na região de $1600-1700 \mathrm{~cm}^{-1}$. 
O mapa assíncrono mostrado na Figura 25 possui, abaixo da linha diagonal, pares de picos cruzados positivos $1653 \times 1633$ e $1653 \times 1638 \mathrm{~cm}^{-1}$ indicando que perturbações na hélice $\alpha\left(1653 \mathrm{~cm}^{-1}\right)$ ocorreram anteriormente à folha $\beta$ (1633 e 1638 $\mathrm{cm}^{-1}$ ). Um pico cruzado positivo em $1684 \times 1633 \mathrm{~cm}^{-1}$, com o sinal síncrono negativo (ver Figura 24), indica que alterações na folha $\beta\left(1633 \mathrm{~cm}^{-1}\right)$ ocorreram antes da folha $\beta$ antiparalela ou contatos intercadeia $\left(1684 \mathrm{~cm}^{-1}\right)$. Assim como na pré-transição em $31^{\circ} \mathrm{C}$ (ver Figura 20), surgem diversos picos cruzados na região de 1615 a $1650 \mathrm{~cm}^{-1}$, indicando diferentes comportamentos diante da perturbação térmica para os diferentes padrões de vibração de folhas $\beta$ e estrutura irregular.

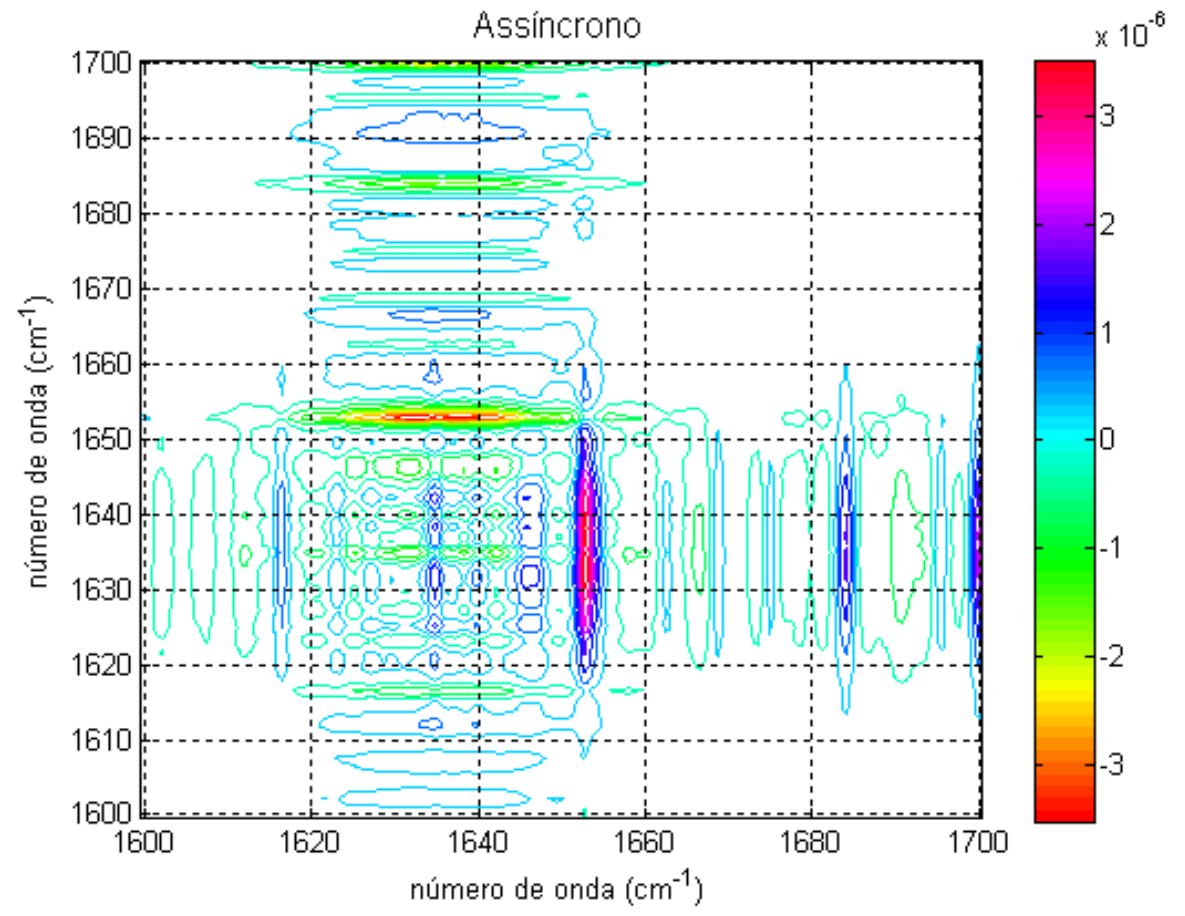

Figura 25: Mapa de contorno da correlação assíncrona generalizada para o desenovelamento da BPT pD 7,2 entre $41^{\circ}$ e $45^{\circ} \mathrm{C}$ na região de $1600-1700 \mathrm{~cm}^{-1}$. 
A região de desenovelamento, entre $45^{\circ}$ e $51^{\circ} \mathrm{C}$, tem como principal contribuição a folha $\beta$ centrada em $1633 \mathrm{~cm}^{-1}$, mostrada no mapa síncrono da Figura 26. Picos cruzados positivos surgem entre $1633 \times 1615$ e $1655 \times 1633 \mathrm{~cm}^{-1}$. A correlação positiva de $1655 \mathrm{~cm}^{-1}$ pode indicar que autoclivagens ainda ocorrem. $\mathrm{O}$ assinalamento da banda de $1615 \mathrm{~cm}^{-1}$ não é bem estabelecido, podendo estar relacionada à exposição de cadeias laterais antes da temperatura de desenovelamento ou contatos intercadeias após a temperatura de desenovelamento (He, et al., 2005).

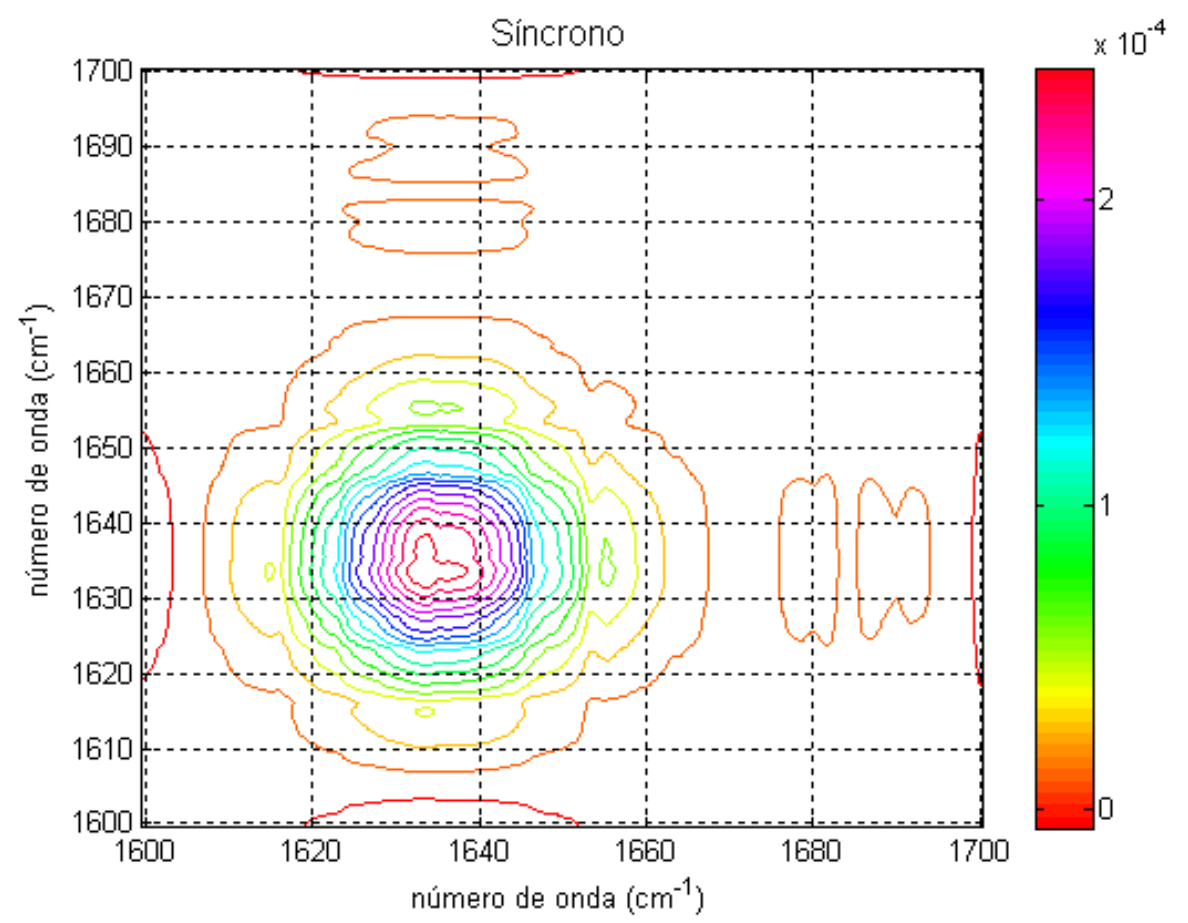

Figura 26: Mapa de contorno da correlação síncrona generalizada para o desenovelamento da BPT pD 7,2 entre $45^{\circ}$ e $51^{\circ} \mathrm{C}$ na região de $1600-1700 \mathrm{~cm}^{-1}$.

No espectro assíncrono mostrado na Figura 27 surgem picos cruzados negativos em 1635x1633, 1646x1633, 1646x1639, 1653x1633, 1653x1639, 1684x1635, 1669x1633 $\mathrm{cm}^{-1}$ e positivos 1633x1616, 1639x1616, 1633x1623, 1639x1623, $1633 \times 1628,1639 \times 1628,1639 \times 1635,1677 \times 1635,1665 \times 1635,1656 \times 1653 \mathrm{~cm}^{-1}$.

Aplicando as regras de Noda, os picos assíncronos sugerem que a diminuição na intensidade da folha $\beta$ em 1633 e $1639 \mathrm{~cm}^{-1}$ antecedem alterações na contribuição de folha $\beta$ em 1635, 1623 e $1628 \mathrm{~cm}^{-1}$. Em geral, as bandas de 1623 e $1628 \mathrm{~cm}^{-1}$ são 
atribuídas a fitas estendidas e atribuídas a uma banda única em torno de $1625 \mathrm{~cm}^{-1}$ por métodos de deconvolução (Prestrelski, et al., 1991).

Simultaneamente à alteração conformacional da folha $\beta$ em 1633 e $1639 \mathrm{~cm}^{-1}$ há alterações espectrais nas voltas $\left(1665,1669,1677 \mathrm{~cm}^{-1}\right)$, fitas estendidas $\left(1693 \mathrm{~cm}^{-1}\right) \mathrm{e}$ na banda assinalada para ao sítio de autoclivagem da BPT em $1656 \mathrm{~cm}^{-1}$ (Prestrelski, et al., 1991). A seguir, simultaneamente a alteração conformacional da folha $\beta$ em 1635 , 1623 e $1628 \mathrm{~cm}^{-1}$ ocorre perturbação na hélice $\alpha\left(1653 \mathrm{~cm}^{-1}\right)$ e na estrutura irregular $\left(1646 \mathrm{~cm}^{-1}\right)$. Seguindo a sequiência e eventos da mudança de estrutura secundária há rearranjos de cadeia lateral $\left(1616 \mathrm{~cm}^{-1}\right)$ e nas folhas $\beta$ antiparalelas ou contatos intercadeia $\left(1684 \mathrm{~cm}^{-1}\right)$.

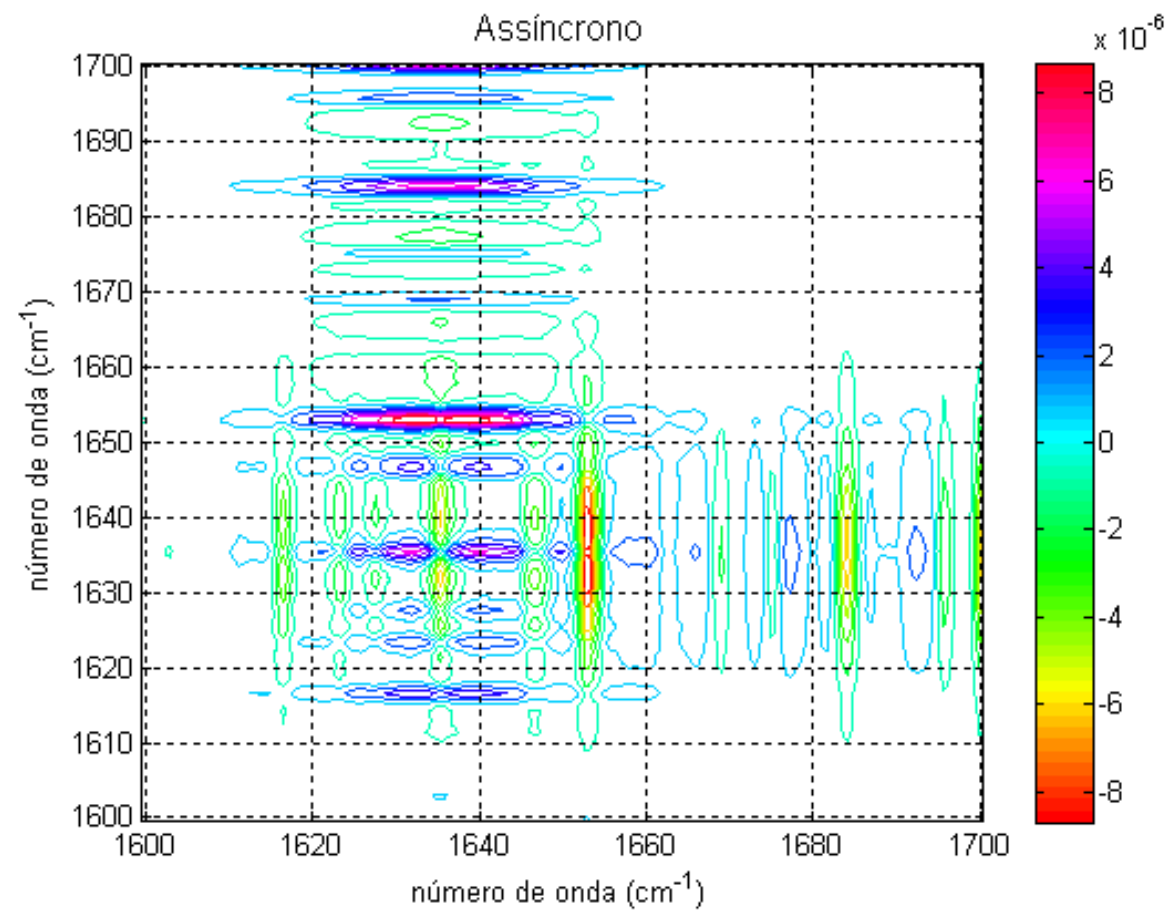

Figura 27: Mapa de contorno da correlação assíncrona generalizada para o desenovelamento da BPT pD 7,2 entre $45^{\circ}$ e $51^{\circ} \mathrm{C}$ na região de $1600-1700 \mathrm{~cm}^{-1}$.

Serão agora descritas as chamadas pós-transições, eventos importantes que ocorrem após a temperatura média de desenovelamento. A primeira pós-transição, localizada entre $51^{\circ}$ e $55^{\circ} \mathrm{C}$ na análise sample-sample (Figura 18), é representada pelos mapas síncrono e assíncrono através das Figuras 28 e 29, respectivamente. 
No espectro síncrono da primeira pós-transição mostrado na Figura 28, a folha $\beta$ é subdividida em três contribuições principais: 1633, 1635 e $1638 \mathrm{~cm}^{-1}$. Pares de picos cruzados negativos surgem entre $1653 \times 1633$ e $1653 \times 1638 \mathrm{~cm}^{-1}, 1684 \mathrm{x} 1633 \mathrm{e}$ $1684 \times 1638 \mathrm{~cm}^{-1}, 1695 \times 1633$ e $1695 \times 1638 \mathrm{~cm}^{-1}$. No entanto, não há autopico para as bandas que assinalam a hélice $\alpha\left(1653 \mathrm{~cm}^{-1}\right)$, folhas $\beta$ antiparalelas ou contatos intercadeias $\left(1684 \mathrm{~cm}^{-1}\right)$ e fitas estendidas $\left(1695 \mathrm{~cm}^{-1}\right)$, indicando que estas estruturas são menos sensíveis à perturbação nesta faixa de temperatura. Picos cruzados com sinal positivo são encontrados entre 1633x1615, 1647x1635, 1649x1633 e 1649x1638 cm-1, indicando que rearranjos de cadeias laterais $\left(1615 \mathrm{~cm}^{-1}\right)$ e alterações na estrutura irregular (1646 e $1649 \mathrm{~cm}^{-1}$ ), embora sem autopico, ocorrem simultaneamente às folhas $\beta\left(1633,1635\right.$ e $\left.1638 \mathrm{~cm}^{-1}\right)$.

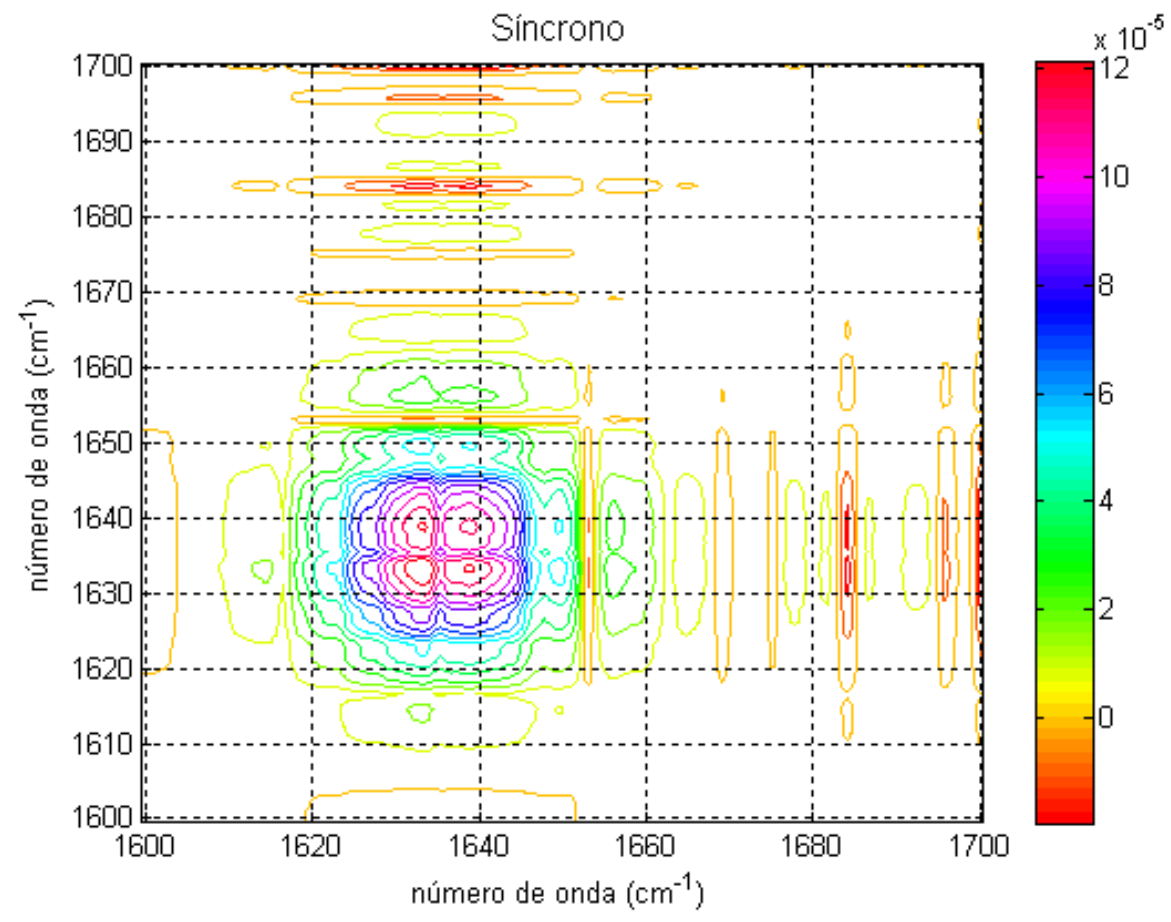

Figura 28: Mapa de contorno da correlação síncrona generalizada para o desenovelamento da BPT pD 7,2 entre $51^{\circ}$ e $55^{\circ} \mathrm{C}$ na região de $1600-1700 \mathrm{~cm}^{-1}$. 


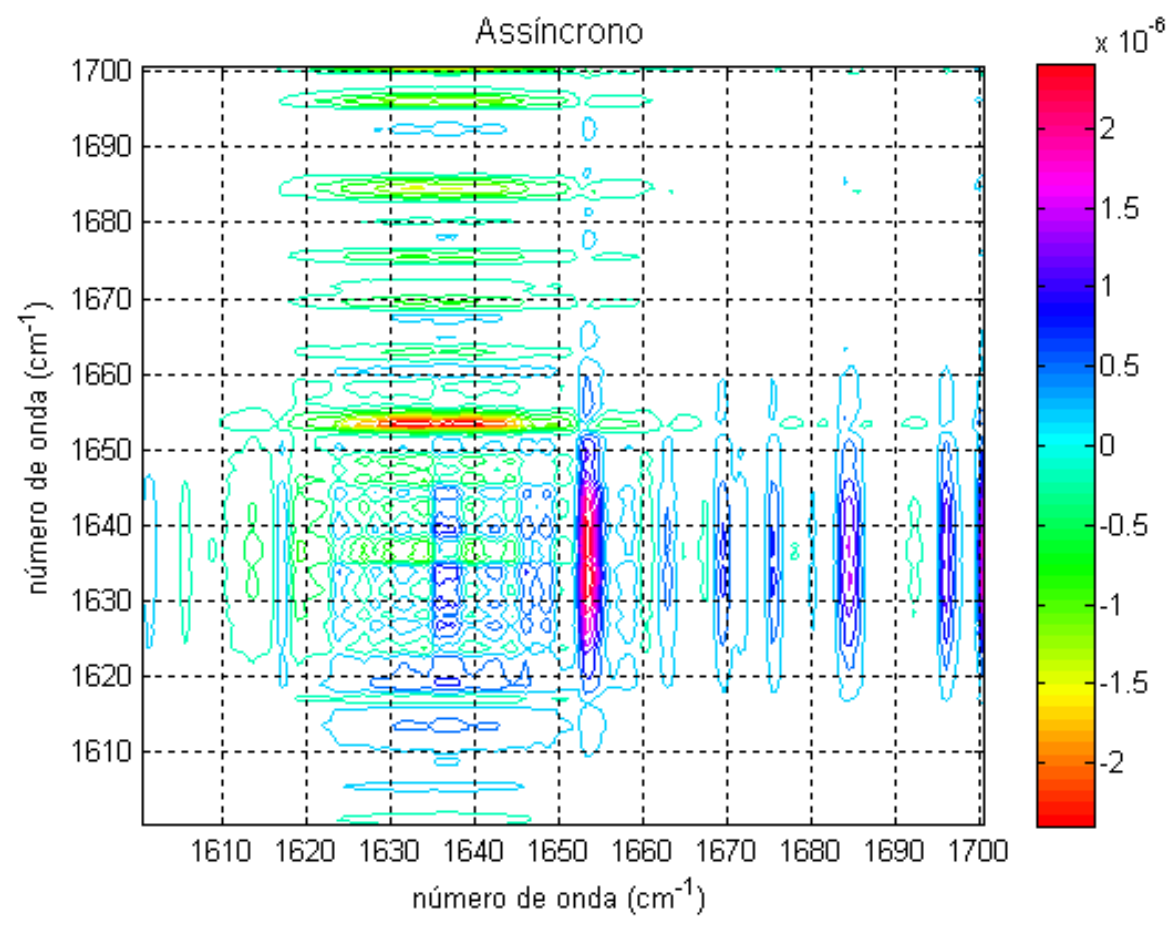

Figura 29: Mapa de contorno da correlação assíncrona generalizada para o desenovelamento da BPT pD 7,2 entre $51^{\circ}$ e $55^{\circ} \mathrm{C}$ na região de $1600-1700 \mathrm{~cm}^{-1}$.

O espectro assíncrono da Figura 29 apresenta picos positivos 1653x1633, $1653 \times 1638,1684 \times 1633,1684 \times 1638$ e $1695 \times 1635 \mathrm{~cm}^{-1}$. A posição destes picos possui sinal negativo também no espectro síncrono (ver Figura 28), indicando que alterações conformacionais na hélice $\alpha\left(1653 \mathrm{~cm}^{-1}\right)$, folhas $\beta$ antiparalelas ou contatos intercadeias $\left(1684 \mathrm{~cm}^{-1}\right)$ e fitas estendidas $\left(1695 \mathrm{~cm}^{-1}\right)$ antecedem às folhas $\beta(1633,1635$ e 1638 $\mathrm{cm}^{-1}$ ). Diversos picos cruzados na região de folha $\beta$ mostram que os diferentes modos de vibração da folha $\beta$ possuem diferentes respostas à perturbação. 
A segunda pós-transição localizada entre $57^{\circ}$ e $63^{\circ} \mathrm{C}$ pelos espectros samplesample na Figura 17 tem em seu espectro síncrono mostrado na Figura 30. Nota-se autopicos em 1636 e $1615 \mathrm{~cm}^{-1}$. O pico cruzado negativo entre 1636 e $1615 \mathrm{~cm}^{-1}$ indica que há a diminuição da intensidade da folha $\beta$ simultaneamente com o aumento de intensidade de $1615 \mathrm{~cm}^{-1}$ e pode haver interconversão entre essas bandas (Iloro, et al., 2004). Como já dito anteriormente esta banda pode estar relacionada à exposição de cadeias laterais de ou contatos intercadeias, no entanto, o aparecimento do autopico após a temperatura de desenovelamento e o pico cruzado negativo sugere o início da agregação da proteína (He, et al., 2005). Picos cruzados positivos, sem autopico correspondente, surgem entre 1669x1636 e 1675x1636 cm ${ }^{-1}$, sendo que 1669 e 1675 $\mathrm{cm}^{-1}$ se encontram na região assinalada a voltas.

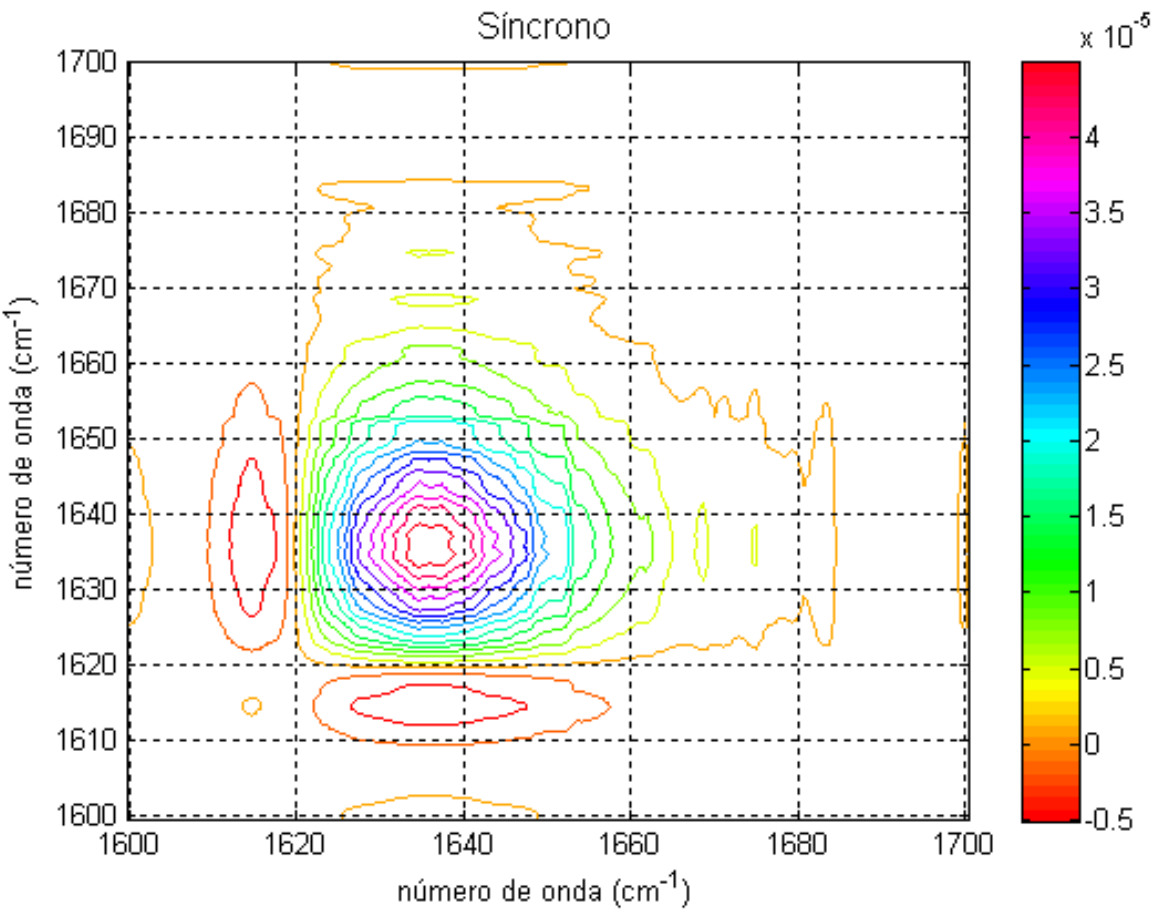

Figura 30: Mapa de contorno da correlação síncrona generalizada para o desenovelamento da BPT pD 7,2 entre $57^{\circ}$ e $63^{\circ} \mathrm{C}$ na região de $1600-1700 \mathrm{~cm}^{-1}$. 
O espectro assíncrono mostrado na Figura 31 possui um comportamento de correlação ruidoso com difícil análise dos picos cruzados fora de fase. Este resultado pode ser interpretado como formação simultânea ou síncrona de contatos intercadeias e o desenovelamento da proteína (Paquet, et al., 2001; Iloro, et al., 2004), cuja contribuição principal de estrutura secundária é a folha $\beta$.

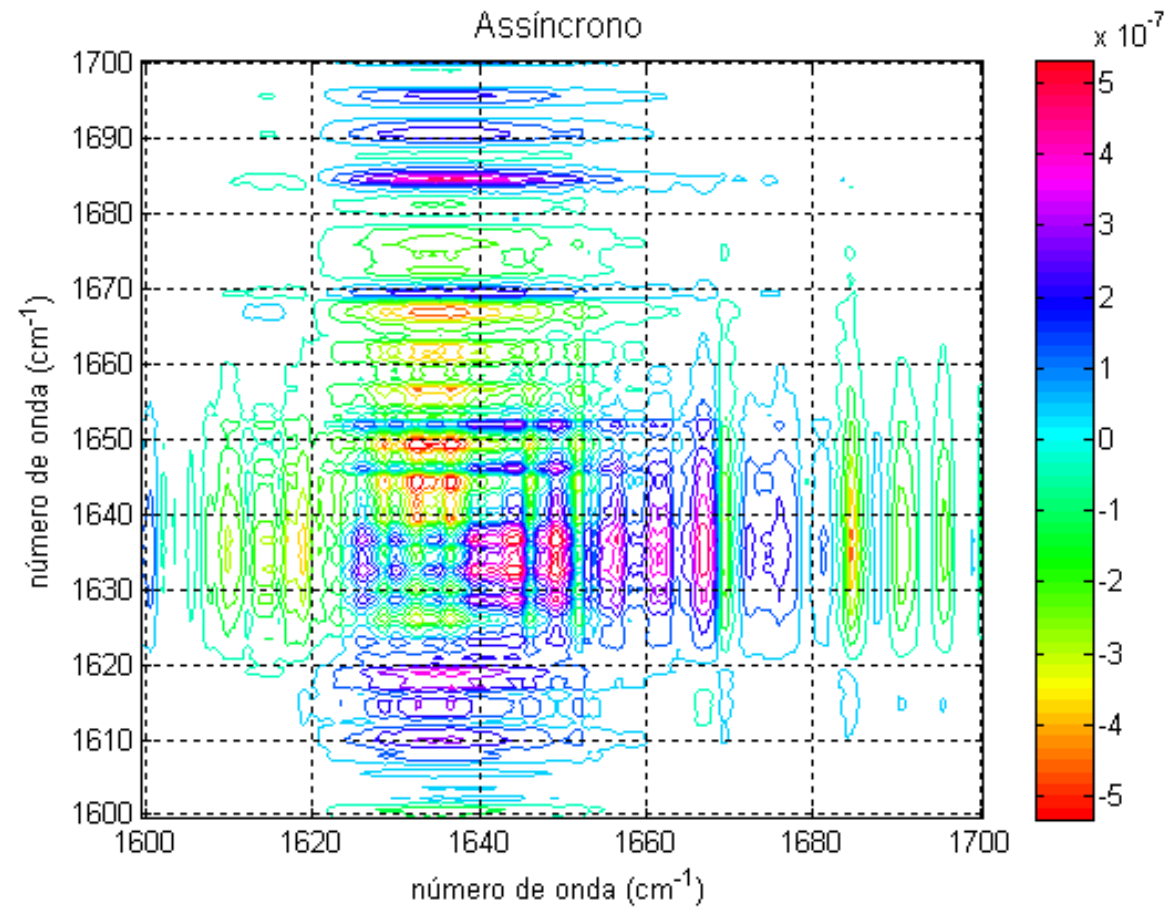

Figura 31: Mapa de contorno da correlação assíncrona generalizada para o desenovelamento da BPT pD 7,2 entre $57^{\circ}$ e $63^{\circ} \mathrm{C}$ na região de $1600-1700 \mathrm{~cm}^{-1}$. 
O espectro síncrono da Figura 32 apresenta a segunda pós-transição entre $67^{\circ} \mathrm{e}$ $71^{\circ} \mathrm{C}$. O mapa possui autopicos principais em 1684, 1653, 1650, $1641 \mathrm{e} 1632 \mathrm{~cm}^{-1}$. O forte autopico em $1684 \mathrm{~cm}^{-1}$ e o pico cruzado positivo $1684 \times 1616 \mathrm{~cm}^{-1}$ indica agregação significativa da tripsina devido a contatos intercadeias. Os picos negativos $1632 \times 1616$, $1641 \times 1616,1684 \times 1632$ e $1684 \times 1641 \mathrm{~cm}^{-1}$ indica que enquanto a intensidade espectral da folha $\beta$ diminui, a da agregação aumenta, com ligeiro deslocamento dos picos da folha $\beta$. Picos positivos são encontrados entre $1653 \times 1616$ e $1653 \times 1684 \mathrm{~cm}^{-1}$, indicando que a hélice $\alpha$ preserva a estrutura mesmo a altas temperaturas.

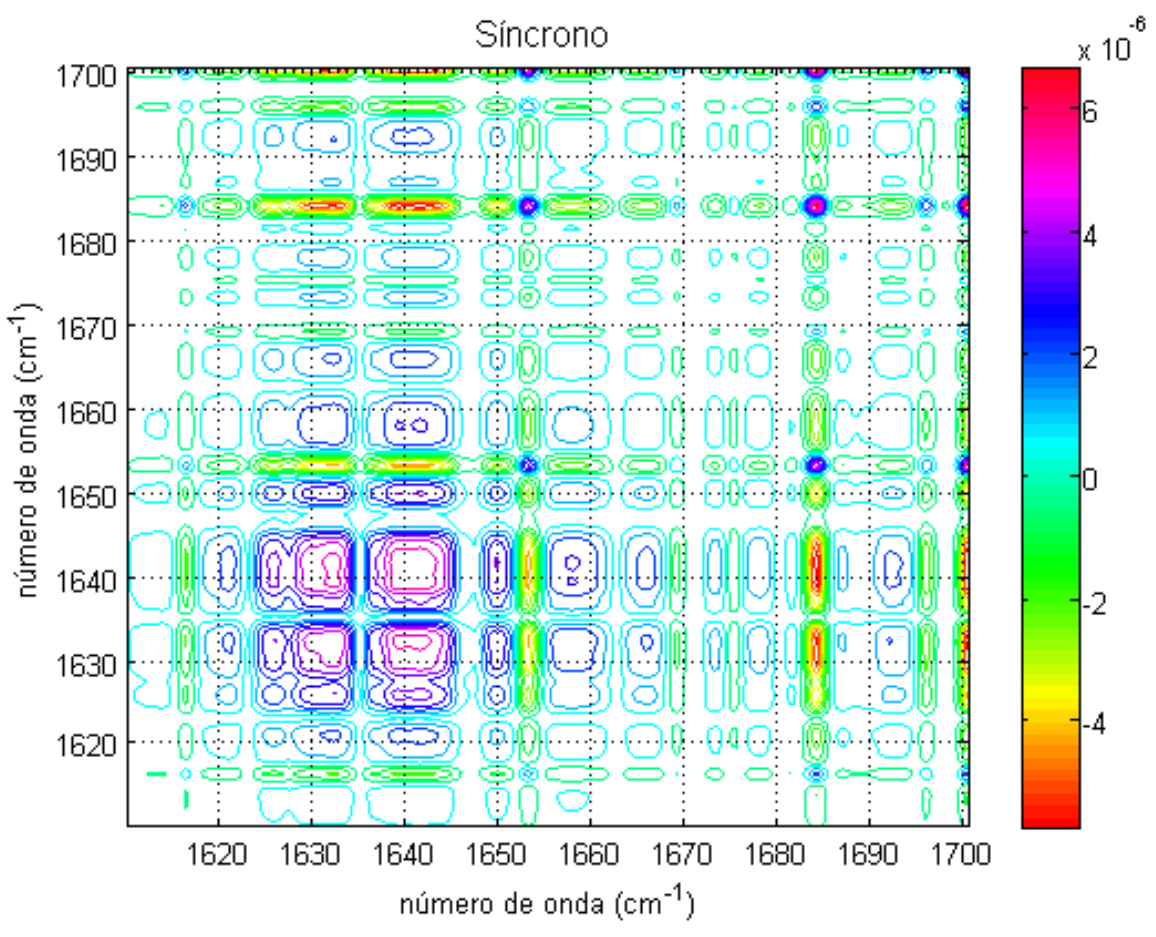

Figura 32: Mapa de contorno da correlação síncrona generalizada para o desenovelamento da BPT pD 7,2 entre $67^{\circ}$ e $71^{\circ} \mathrm{C}$ na região de $1600-1700 \mathrm{~cm}^{-1}$. 
O espectro assíncrono da Figura 33 para a pós-transição entre $67^{\circ}$ e $71^{\circ} \mathrm{C}$ apresenta comportamento de correlação ruidoso, assim como na pós-transição entre 57 e $63^{\circ} \mathrm{C}$.

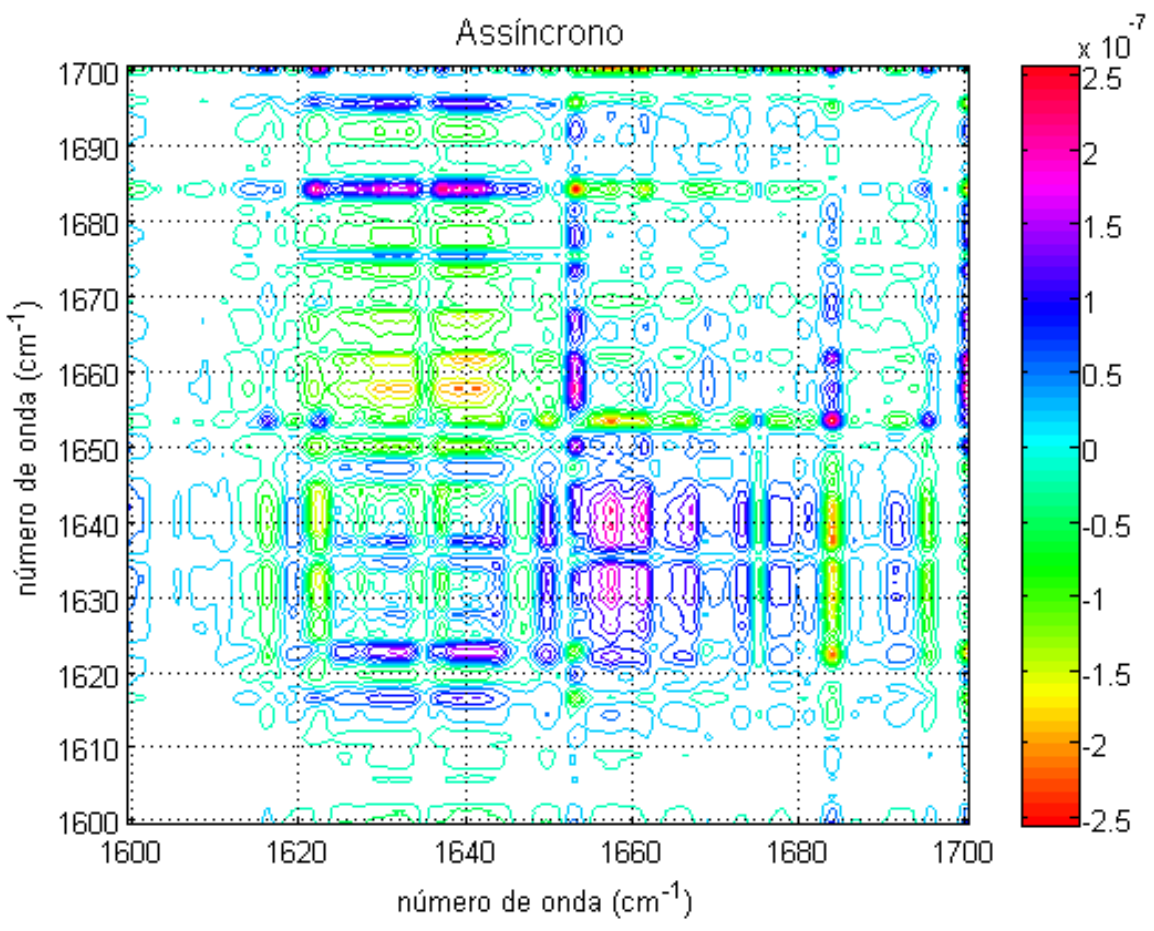

Figura 33: Mapa de contorno da correlação assíncrona generalizada para o desenovelamento da BPT pD 7,2 entre $67^{\circ} \mathrm{e} 71^{\circ} \mathrm{C}$ na região de $1600-1700 \mathrm{~cm}^{-1}$. 


\subsubsection{Perfil de calorimetria exploratória diferencial (DSC)}

O desenovelamento e a agregação da tripsina pancreática bovina foram acompanhados por calorimetria exploratória diferencial (DSC) sob condições semelhantes às medidas de infravermelho. A amostra foi equilibrada à temperatura de $15^{\circ} \mathrm{C}$ por 20 minutos antes do início do experimento. A Figura 34 mostra a curva de DSC da BPT a $30 \mathrm{mg} / \mathrm{mL}$ sob razão de aquecimento de $6^{\circ} \mathrm{C} / \mathrm{h}$.

É possível observar nesta figura um grupo de transições endotérmicas que se iniciam em $30^{\circ} \mathrm{C}$ e terminam em torno de $66^{\circ} \mathrm{C}$, quando a curva passa a ser exotérmica com um pico bem definido em $83^{\circ} \mathrm{C}$. Uma transição endotérmica, seguida de uma transição exotérmica geralmente caracteriza o desenovelamento e a agregação de proteínas, respectivamente, como encontrado para a insulina bovina e a proteína C9 (Dzwolak, et al., 2003). Conforme observado, a agregação exotérmica conduz às distorções e capacidades caloríficas negativas nas curvas de DSC.

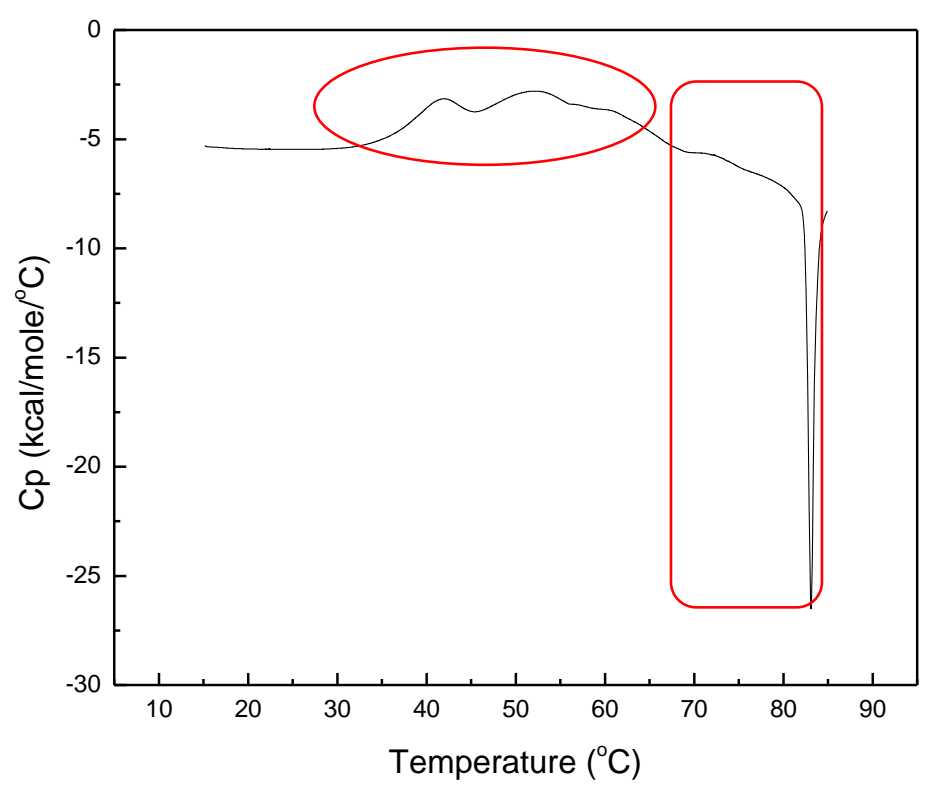

Figura 34: Curva de DSC mostrando capacidade calorífica molar aparente da agregação da BPT 30mg/mL em a pD 7,0 e razão de aquecimento de $6^{\circ} \mathrm{C} / \mathrm{h}$.

A temperatura de $83^{\circ} \mathrm{C}$ não foi atingida nas medidas de infravermelho para a análise de correlação bidimensional por questões técnicas. No entanto, a segunda póstransição, obtida na análise de correlação sample-sample (Figura 19) e avaliada pela correlação bidimensional generalizada na faixa de $67^{\circ}$ a $71^{\circ} \mathrm{C}$ (Figuras 32 e 33), indica 
agregação da proteína. Esta indicação concorda com o início aparente da transição exotérmica próximo a $70^{\circ} \mathrm{C}$ obtido por DSC e mostrado na Figura 34.

Análises de deconvolução para separação de sub-transições têm sido descritas quantitativamente e com as alterações de estrutura secundária acompanhadas por dados de CD e espectroscopia UV para a HSA (Tavirani, et al., 2006). A distorção dos valores de capacidade calorífica a pressão constante $C_{p}$ torna difícil uma análise quantitativa das entalpias de transição envolvidas no desenovelamento e agregação da tripsina pancreática bovina. No entanto, a curva endotérmica na faixa de $20^{\circ}$ a $70^{\circ} \mathrm{C}$ pode ser deconvoluída com um bom fator de ajuste assumindo cinco sub-transições com picos localizados em $40^{\circ}, 42^{\circ}, 49^{\circ}, 55^{\circ}$ e $62^{\circ} \mathrm{C}$ (Figura 35).

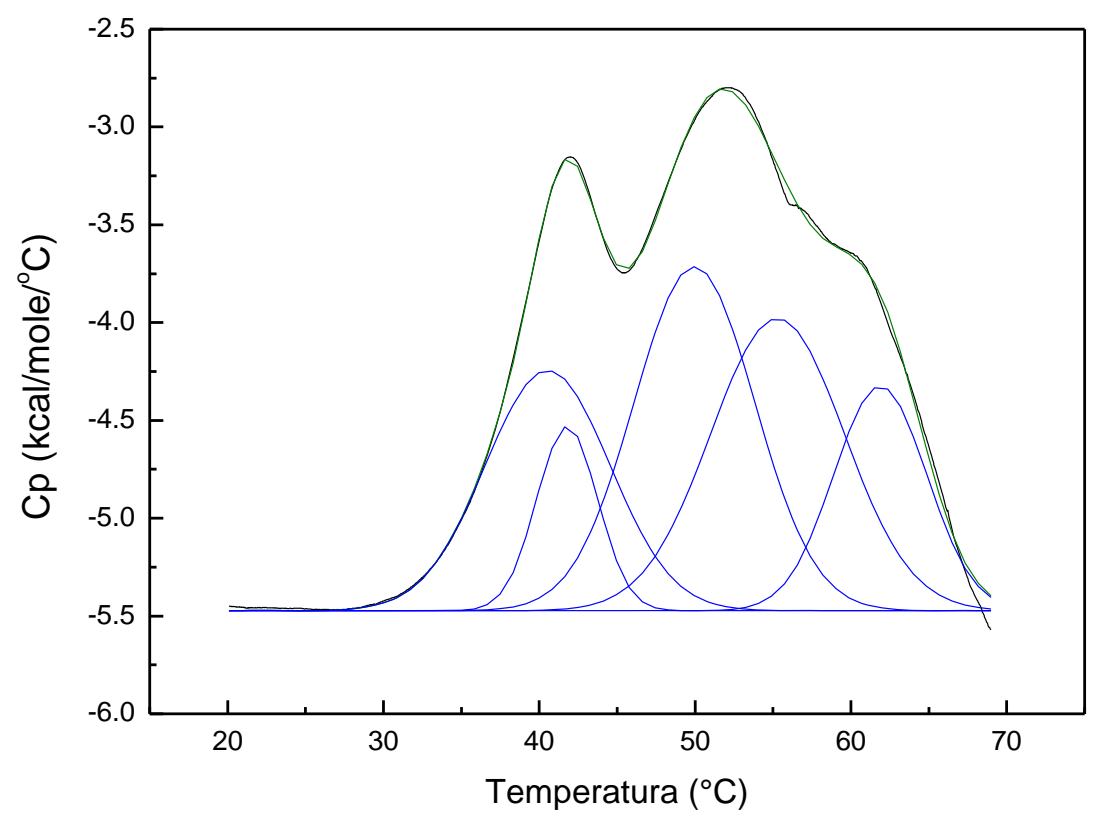

Figura 35: Deconvolução da capacidade calorífica aparente da transição endotérmica. (一) curva experimental, (-) sub-transições e (-) curva calculada pela soma das sub-transições.

A Tabela 1 compara as transições encontradas através da análise de correlação sample-sample para o infravermelho e o centro dos sub-picos encontrados pelos dados de DSC. A primeira pré-transição em $31^{\circ} \mathrm{C}$ não possui correspondente na análise calorimétrica, no entanto, esta pré-transição poderia marcar o início da transição endotérmica que se encontra em torno de $29^{\circ} \mathrm{C}$ na Figura 35. As pré-transições 2 e 3, a transição principal e as pós-transições 1 e 2 apresentam temperaturas próximas aos subpicos obtidos por deconvolução, considerando o incremento de temperatura de $2^{\circ} \mathrm{C}$ para 
os espectros de infravermelho e que a correlação sample-sample indica apenas regiões de transição a serem avaliadas pela correlação generalizada.

Tabela 1: Comparação entre as temperaturas encontradas através da análise de correlação sample-sample e DSC para o desenovelamento da BPT a 30 $\mathrm{mg} / \mathrm{mL}$. Precisão do banho térmico: $\operatorname{Ir}\left(+/-0,5^{\circ} \mathrm{C}\right)$ e $\mathrm{DSC}\left(+/-0,1^{\circ} \mathrm{C}\right)$.

\begin{tabular}{|l|l|l|}
\hline \multicolumn{2}{|c|}{ Correlação 2D-IR Sample-Sample } & \multicolumn{1}{c|}{ DSC } \\
\hline Pré-transição 1 & $31^{\circ} \mathrm{C}$ & Inicio da transição endotérmica $\left(30^{\circ} \mathrm{C}\right)$ \\
\hline Pré-transição 2 & $37^{\circ} \mathrm{C}$ & $40^{\circ} \mathrm{C}$ \\
\hline Pré-transição 3 & $43^{\circ} \mathrm{C}$ & $42^{\circ} \mathrm{C}$ \\
\hline Transição principal & $48^{\circ} \mathrm{C}$ & $49^{\circ} \mathrm{C}$ \\
\hline Pós-transição 1 & $54^{\circ} \mathrm{C}$ & $55^{\circ} \mathrm{C}$ \\
\hline Pós-transição 2 & $59^{\circ} \mathrm{C}$ & $62^{\circ} \mathrm{C}$ \\
\hline Pós-transição 3 Agregação* & Início da Transição Exotérmica $\left(70^{\circ} \mathrm{C}\right)$ \\
\hline \multicolumn{2}{|c|}{ Agre } & $83^{\circ} \mathrm{C}$ \\
\hline
\end{tabular}

* temperatura não atingida nos experimentos de infravermelho

O desenovelamento da BPT comercial a pH neutro é complexo e constituído de múltiplos estados, diferente do comportamento obtido a $\mathrm{pH}$ ácido para $\beta$ - e $\alpha$-tripsina com variações de entalpia de desenovelamento de 99,1 e 101,8 kcal/mol, respectivamente (Santos, et al., 2008; Bittar, et al., 2003). No entanto, a espectroscopia de correlação bidimensional é útil na complementação de estudos calorimétricos, permitindo o acompanhamento da autoclivagem e das estruturas secundárias envolvidas em cada transição, além de esclarecer a seqüência de evento envolvida no processo.

A entalpia de desenovelamento aparente para a BPT foi obtida a partir da integração da curva endotérmica da Figura 35 indicando uma variação de entalpia calorimétrica, $\Delta H_{c a l}$, em torno de $59,3 \mathrm{kcal} / \mathrm{mol}$. Nota-se que $\Delta H_{c a l}$ é maior que a variação de entalpia obtida na seção 4.1 a partir da equação de van't Hoff, $\Delta H_{V H}$, em torno de 28,1 kcal/mol. Segundo Cooper (Cooper, 2001) $\Delta H_{c a l}>\Delta H_{V H}$ pode ocorrer quando o desenovelamento não envolve o modelo de dois estados como ocorre para a tripsina bovina comercial. 


\subsection{Re-enovelamento térmico abaixo da transição principal}

A BPT preparada em temperatura ambiente é aquecida a $45^{\circ} \mathrm{C}$ por 20 minutos, diminuiu-se então a temperatura até $25^{\circ} \mathrm{C}$ com decremento de $2^{\circ} \mathrm{C}$ e os respectivos espectros no infravermelho para a banda de amida I' se encontram na Figura 36. Neste caso, a proteína não parte do estado desenovelado para o enovelado, mas é aquecida a uma temperatura abaixo da temperatura média de desenovelamento com o intuito de evitar a formação de agregados que conduziria o processo para um estado enovelado não nativo. Espera-se observar a busca conformacional pelo estado nativo através da espectroscopia de correlação bidimensional.

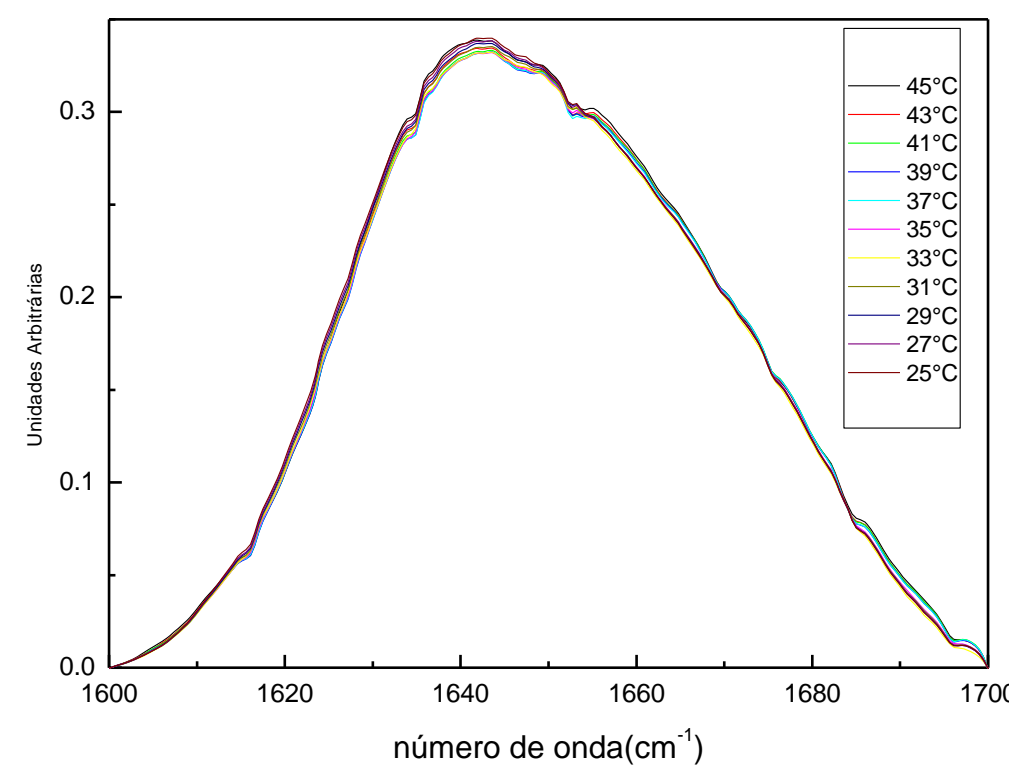

Figura 36: Espectros de infravermelho dependentes da temperatura da tripsina pancreática bovina após correção de linha de base na região de amida I'. Os espectros representam a variação de temperatura de $45^{\circ}$ a $25^{\circ} \mathrm{C}$ com incremento de $2^{\circ} \mathrm{C}$ em $0,05 \mathrm{mM}$ de Tris-HCl e pD 7,0.

Assim como no processo de desenovelamento, as temperaturas críticas de transição serão avaliadas pela espectroscopia de correlação sample-sample e a dinâmica conformacional através da espectroscopia de correlação variable-variable. 


\subsubsection{Análise de correlação sample-sample-2D}

O espectro de correlação sample-sample é representado como mapa de contorno na Figura 37. Nesta figura, observam-se duas regiões negativamente correlacionadas que envolvem transições de fase, a primeira envolve a região de $45^{\circ}$ a $35^{\circ} \mathrm{C}$ e a segunda entre $35^{\circ}$ e $25^{\circ} \mathrm{C}$.

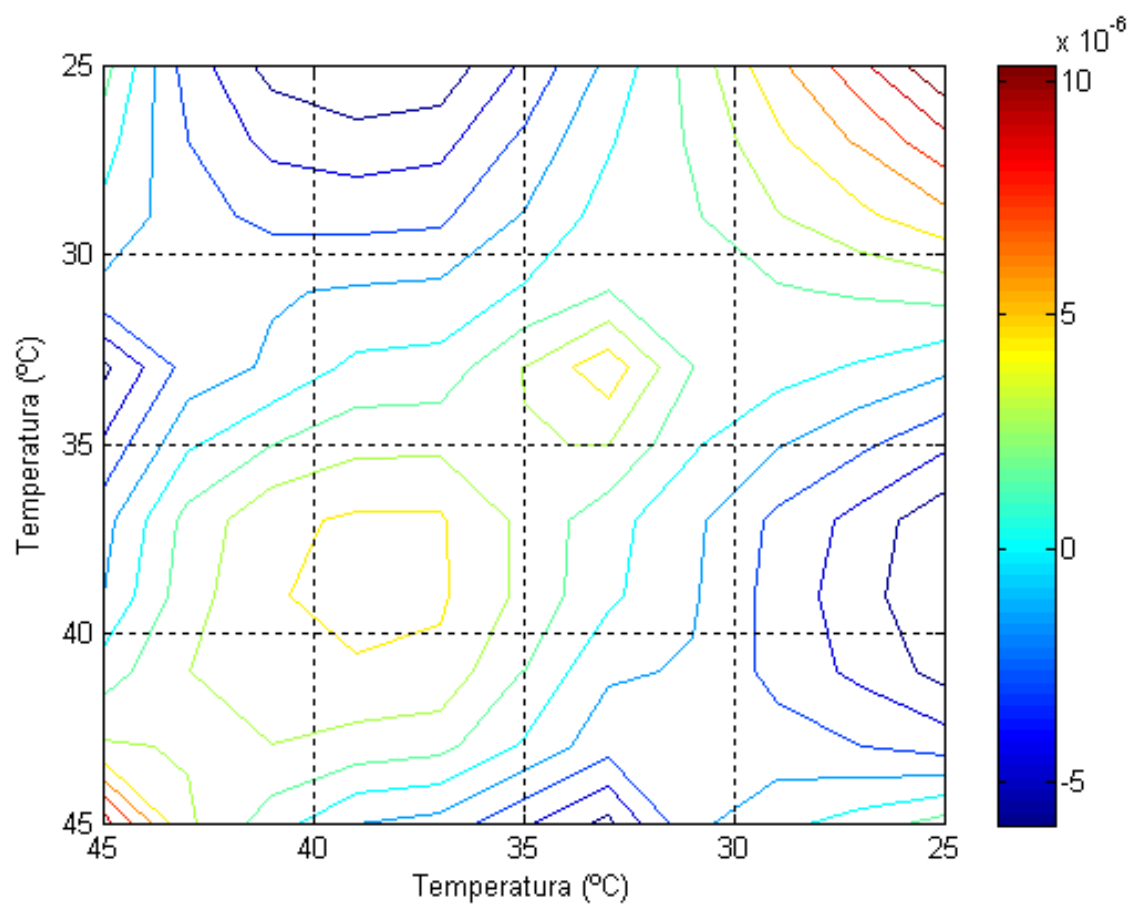

Figura 37: Mapa de contorno do espectro de correlação sample-sample, construído a partir de dados de

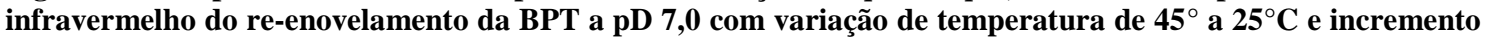
de $2^{\circ} \mathrm{C}$.

A Figura 38 é a representação da correlação sample-sample na forma de cortes ortogonais. Pontos de convergência bem definidos não podem ser observados, como no caso do desenovelamento da tripsina. Isto pode ser atribuído ao amplo espaço conformacional que a proteína deve pesquisar para encontrar a rota do estado nativo, pois com a proteína disposta em temperaturas mais altas acessam-se muitos estados de alta energia (Dill, et al., 2008). Outro aspecto importante é que durante o reenovelamento é possível se deparar com heterogeneidade conformacional, podendo haver divesas subpopulações de conformações coexistindo uma com a outra e com rotas independentes (Udgaonkar, 2008).

As setas em vermelho indicam os possíveis pontos de transição em torno de $43^{\circ}$, $35^{\circ}$ e $31^{\circ} \mathrm{C}$. Estas transições estão localizadas em temperaturas próximas às encontradas 
para as pré-transições no processo de desenovelamento que foram em torno de $31^{\circ}, 37^{\circ}$ e $42^{\circ} \mathrm{C}$.

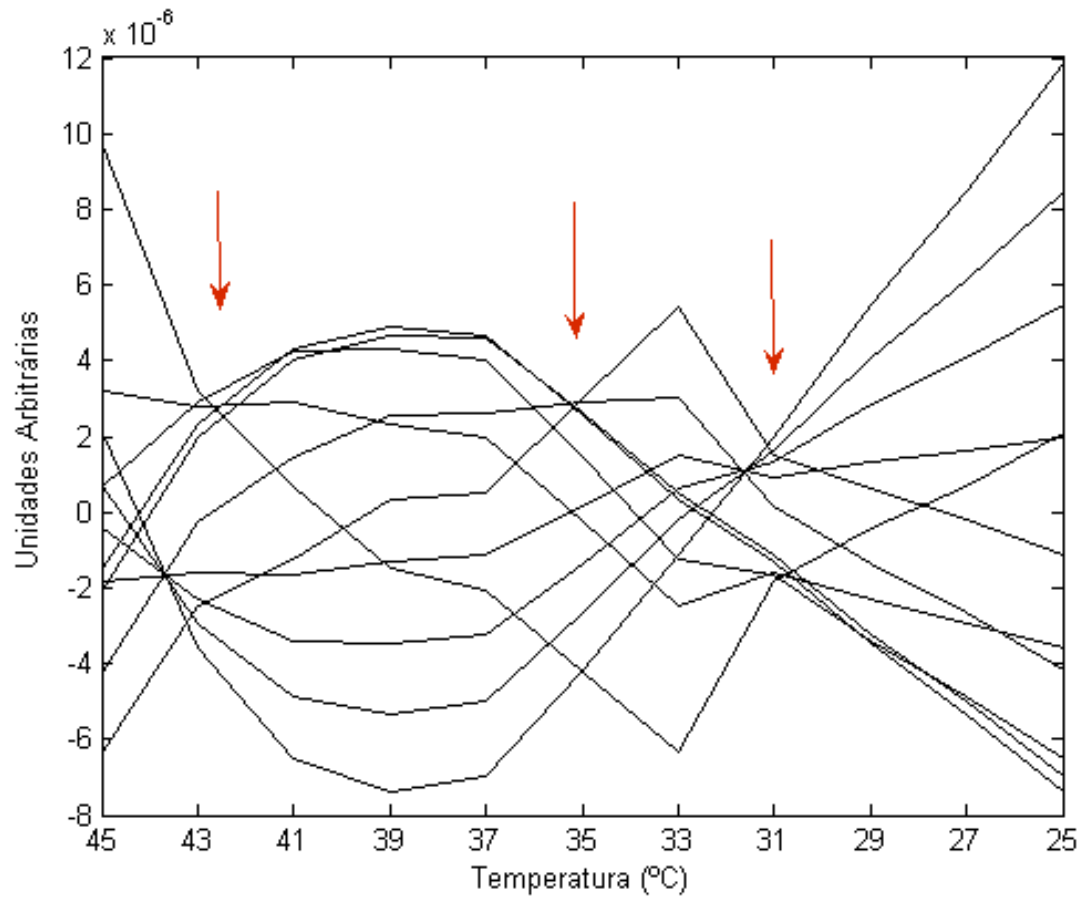

Figura 38: Corte ortogonal do espectro de correlação sample-sample, construído a partir de dados de infravermelho do re-enovelamento da BPT a pD 7,0 com a variação de temperatura de $45^{\circ}$ a $25^{\circ} \mathrm{C}$ e incremento de $2^{\circ} \mathrm{C}$.

No entanto, faz-se necessária a análise de correlação bidimensional generalizada destas três regiões de transição no re-enovelamento, $43^{\circ}, 35^{\circ}$ e $31^{\circ} \mathrm{C}$, e a descrição da dinâmica conformacional envolvida para verificar se a rota de re-enovelamento se assemelha à de desenovelamento. 


\subsubsection{Análise de correlação bidimensional generalizada}

O espectro síncrono referente à região de $43^{\circ} \mathrm{C}$ foi obtido a partir do subconjunto de dados entre $45^{\circ}$ e $41^{\circ} \mathrm{C}$ e se encontra na Figura 39. Um autopico intenso em 1635 $\mathrm{cm}^{-1}$ é assinalado às folhas $\beta$ e indica que estas estruturas são mais sensíveis a perturbação nesta faixa de temperatura. Outro autopico é observado em $1655 \mathrm{~cm}^{-1}$ e os picos cruzados $1653 \times 1635$ e $1656 \times 1635 \mathrm{~cm}^{-1}$ indicam que este autopico deve representar a sobreposição de modos vibracionais da hélice $\alpha$ em $1653 \mathrm{~cm}^{-1}$ e de voltas envolvidas na autoclivagem da BPT $\alpha \mathrm{em} 1656 \mathrm{~cm}^{-1}$ (Prestrelski, et al., 1991).

Picos cruzados positivos são encontrados entre 1653x1635, 1656x1635 e $1684 \times 1635 \mathrm{~cm}^{-1}$ e indicam que as folhas $\beta\left(1635 \mathrm{~cm}^{-1}\right)$, hélices $\alpha\left(1653 \mathrm{~cm}^{-1}\right)$, voltas específicas $\left(1656 \mathrm{~cm}^{-1}\right)$ e folhas $\beta$ antiparalelas ou contatos intercadeia $\left(1684 \mathrm{~cm}^{-1}\right)$ respondem sincronamente.

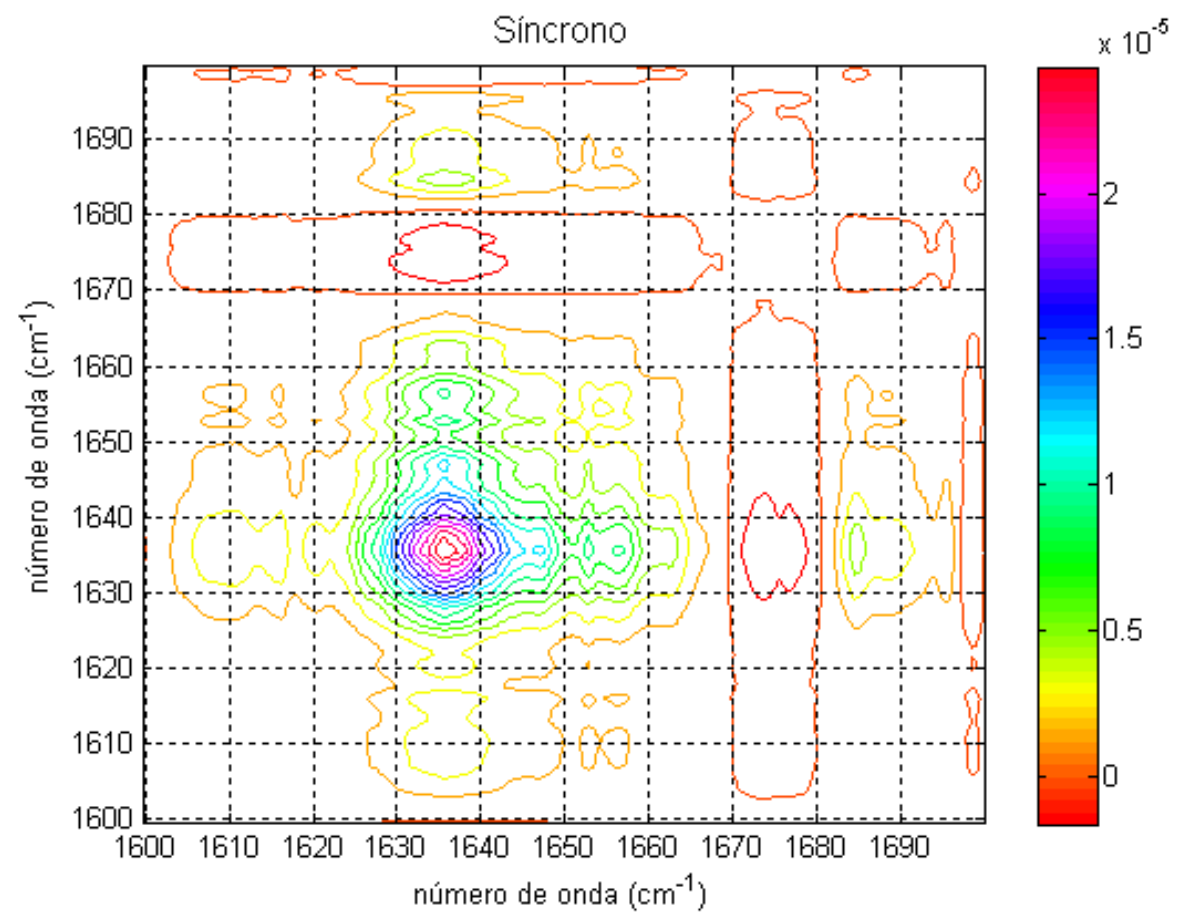

Figura 39: Mapa de contorno da correlação síncrona generalizada para o re-enovelamento da BPT pD 7,0 entre $45^{\circ}$ e $41^{\circ} \mathrm{C}$ na região de $1600-1700 \mathrm{~cm}^{-1}$. 
Comparando esta transição no re-enovelamento entre $45^{\circ}$ e $41^{\circ} \mathrm{C}$ com o espectro síncrono da pré-transição entre $41^{\circ}$ e $45^{\circ} \mathrm{C}$ (ver Figura 24) no desenovelamento, nota-se que em ambas as transições a contribuição principal no espectro síncrono é a da folha $\beta$, no entanto, durante o processo de desenovelamento a banda é claramente subdividida em 1633, 1635 e $1638 \mathrm{~cm}^{-1}$. A banda em $1656 \mathrm{~cm}^{-1}$, assinalada voltas envolvidas na autoclivagem da BPT, é encontrada nas duas transições com pico cruzado positivo referente às folhas $\beta$. Durante a desenovelamento não há indícios de alteração conformacional na hélice $\alpha$ como encontrado para o re-enovelamento. $\mathrm{O}$ pico cruzado da folha $\beta$ em $1635 \mathrm{~cm}^{-1}$ com as folhas $\beta$ ou contatos intercadeia em $1684 \mathrm{~cm}^{-1}$ é negativo esta transição no desenovelamento e positivo no re-enovelamento e, em ambos os processos há rearranjos de cadeia lateral em torno de $1615 \mathrm{~cm}^{-1}$.

O espectro assíncrono mostrado na Figura 40 possui comportamento de correlação ruidoso, o que pode indicar que todos os eventos ocorrem sincronamente (Iloro, et al., 2004; Paquet, et al., 2001).

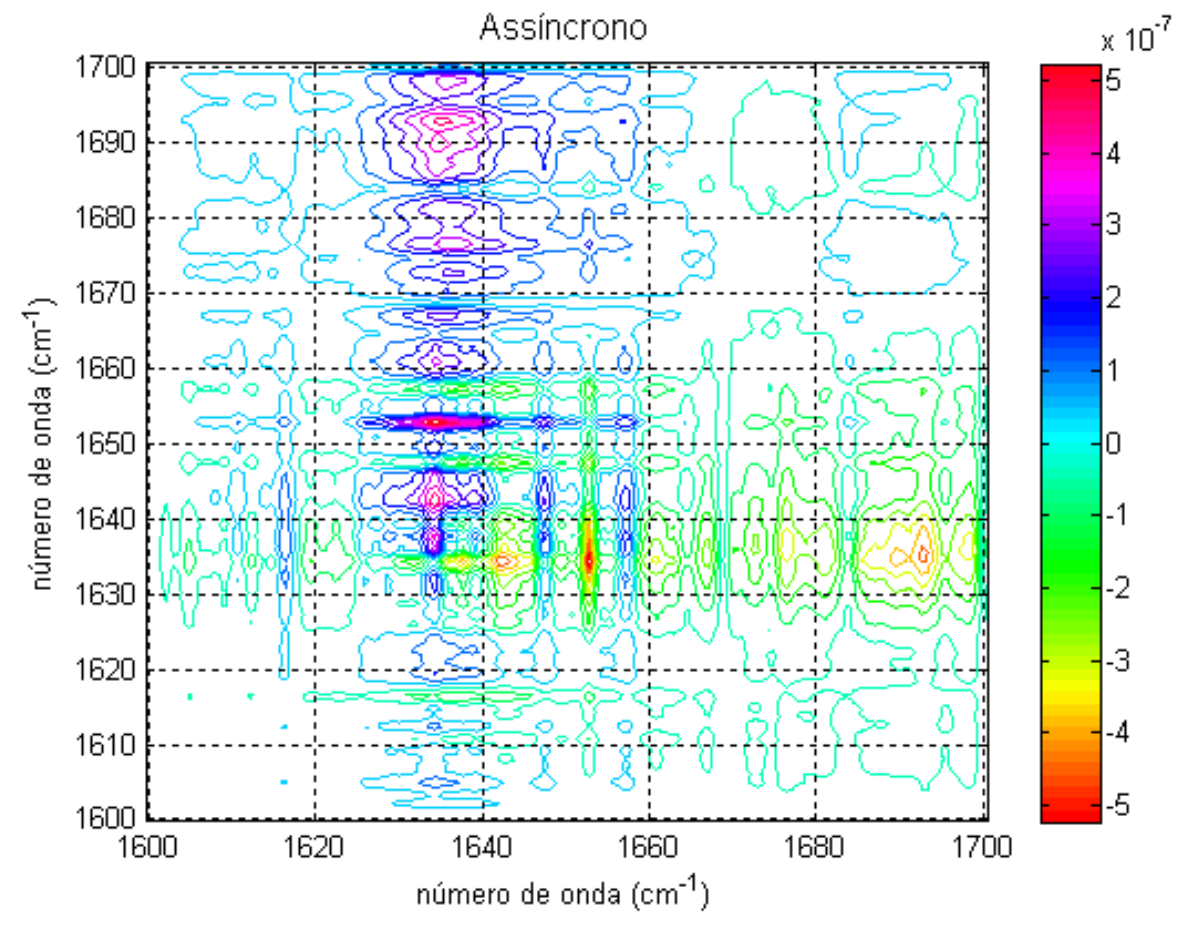

Figura 40: Mapa de contorno da correlação assíncrona generalizada para o re-enovelamento da BPT pD 7,0 entre $45^{\circ}$ e $41^{\circ} \mathrm{C}$ na região de $1600-1700 \mathrm{~cm}^{-1}$. 
Na Figura 41 se encontra o mapa síncrono para a faixa de temperatura de $37^{\circ}$ a $33^{\circ} \mathrm{C}$. Há um primeiro conjunto de autopicos bem definidos em 1616, 1623, 1628, 1635 e $1653 \mathrm{~cm}^{-1}$, com picos cruzados de correlação positivos entre si. Logo, devido aos picos cruzados possuírem correlação positiva, aumentam sincronamente as folhas $\beta$ assinaladas em 1623, 1628 e $1635 \mathrm{~cm}^{-1}$ e os rearranjos de cadeia lateral em $1616 \mathrm{~cm}^{-1}$.

O segundo conjunto de autopicos, na região de 1655 a $1700 \mathrm{~cm}^{-1}$, é bastante sobreposto e, como no primeiro conjunto, há diversos picos cruzados positivos, indicando que as variações de intensidade estão ocorrendo no mesmo sentido. Entre estes autopicos, destacam-se picos em assinalados a voltas no sítio de autoclivagem na BPT $\left(1657 \mathrm{~cm}^{-1}\right)$, voltas $\left(1665,1674\right.$ e $\left.1678 \mathrm{~cm}^{-1}\right)$, folhas $\beta$ antiparalelas ou contatos intercadeia (1681 e $1686 \mathrm{~cm}^{-1}$ ) e fitas estendidas (1692 e $\left.1697 \mathrm{~cm}^{-1}\right)$, não havendo nesta transição autopico ou pico cruzado em $1684 \mathrm{~cm}^{-1}$.

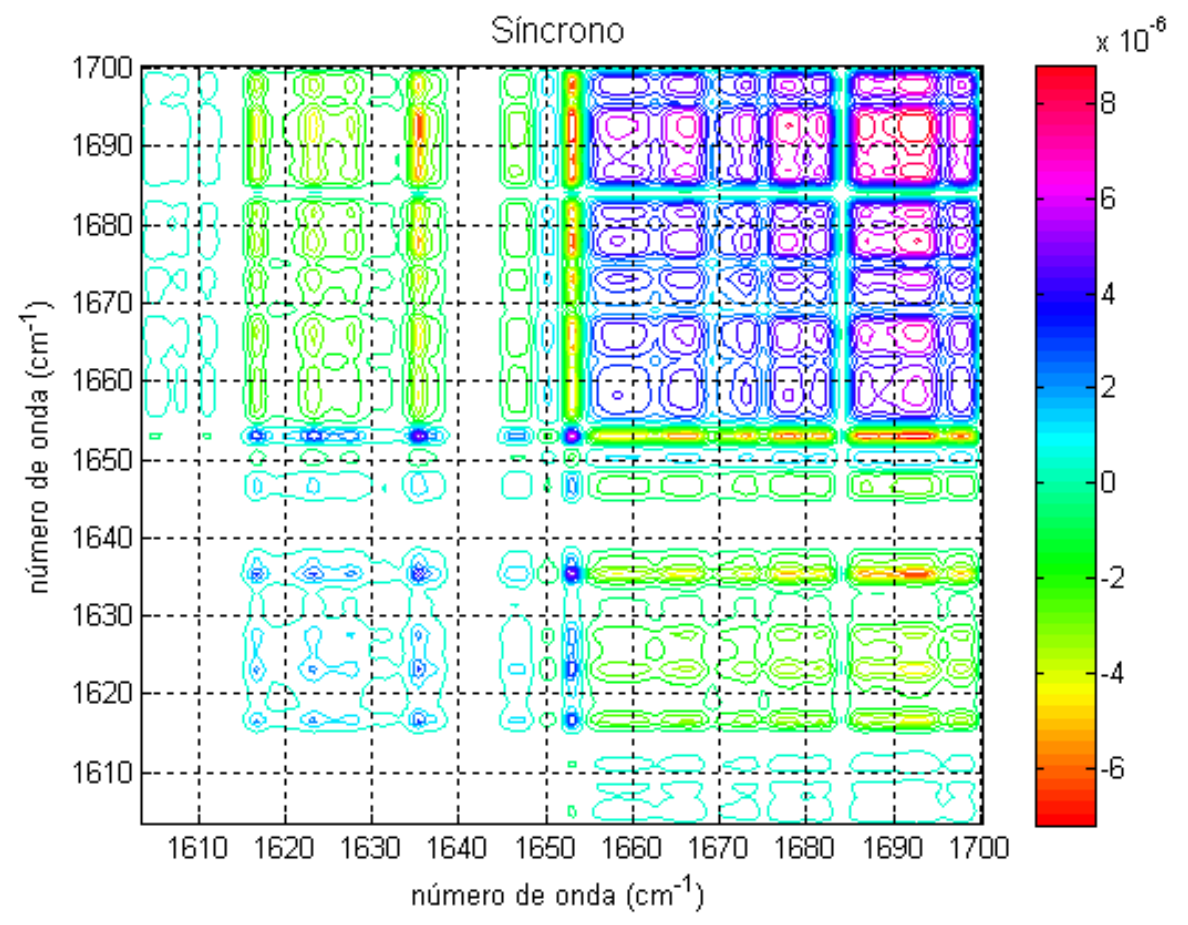

Figura 41: Mapa de contorno da correlação síncrona generalizada para o re-enovelamento da BPT pD 7,0 entre $37^{\circ}$ e $33^{\circ} \mathrm{C}$ na região de $1600-1700 \mathrm{~cm}^{-1}$.

Nota-se que os picos cruzados gerados tanto no primeiro conjunto de autopicos como no segundo conjunto são positivos. No entanto, os picos cruzados gerados entre os dois conjuntos são negativos, indicando que enquanto a intensidade do primeiro conjunto aumenta a do segundo diminui. Logo, têm-se voltas, fitas e folhas $\beta$ antiparalelas não nativas podem estar se desestruturando na tentativa de formar folhas $\beta$ e hélices $\alpha$ nativas. 
Quando se compara este comportamento ao que espectro síncrono que é obtido na pré-transição entre $35^{\circ}$ e $39^{\circ} \mathrm{C}$ (Ver Figura 22) no desenovelamento, percebe-se que durante o desenovelamento a principal contribuição é pico largo assinalado a folhas $\beta$ centrado em $1635 \mathrm{~cm}^{-1}$, enquanto no re-enovelamento há picos bem definidos referentes a folhas $\beta$ em 1623, 1628 e $1635 \mathrm{~cm}^{-1}$. A região de hélice $\alpha$ em $1653 \mathrm{~cm}^{-1}$ é encoberta pela larga banda de folha $\beta$ durante o desenovelamento, enquanto um pico definido é notado no re-enovelamento. No desenovelamento também não se observam picos cruzados negativos como observado no re-enovelamento.

O espectro assíncrono mostrado na Figura 42 apresenta inúmeros picos de correlação, tornando a análise da seqüência de eventos inviável e pode indicar um comportamento de correlação ruidoso.

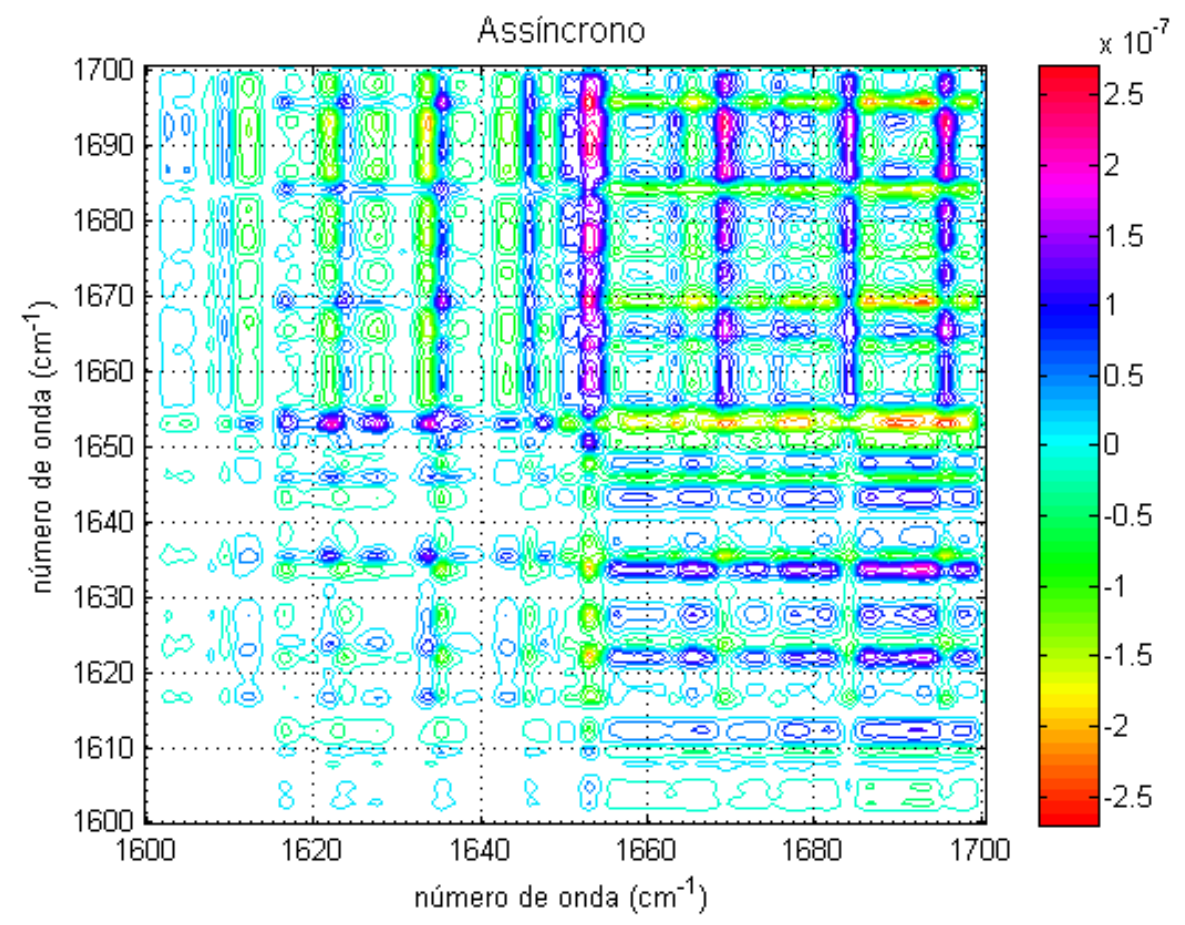

Figura 42: Mapa de contorno da correlação assíncrona generalizada para o re-enovelamento da BPT pD 7,0 entre $37^{\circ}$ e $33^{\circ} \mathrm{C}$ na região de $1600-1700 \mathrm{~cm}^{-1}$. 
Na faixa de temperatura de $33^{\circ}$ a $29^{\circ} \mathrm{C}$, o espectro síncrono mostrado na Figura 43 apresenta-se ruidoso e com todas as intensidades de correlação positivas. Autopicos são encontrados em 1615, 1632, 1643, 1648, 1650, 1656, 1668, 1672, 1676 e $1692 \mathrm{~cm}^{-1}$. Picos todos positivos podem indicar que a proteína continua a busca pelo estado nativo, porém, nesta transição nenhuma conformação é perdida durante o rearranjo no reenovelamento.

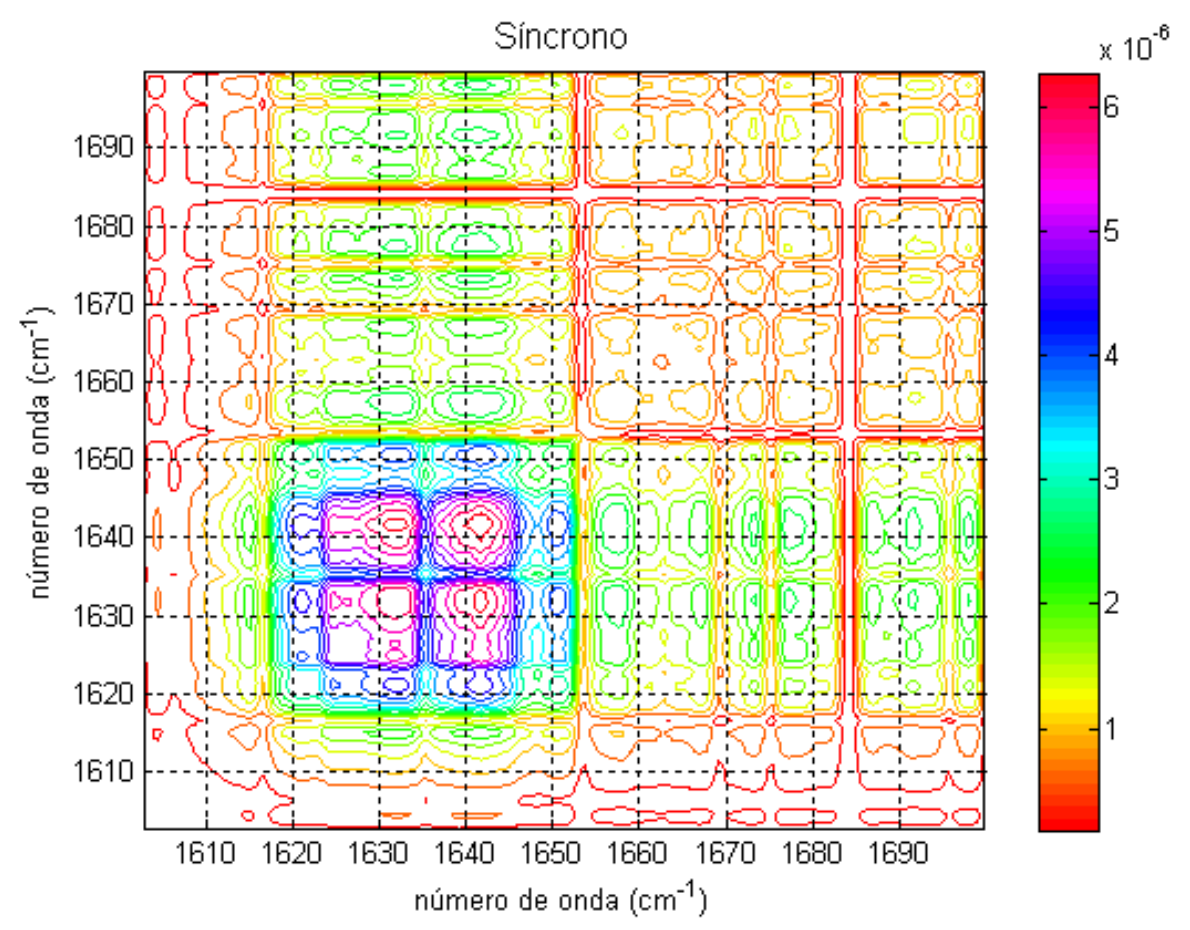

Figura 43: Mapa de contorno da correlação síncrona generalizada para o re-enovelamento da BPT pD 7,0 entre $33^{\circ}$ e $29^{\circ} \mathrm{C}$ na região de $1600-1700 \mathrm{~cm}^{-1}$.

A pré-transição entre 29 e $33^{\circ} \mathrm{C}$ (ver Figura 20) no desenovelamento apresenta correlação intensa na região de 1620 a $1645 \mathrm{~cm}^{-1}$ assim como para o re-enovelamento, e em ambas as transição há autopico referente a voltas envolvidas na autoclivagem da BPT em $1656 \mathrm{~cm}^{-1}$. No entanto, são encontradas algumas correlações cruzadas negativas no desenovelamento, destacando os pares $1684 \times 1633$ e $1684 \times 1638 \mathrm{~cm}^{-1}$. 
O espectro assíncrono mostrado na Figura 44 para o re-enovelamento entre 33 e $29^{\circ} \mathrm{C}$ apresenta comportamento de correlação ruidoso, assim como os outros espectros assíncronos do re-enovelamento (ver Figuras 40 e 42).

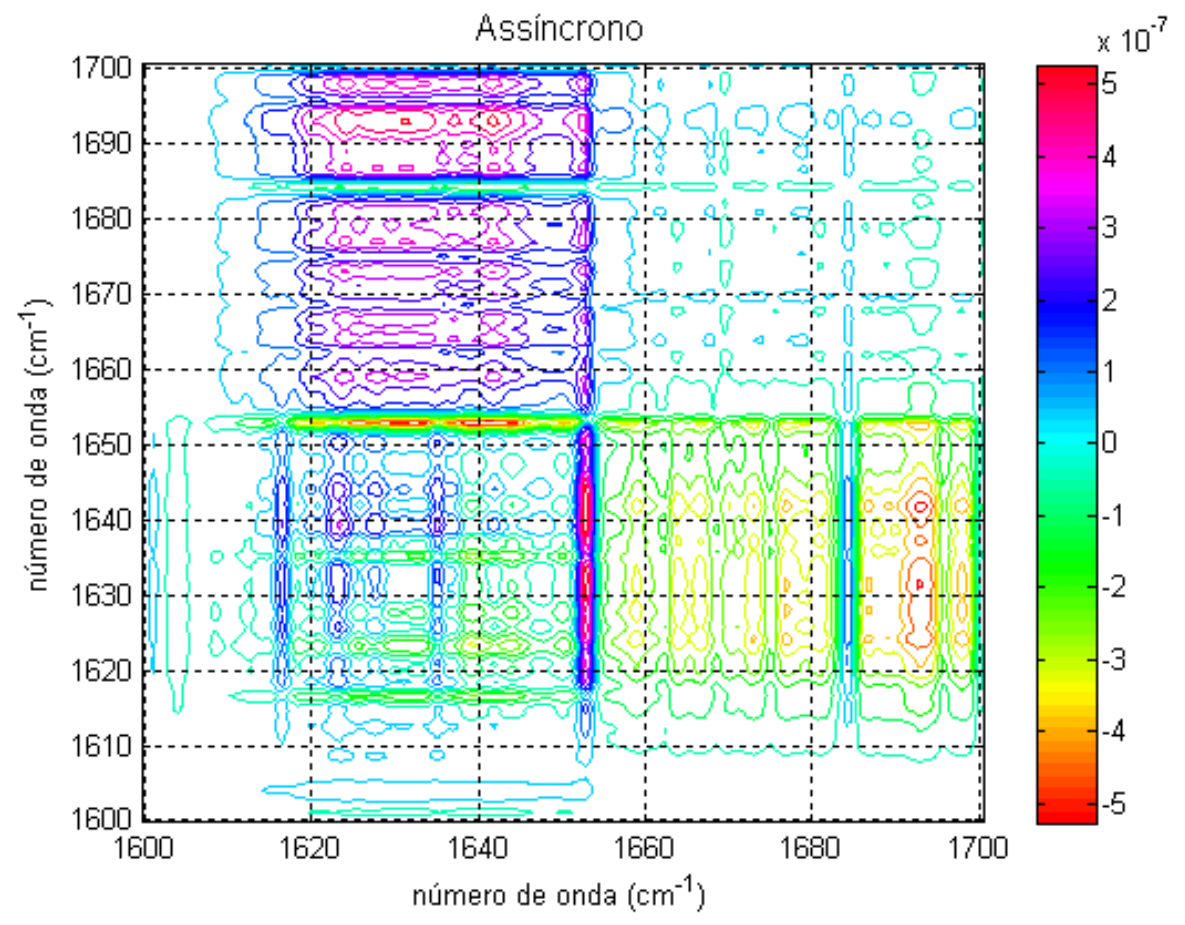

Figura 44: Mapa de contorno da correlação síncrona generalizada para o re-enovelamento da BPT pD 7,0 entre $33^{\circ}$ e $29^{\circ} \mathrm{C}$ na região de $1600-1700 \mathrm{~cm}^{-1}$. 


\section{Conclusões}

O desenvolvimento de um programa foi fundamental para o entendimento e aplicação da espectroscopia de correlação bidimensional generalizada. Além disso, a possibilidade de aprimoramento e implementação de novas técnicas de correlação 2D, como a correlação sample-sample, permite estudos complementares e mais detalhados dos processos de enovelamento e desenovelamento protéicos.

O processo de desenovelamento da tripsina pancreática bovina a $\mathrm{pH}$ próximo do neutro se mostrou complexo e constituído de múltiplas transições. Através da espectroscopia de correlação bidimensional sample-sample foram distinguidos eventos anteriores e posteriores à temperatura de ponto médio de desenovelamento com a ajuda da técnica de moving window. Temperaturas de pré-transição foram encontradas em $31^{\circ}, 37^{\circ}$ e $43^{\circ} \mathrm{C}$ e temperaturas de pós-transição em $54^{\circ}, 59^{\circ}$ e $69^{\circ} \mathrm{C}$.

A temperatura obtida pela análise de correlação sample-sample indicou uma temperatura de desenovelamento em $48^{\circ} \mathrm{C}$ para a BPT comercial, sem purificação. A correlação bidimensional sample-sample associada à correlação bidimensional generalizada mostrou-se eficiente na descrição dos vários passos do processo de desenovelamento, bem como no acompanhamento da autoclivagem da BPT através da banda em $1656 \mathrm{~cm}^{-1}$.

Os eventos pré e pós-transição foram corroborados por calorimetria exploratória diferencial (DSC), de modo que próximo a $30^{\circ} \mathrm{C}$ é iniciado o grupo de transições endotérmicas e sub-picos provenientes da análise de deconvolução da curva de DSC foram encontrados em $40^{\circ}, 42^{\circ}, 49^{\circ}, 55^{\circ}$ e a transição em $62^{\circ} \mathrm{C}$ marca a última transição endotérmica. Em torno de $69^{\circ} \mathrm{C}$ inicia-se a transição exotérmica que indica o início da agregação, seguido de um pico em $83^{\circ} \mathrm{C}$, temperatura não atingida nas medidas de infravermelho por questões técnicas.

Os experimentos de DSC e IR indicaram $\Delta H_{c a l}>\Delta H_{V H}$, sendo que $\Delta H_{c a l}$ é a variação de entalpia aparente da curva endotérmica de $59,3 \mathrm{kcal} / \mathrm{mol}$ e $\Delta H_{V H}$ a variação de entalpia estimada a partir da equação de van’t Hoff em torno de $28,1 \mathrm{kcal} / \mathrm{mol}$, acompanhando apenas a intensidade da folha $\beta \mathrm{em} 1635 \mathrm{~cm}^{-1}$. A razão $\Delta H_{V H} / \Delta H_{c a l}$ 
menor que 1 pode indicar a presença de múltiplos estados como observado na curva endotérmica e através da correlação sample-sample.

Nos experimentos de re-enovelamento, a análise de correlação sample-sample, indicou temperaturas de transição em torno de $43^{\circ}, 35^{\circ}$ e $31^{\circ} \mathrm{C}$, embora os pontos de convergência não sejam nítidos devido ao amplo espaço conformacional a ser pesquisado e possibilidade de heterogeneidade conformacional. As temperaturas encontradas foram próximas às temperaturas de pré-transição encontradas no processo de desenovelamento em $31^{\circ}, 37^{\circ}$ e $43^{\circ}$, no entanto, a correlação bidimensional generalizada, ou variável-variável, destas transições mostra dinâmicas conformacionais diferentes durante os processos de re-enovelamento e desenovelamento.

A espectroscopia de correlação bidimensional generalizada tem avançado em teoria e aplicações nos últimos anos e novas técnicas de correlação $2 \mathrm{D}$, a análise de correlação $\beta v$ (Elmore, et al., 2001), distância euclidiana entre espectros bidimensionais (Chen, et al., 2009), mapas de fase e de coeficientes de correlação, entre outros, têm sido desenvolvidas. Algumas destas técnicas, assim como métodos de pré-tratamento de espectros unidimensionais, vêm sendo testados e implementados ao programa para aplicação no estudo de proteínas e serão explorados em estudos posteriores. 


\section{Bibliografia}

Ausili, Alessio, et al. 2005. Temperature-Induced Molten Globule-like State in Human a1-Acid Glycoprotein: An Infrared Spectroscopy Study. Biochemistry. 2005, Vol. 44, 15997-16006.

Barth, Andreas. 2007. Infrared Spectroscopy of proteins. Biochimica et Biofisica Acta. 2007, Vol. 1767, 1073-1101.

Bittar, E. R., et al. 2003. Characterization of $\beta$-Trypsin at Acid $\mathrm{pH}$ by Differential Scanning Calorimetry. Brazilian Journal of Medical and Biological Research. 2003, Vol. 36, 1621-1627.

Chen, Jianbo, et al. 2009. Quantitative Classification of Two-Dimensional Correlation Spectra. Applied Spectroscopy. 2009, Vol. 63, 8, 920-925.

Cooper, Alan. 2001. http://www.chem.gla.ac.uk/staff/alanc/dscbrief.pdf. [Online] University of Glasgow, 24 de Abril de 2001.

Dill, Ken A., et al. 2008. The Protein Folding Problem. Annual Review of Biophysics. 2008, Vol. 37, 289-316.

Dobson C. M. 1998. How Do We Explore the Energy Landscape for Folding. [A. do livro] H. Frauenfelder, J. Deisenhofer e P. Wolynes. Simplicity and Complexity in Proteins and Nucleic Acids. Berlin : Dahlem University Press, 1998.

Dzwolak, Wojciech, et al. 2003. Aggregaton of Bovine Insulin Probed by DSC/PPC Calorimetry and FTIR Spectroscopy. Biochemistry. 2003, Vol. 42, 11347-11355.

Elmore, Douglas L. e Dluhy, Richard A. 2001. $\beta v$-Correlation Analysis: A Modified Two-Dimensional Infrared Correlation Method for Determining Relative Rates of Intensity Change. Jounal of Physical Chemistry B. 2001, Vol. 105, 11377-11386.

Fabian, Heinz, Mantsch, Henry e Schultz, Christian P. 1999. Two-Dimensional IR Correlation Spectroscopy: Sequential Events in the Unfolding Process of the $\lambda$ CroV55C Repressor Protein. Biophysics. 1999, Vol. 96, 23, 13153-13158.

Filosa, Angelo, et al. 2001. Two-Dimensional Infrared Correlation Spectroscopy as a Probe of Sequential Events in the Thermal Unfolding of Cytochromes c. Biochemistry. 2001, Vol. 40, 8256-8263.

He, Hua-Wei, et al. 2005. Conformational Change in the C-Terminal Domain is Responsible for the Initiation of Creatine Kinase Thermal Agregation. Biophysical Journal. 2005, Vol. 89, 2650-2658. 
Iloro, Ibon, et al. 2004. Methionine Adenosyltransferase $\alpha$-Helix Structure Unfolds at Lower Temperatures than $\beta$-Sheet: A 2D-IR Study. Biophysical Journal. 2004, Vol. 86, 3931-3958.

Noda, Isao. 2000. Determination of Two-Dimensional Correlation Spectra Using the Hilbert Transform. Applied Spectroscopy. 2000, Vol. 54, 7, 994-999.

Noda, Isao e Ozaki, Yukihiro. 2004. Two-dimensional Correlation Spectroscopy Applications in Vibrational and Optical Spectroscopy. s.l. : John Wiley \& Sons Ltda, 2004.

Noda, Isao. 1993. Generalized Two-Dimensional Correlation Method Applicable to Infrared, Raman and Other Types of Spectroscopy. Applied Spectroscopy. 1993, Vol. 47, 9,1329-1336.

-. 2008. Recent Advancement in the Field of Two-dimensional Correlation Spectroscopy. Journal of Molecular Structure. 2008, Vols. 883-884, 2-26.

-. 1990. Two-Dimensional Infrared (2D-IR) Spectroscopy: Theory and Applications. Applied Spectroscopy. 1990, Vol. 44, 4,550-561.

Ohshima, Yuji, et al. 2008. Refolding of Fully Reduced Bovine Pancreatic Trypsin. Journal of Biocience and Bioengineering. 2008, Vol. 106, 4, 345-349.

Paquet, Marie-Josée, et al. 2001. Two-Dimensional Infrared Correlation Spectroscopy Study of the Aggregation of Cytochrome c in the Presence of Dimyristoylphosphatidylglycerol. Biophysical Journal. 2001, Vol. 81, 305-312.

Prestrelski, Steven J., Byler, D. Michael e Liebman, N. Michael. 1991. Comparison of Various Molecular Forms of Bovine Trypsin: Correlation of Infrared Spectra with Xray Crystal Structures. Biochemistry. 1991, Vol. 30, 133-143.

Santos, A. M. C., et al. 2008. Physical-Chemical Characterization and Stability Study of $\alpha$-Trypsin at pH 3.0 by Differential Scanning Calorimetry. International Journal of Biological Macromolecules. 2008, Vol. 42, 278-284.

Sasic, Slobodan, Muszynski, Andrzej e Ozaki, Yukihiro. 2000. A Ney Possibility of the Generalized Two-Dimensional Correlation Spectroscopy. 1. Sample-Sample Correlation Spectroscopy. J. Phys. Chem. A, 2000, Vol. 104, 6380-6387.

Schroeder, Duane D. e Shaw, Elliot. 1968. Cromatography of Trypsin and Its Derivatives. The Journal of Biological Chemistry. 1968, Vol. 243, 11.

Smith, Robert L. e Shaw, Elliot. 1969. Pseudotrypsin: A Modified Bovine Trypsin Produced by Limited Autodigestion. The Journal of Biological Chemistry. 1969, Vol. 244, 17.

Tavirani, Mostafa Rezaei, et al. 2006. Conformational Study of Human Serum Albumin in Pre-denaturation Temperatures by Differental Scanning Calorimetry, 
Circular Dichroism and UV Spectroscopy. Journal of Biochemistry and Molecular Biology. 2006, Vol. 35, 5, 530-536.

Udgaonkar, Jayant B. 2008. Multiple Routes and Strutuctural Heterogeneity in Protein Folding. Annual Review of Biophysics. 2008, Vol. 37, 789-510.

Voet, Donald, Voet, Judith G. e Prat, Charlot W. 2008. Fundamentos de Bioquímica: A Vida em Nível Molecular. Porto Alegre : Artmed, 2008. $2^{\mathrm{a}} \mathrm{Ed}$.

Wang, Li-Xu, Wu, Yuqing e Meersman, Filip. 2006. Two-dimensional correlation infrared spectroscopic study on the conformational changes occurring in the thermally induced pretransition of ribonuclease A. Journal of Molecular Structure. 2006, Vol. 799, 85-90.

Yan, Yong-Bin, et al. 2003. Two-Dimensional Infrared Correlation Spectroscopy Study of Sequential Events in the Heat-Induced Unfolding and Aggregation Process of Myoglobin. Biophysical Journal. 2003, Vol. 85, 1959-1967. 


\section{Apêndice A}

O teorema de Wiener-Khintchine estabelece uma relação conveniente entre a função de correlação cruzada de duas funções e suas transformadas de Fourier. Dada a função de correlação cruzada clássica

$$
C(\tau)=\frac{1}{T_{\text {máx }}-T_{\min }} \int_{T_{\min }}^{T_{\max }} \tilde{y}\left(v_{1}, t\right) \cdot \tilde{y}\left(v_{2}, t+\tau\right) d t,
$$

sendo que $\tau$ é o tempo de correlação, o termo $\tilde{y}\left(v_{2}, t+\tau\right)$ pode ser escrito como a inversa transformada de Fourier de $\tilde{Y}_{2}(\omega)$ como mostrado abaixo:

$$
C(\tau)=\frac{1}{T_{\text {máx }}-T_{\min }} \int_{T_{\min }}^{T_{\operatorname{ma} a x}} \tilde{y}\left(v_{1}, t\right)\left[\frac{1}{2 \pi} \int_{-\infty}^{\infty} \tilde{Y}_{2}(\omega) e^{i \omega(t+\tau)} d \omega\right] d t .
$$

A equação A.2 ainda pode ser simplificada de modo que

$$
C(\tau)=\frac{1}{2 \pi\left(T_{\text {máx }}-T_{\text {min }}\right)} \int_{T_{\text {mín }}}^{T_{\text {máx }}} \tilde{y}\left(v_{1}, t\right) \int_{-\infty}^{\infty} \tilde{Y}_{2}(\omega) e^{i \omega t} e^{i \omega \tau} d \omega d t .
$$

Rearranjando a equação A.3, temos

$$
C(\tau)=\frac{1}{2 \pi\left(T_{\text {máx }}-T_{\text {min }}\right)} \int_{-\infty}^{\infty}\left[\int_{T_{\text {min }}}^{T_{\text {máx }}} \tilde{y}\left(v_{1}, t\right) e^{i \omega t} d t\right] \tilde{Y}_{2}(\omega) e^{i \omega \tau} d \omega,
$$

sendo que a integração de contorno $\left(\mathrm{T}_{\text {mín }}, \mathrm{T}_{\text {máx }}\right)$ pode ser expandida à $(-\infty,+\infty)$ dada a condição imposta na equação 2.1. Logo, a integração entre colchetes é equivalente ao conjugado da transformada de Fourier:

$$
C(\tau)=\frac{1}{2 \pi\left(T_{\text {máx }}-T_{\text {min }}\right)} \int_{-\infty}^{\infty} \tilde{Y}_{1}^{*}(\omega) \tilde{Y}_{2}(\omega) e^{i \omega \tau} d \omega
$$


Autorizo a reprodução xerográfica para fins de pesquisa.

São José do Rio Preto, 19 de março de 2010

Assinatura 